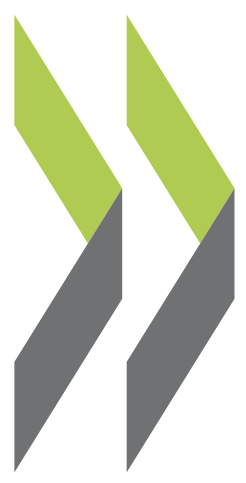

OECD Economics Department Working Papers No. 1132

Overcoming Vulnerabilities of Health Care Systems

\author{
Mauro Pisu
}

https://dx.doi.org/10.1787/5jz159228n6j-en 
Organisation de Coopération et de Développement Économiques

Organisation for Economic Co-operation and Development

03-Jul-2014

ECONOMICS DEPARTMENT

English - Or. English

\section{OVERCOMING VULNERABILITIES OF HEALTH CARE SYSTEMS}

ECONOMICS DEPARTMENT WORKING PAPERS No. 1132

\section{By Mauro Pisu}

OECD Working Papers should not be reported as representing the official views of the OECD or of its member countries. The opinions expressed and arguments employed are those of the author(s).

Authorised for publication by Jean-Luc Schneider, Deputy Director, Policy Studies Branch, Economics Department.

All Economics Department Working Papers are available through OECD's Internet website at http://www.oecd.org/eco/workingpapers

JT03360119

Complete document available on OLIS in its original format

This document and any map included herein are without prejudice to the status of or sovereignty over any territory, to the delimitation of international frontiers and boundaries and to the name of any territory, city or area. 
OECD Working Papers should not be reported as representing the official views of the OECD or of its member countries. The opinions expressed and arguments employed are those of the author(s).

Working Papers describe preliminary results or research in progress by the author(s) and are published to stimulate discussion on a broad range of issues on which the OECD works.

Comments on Working Papers are welcomed, and may be sent to the Economics Department, OECD, 2 rue André-Pascal, 75775 Paris Cedex 16, France, or by e-mail to eco.contact@oecd.org.

This document and any map included herein are without prejudice to the status of or sovereignty over any territory, to the delimitation of international frontiers and boundaries and to the name of any territory, city or area.

The statistical data for Israel are supplied by and under the responsibility of the relevant Israeli authorities. The use of such data by the OECD is without prejudice to the status of the Golan Heights, East Jerusalem and Israeli settlements in the West Bank under the terms of international law.

\section{() OECD (2014)}

You can copy, download or print OECD content for your own use, and you can include excerpts from OECD publications, databases and multimedia products in your own documents, presentations, blogs, websites and teaching materials, provided that suitable acknowledgment of OECD as source and copyright owner is given. All requests for commercial use and translation rights should be submitted to rights@oecd.org 


\section{ABSTRACT / RÉSUMÉ \\ Overcoming vulnerabilities of health care systems}

This paper investigates the vulnerabilities of health care systems in OECD and BRIICS countries to adverse secular trends and large macroeconomic shocks. It identifies policies that can ally vulnerabilities considering the institutional setting of health care systems, such as the public-private mix and the main sources of revenues, and the need to balance economic sustainability with the adequacy of services.

JEL classification codes: I13; I14; I18

Keywords: Health care systems, macroeconomic shocks, risk pooling, sustainability, adequacy

$* * * * *$

\section{Surmonter les vulnérabilités des systèmes de santé}

Ce document examine les vulnérabilités des systèmes de santé, dans les pays de l'OCDE et dans les pays BRIICS, face à des tendances séculaires négatives et à d'importants chocs macroéconomiques. Il identifie les politiques qui peuvent permettre de concilier les vulnérabilités compte tenu des caractéristiques structurelles des systèmes de santé qui dépendent notamment de l'articulation public-privé et des principales sources de financement, et la nécessité de trouver un compromis entre durabilité économique et niveau adéquat des services.

Classification JEL : I13 ; I14 ; I18

Mots clés : systèmes de santé, chocs macroéconomiques, mutualisation des risques, durabilité, niveau suffisant des services 


\section{TABLE OF CONTENTS}

OVERCOMING VULNERABILITIES OF HEALTH CARE SYSTEMS................................................. 6

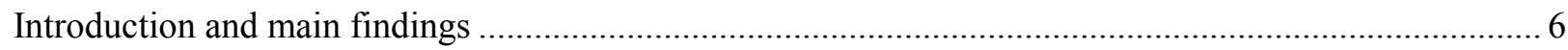

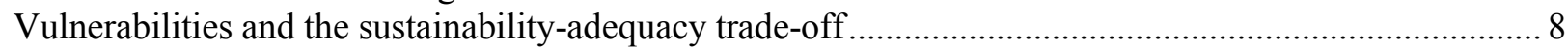

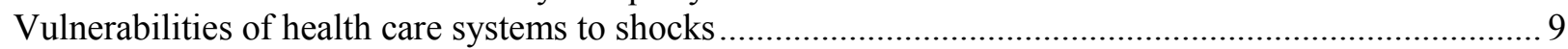

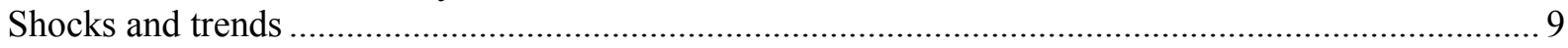

Main determinants of health care spending and policies to contain it ................................................ 17

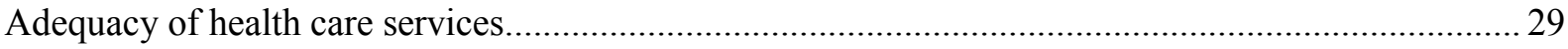

Policy reforms could make health care systems more resilient to shocks ............................................ 33

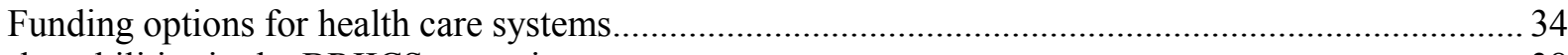

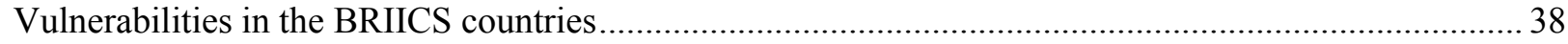

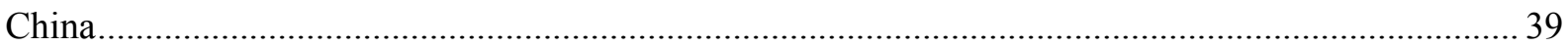

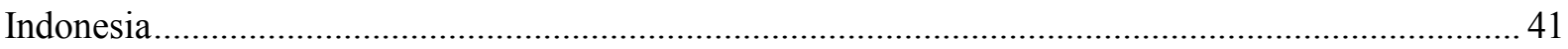

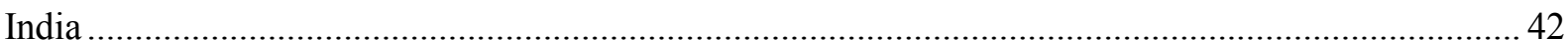

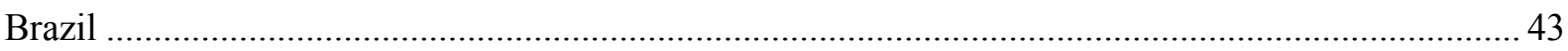

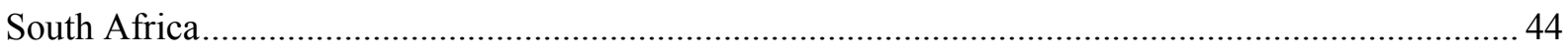

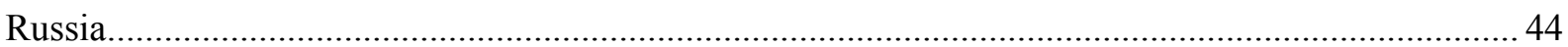

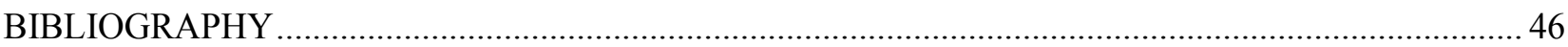

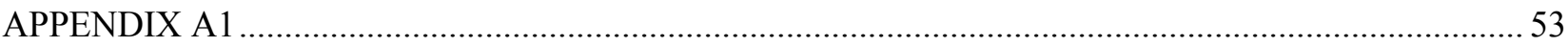

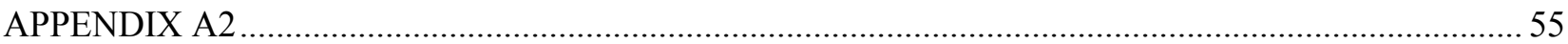

\section{Tables}

1. Breakdown of the projections of public health care expenditure for each driver ............................. 12

2. Health care funding options have equity and efficiency effects .................................................... 35

3. The projected growth in public health care expenditure for the BRIICS countries............................ 39

\section{Figures}

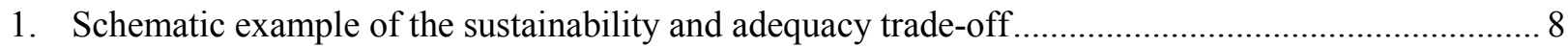

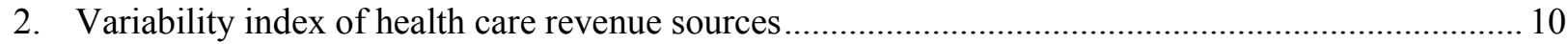

3. The vulnerability of health spending to GDP shocks is not overwhelming .................................... 14

4. Health status in old age affects public health care spending ....................................................... 16

5. The public health spending to GDP ratio is little affected by productivity changes .......................... 16

6. Price and technological developments affect the public health spending-to-GDP ratio.................... 17

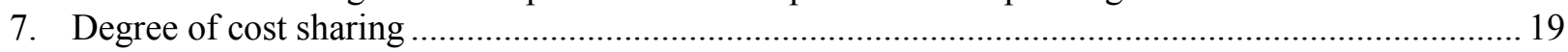

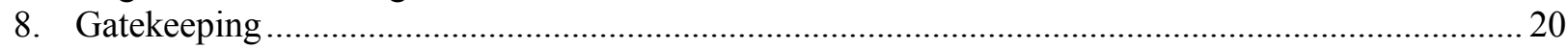

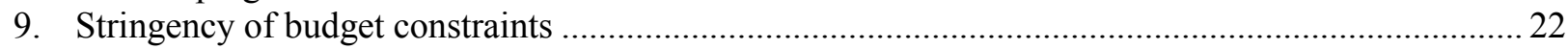

10. Stringent budget constraints make the implementation of cost containment policies

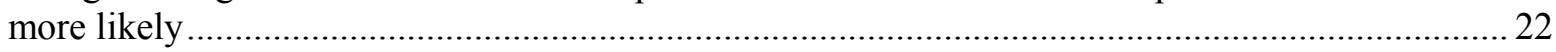

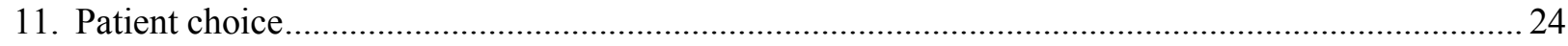

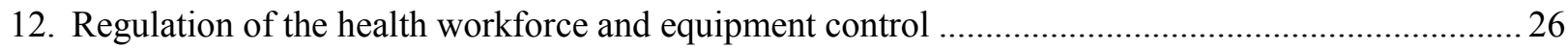




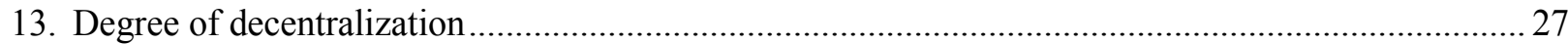

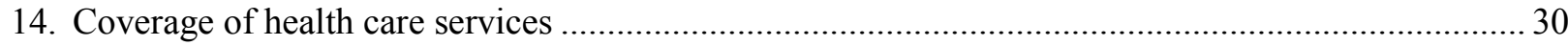

15. Real disposable income shocks affect private health insurance coverage ........................................ 32

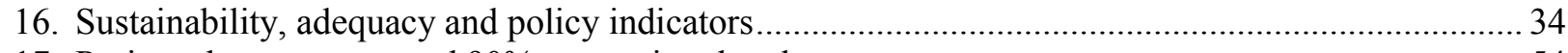

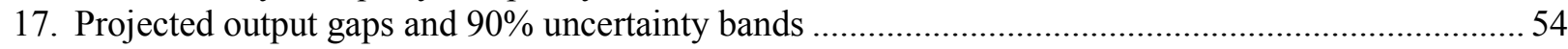

\section{Boxes}

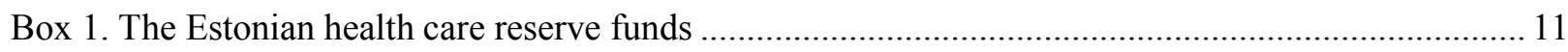

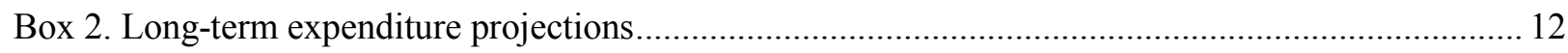




\title{
OVERCOMING VULNERABILITIES OF HEALTH CARE SYSTEMS
}

\author{
By
}

\author{
Mauro Pisu ${ }^{1}$
}

\section{Introduction and main findings}

1. Health care systems are a central component of modern welfare states and greatly contribute to social welfare and personal well-being. It is widely recognised that health care systems will continue to face adverse secular trends in the coming years due to aging, price and technology developments, which in the long run may undermine their capacity to deliver the services the population expects. On top of this, the recent crisis has shown how large macroeconomic shocks can severely affect public and private health care systems in different ways, the precise impact depending on the health care systems' institutional settings and their degree of crisis preparedness.

2. This paper is part of an OECD project on the Vulnerability of Social Institutions. It builds on previous OECD work on health care, which focused, among other things, on institutional aspects, efficiency and spending determinants (Paris and Devaux, 2010; Joumard et al., 2010; de la Maisonneuve and Oliveira Martins, 2013). Its aim is to help understanding the vulnerability of health care systems to different shocks and long-term trends and identify how reforms can enhance the resilience of health care systems.

3. The main findings are:

- Health care systems are vulnerable to short-run shocks (e.g. epidemics or macroeconomic shocks) and adverse long-term trends (e.g. ageing); adverse long-term trends, if unaddressed can heighten the vulnerability of health care systems to short-run shocks.

- Macroeconomic fluctuations are a source of vulnerability for health care systems. Highly volatile revenue sources may strain health care systems' capacity to provide an adequate level of services. Large and unexpected revenue losses can force governments to cut health care spending drastically. Health care revenue volatility varies across countries depending on the volatility and share of the different health care funding components in total revenue. Buffer funds can play a role in damping the effect of health revenue volatility as shown by the experience of Estonia during the recent crisis.

1. The author is member of the Economics Department of the OECD. The author thanks Francesca Colombo, Jørgen Elmeskov, Ankit Kumar, Valerie Paris, Mark Pearson and Jean-Luc Schneider for comments on earlier drafts, Debbie Bloch for statistical support and Celia Rutkoski for assistance in preparing the document. 
- Macroeconomic fluctuations also lead to a ratcheting up of the health care spending-to-GDP ratio as the response of health spending to GDP changes is asymmetric. When GDP rises health spending tends rise too, but when the GDP declines the latter does not decrease commensurably and it often keeps rising.

- Epidemic shocks are one of the major risks health care systems face. In all OECD countries, the public authorities are responsible for epidemic prevention and control. In a globalised world, international coordination under the aegis of the WHO is key to prevent and control epidemics, but OECD countries must ensure that efforts spent on preventing the onset of epidemics in less developed countries are commensurable to those focusing on preventing the international spread of epidemics.

- Private health insurance coverage can be sensitive to negative personal income shocks as private health insurance premiums can become unaffordable for low income people. Countries relying on private health insurance to provide basic coverage should therefore ensure that individuals who lose private health coverage are eligible for alternative health care programmes offering basic coverage. For instance, in the United States the 2010 Affordable Care Act has allowed children under 26 years to stay on their parent's health insurance plans and thus prevented a large increase in the number of uninsured among young adults. The individual mandate of the Affordable Care Act, that is being progressively implemented, is a step in the right direction to extend health care coverage to the whole population.

- Some policy reforms to contain the secular rise of health spending can make the health care systems more resilient to shocks, but sustainability and adequacy considerations need to be balanced. For instance, high cost sharing, private health insurance enrollment incentives and workforce supply controls help curb expenditure in the short term but can also worsen adequacy. These policies tend to reduce risk pooling, make access to services more inequitable, distort labour supply choices and insurance subsidies accrue mostly to the well off. On the other hand, mandated generic substitution, regulated competition among health care service providers, welldesigned budgetary caps and spending rules, hospital payments based on diagnostic related groups and health technology assessment can improve the sustainability without damaging the adequacy of services. They can even improve it, as, for instance, health technology assessments may steer patients and doctors towards the most effective treatments.

- Governments need to carefully balance the mix of heath care systems' revenue sources (i.e. general taxation, social security contributions, private insurance premiums and out-of-pocket payments). Shocks to revenue sources affect social welfare as the different revenues sources affect the income distribution, risk pooling, expenditure smoothing and deadweight losses. Income taxation is in principle the most progressive form of revenue and ensures a high degree of risk pooling and expenditure smoothing. Social security contributions are generally not progressive, risk pooling is more limited or fragmented and they can generate large labour market distortions, though they provide expenditure smoothing. Private insurance premiums and out-ofpocket payments are generally regressive, offer limited or no risk pooling and expenditure smoothing.

- For BRIICS countries, the most immediate priority is to enhance the adequacy of health care services, by expanding coverage and improving quality. More specifically, there is a need to lower out-of-pocket payments to improve equity of access to services and preventive care. Extending universal coverage and increasing risk pooling is a necessary step to reduce the risk that individuals have to pay a very high health treatment bill. The BRIICS countries suffer from wide-spread labour market informality, which make extending the coverage of social security contributions challenging. General taxation is less sensitive to the effects of fast-ageing population, more equitable and will augment risk pooling. 
4. This paper discusses revenue, macroeconomic and epidemic shocks first along with the various policies adopted - or being considered - to curb the secular increase in health spending in light of their effects on the sustainability-adequacy trade-off. Next, service adequacy is analysed. The following section deals with the funding options for health care systems and their effects on risk pooling, expenditure smoothing and deadweight losses. The last section reviews vulnerabilities in the BRIICS countries.

\section{Vulnerabilities and the sustainability-adequacy trade-off}

5. To perform their social purposes well, health care systems need balance long-term economic sustainability and the adequacy of services. The vulnerabilities of health care systems can be analysed based on the trade-off between these two dimensions (Figure 1). The trade-off can be eased or even be overcome through efficiency gains, policy reforms and technological changes.

Figure 1. Schematic example of the sustainability and adequacy trade-off

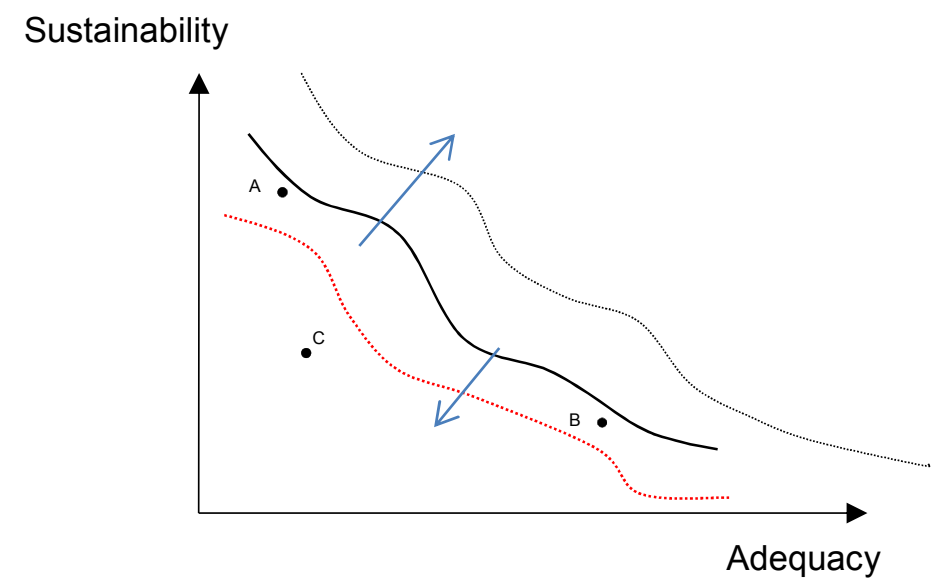

6. Economic sustainability refers to the balance between spending and revenues. If policies to make health care systems sustainable are delayed, heavy adverse shocks, such as the recent crisis, may make abrupt policy reforms inevitable. Reforms planned and implemented in periods of crisis are likely to involve a mixture of severe cuts in the coverage of benefits and revenue-raising initiatives, such as raising co-payments that may have long-lasting negative health and social effects.

7. Adequacy of health care systems refers to the coverage and quality of basic health care services. Lowering service adequacy - due to diminished coverage, low-quality or inequitable access to services while enhancing sustainability may be socially and politically unacceptable as it undermines the main purpose of health care systems, which is individual risk protection.

8. For health care systems lying close to the sustainability-adequacy frontier (e.g. point A and B in Figure 1), there is a trade-off between sustainability and adequacy. These systems can improve adequacy by increasing spending, thus reducing sustainability, or enhance sustainability by worsening adequacy, by for instance reducing the quality of services and/or their coverage. Over the long run, deep policy reforms and technological innovations can lead to improvements in both adequacy and sustainability by shifting the frontier outward.

9. Health care systems that are below the sustainability-adequacy frontier can improve the sustainability and adequacy of health care services at the same time by, for instance, adopting best practices. This will move them closer to the frontier (point $C$ in Figure 1). For instance the output-oriented 
efficiency estimates by Joumard et al. (2010), which gauge the potential gain in life expectancy (which can be deemed a measure of health care system's adequacy) for the same level of spending, can be interpreted as improvements along the adequacy dimension, keeping sustainability constant. ${ }^{2}$ Likewise, the inputoriented efficiency estimates can be interpreted as gains in sustainability (i.e. lower spending), while preserving the same level of adequacy.

\section{Vulnerabilities of health care systems to shocks}

\section{Shocks and trends}

\section{Shocks to health revenue sources}

10. The funding sources of health care systems are: general taxation, social insurance contributions, private insurance premiums and out-of-pocket payments. Medical saving accounts could be another source of health care funding. They are, however, not common among OECD countries.

11. The sensitivity of health care systems to revenue shocks depends on the relative importance of the different funding options. For instance, general taxation is especially sensitive to GDP fluctuations, social insurance contributions to the wage bill, whereas private insurance and out-of-pocket financing are especially responsive to personal income shocks. Shocks hitting the different sources of funding will affect the distribution of income, risk pooling and expenditure smoothing of health care system financing.

12. Highly volatile revenue sources may strain health care systems' capacity to provide a stable and adequate level of services. Figure 2 shows the volatility of health care funding. It is calculated as a weighted average of the volatility of the different revenue components (i.e. general taxes, social security contributions, private insurance and out-of-pocket payments plus a covariance term capturing the comovement of the different components). Health care funding is most volatile in Estonia, Korea and Japan. It is much less volatile in Switzerland, Australia and Germany. On overage, the main source of revenue volatility in countries showing a high volatility of total revenue seems to be social security contributions, on account of their importance in total revenue.

13. Reserves or buffer funds can play an important role in smoothing health expenditure and revenues over the business cycle. Abrupt and protracted revenue shortfalls can make it challenging for health care systems to provide the level and quality of services the population deems adequate. Reserve funds can help maintain an adequate service level during crisis periods.

2. These efficiency estimates measure the gain in life expectancy that countries could achieve for the same level of spending. They are derived from a DEA health care production function with life expectancy as output and health care spending, plus other socio-economic controls, as inputs. 
Figure 2. Variability index of health care revenue sources

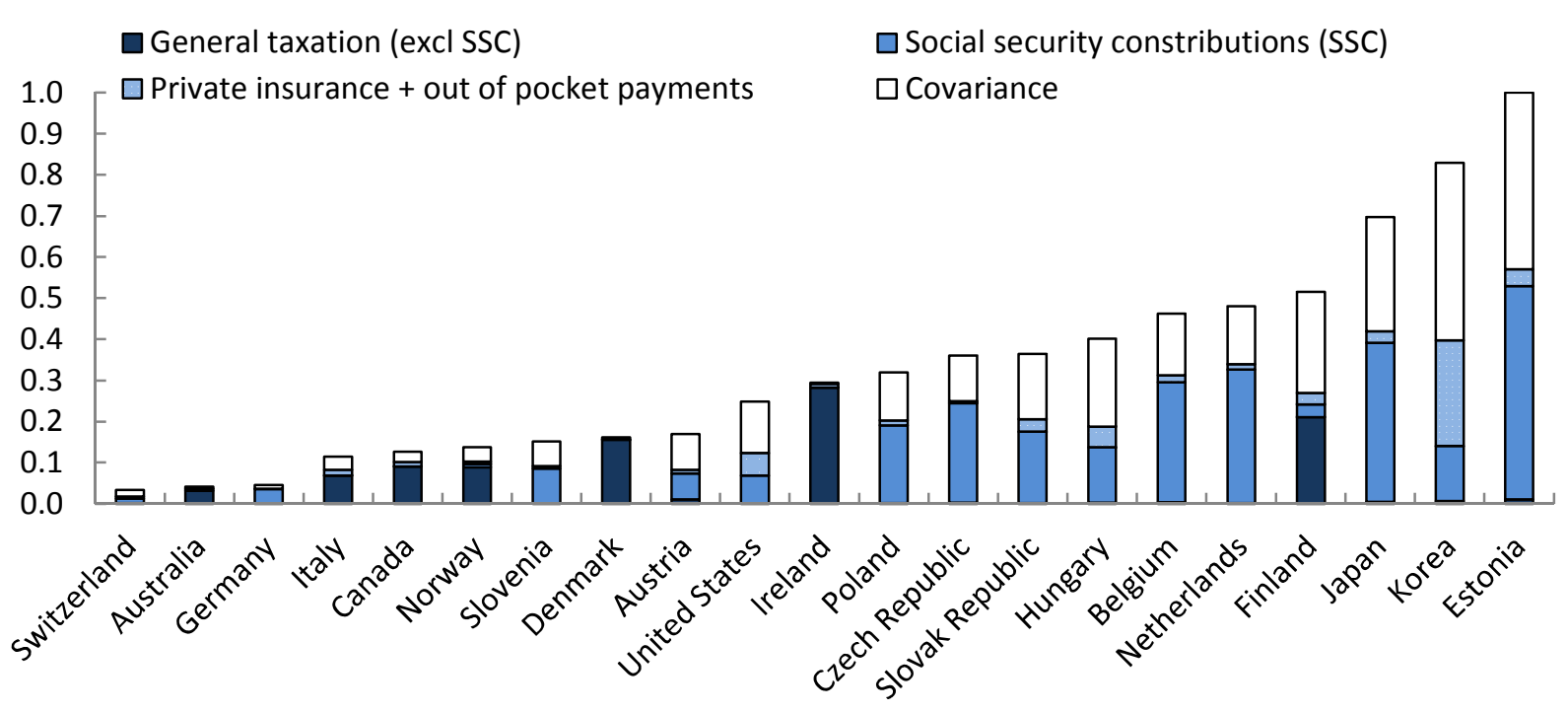

Note: As no comprehensive data on health care revenue are available, total revenue is assumed to equal spending. Total revenue is decomposed into general taxation, social security contributions and revenue from private insurance premiums plus out-of-pocket payments in proportion of the share of spending financed by, respectively, general government (excluding social security funds), social security funds and private insurance plus out-of-pocket payments. The index is calculated as the coefficient of variation (i.e. ratio of the variance to the squared mean) of the deviation of real health care revenues, inferred as described above, from a nonlinear trend and is rescaled to lie between zero and one. The contributions of the components to the total reflect the volatility of the components and the share of the components in total revenue. Shares are kept constant and based on 2006-10 averages. The estimation period differs across the countries. The whole time span for which data are available is used.

Source: SHA and OECD calculations.

14. Estonia offers an example of this type of reserves. Over the recent crisis the reserves proved useful to smooth health expenditure, although the government decided to draw on them only to a limited extent (Box 1). In Estonia, the share of the population reporting unmet medical needs, because of cost reasons, rose from 2008 to 2011, but by less than in other OECD countries similarly hard hit by the crisis. Moreover, the use of reserve funds seems to have guaranteed the same level of equity to access to health care services as the poor did not experience a larger increase in unmet medical needs than the rich. 


\section{Box 1. The Estonian health care reserve funds}

The Estonian health care system is based on a social insurance model. At the beginning of the economic crisis, the Estonian Health Insurance Fund (EHIF) was in a more comfortable position compared with other health care systems. The EHIF had accumulated reserves in the preceding years that amounted to $35 \%$ of its annual expenditure in 2008. The funds enabled to smooth health expenditure - especially in 2009 when health care revenues dropped precipitously (Habicht, 2012).

The EHIF has three types of reserves (Sikk, 2013):

- A legal reserve to deal with macroeconomic fluctuations; it has been created by transferring at least $6 \%$ of the budget every year; it can be used only in exceptional circumstances under the government's permission.

- A risk reserve intended to meet future health care obligations; it constitutes $2 \%$ of health care budget and the supervisory board of the EHIF decides on its use.

- A cash reserve built up from surpluses in preceding years resulting from larger tax revenues than forecast in the budget; the supervisory board of the EHIF decides on its use.

From 2008 to 2010, health care revenues dropped by around 15\%. The government considered several measures to cope with the dearth of funding: using reserves, reducing health service prices paid to providers, cutting access to health care services and cash benefits to patients (Sikk, 2013). The government opted for a mixed strategy consisting of a limited utilisation of reserves coupled with health care budget reforms, which involved a $6 \%$ cut in health care service prices, longer waiting times for specialised health care and a temporary reduction in temporary sick leave benefits and dental care benefits. By 2012, health prices had recovered to the pre-crisis level and reserve funds accounted for about $25 \%$ of health expenditure.

\section{GDP shocks and health spending}

15. Large GDP variations can be a source of vulnerability for health care systems as the relationship between income and health-care spending may not be constant over the cycle. When GDP rises, health spending tends to rise too, but when the former contracts the latter does not decrease commensurably and it often keeps rising. Therefore, large negative GDP shocks can push up the health spending-to-GDP ratio.

16. Overall, the importance of GDP shocks for the vulnerability of health care systems depends on two factors: 1) how strongly income affects health-spending; and 2) the size and frequency of shocks as the effect of shocks will cumulate over time. To quantify the vulnerability of health spending to GDP shocks, this study starts from the empirical model employed by de la Maisonneuve and Oliveira Martins (2013) for their long-term health-care expenditure projections for OECD and BRIICS countries (Box 2). 


\section{Box 2. Long-term expenditure projections}

The projections by de la Maisonneuve and Oliveira Martins (2013) are based on the following framework:

$\Delta \ln \frac{H E}{P Y}=\beta \Delta \ln$ Demo $+(\varepsilon-1) \Delta \ln \frac{Y}{N}+\Delta \ln ($ Res $)$

where $H E / P Y$ is the health expenditure-to-GDP ratio, Demo is a combination of demographic-related factors, $Y / N$ is real GDP per capita and Res a residual accounting for the quality of health-care expenditure and other factors; $\varepsilon$ is the elasticity of health spending to GDP per capita, which in their benchmark scenario takes the value of $0.8-$ consistent with their empirical estimates and the literature. The health spending-to-GDP ratio is projected over the 2010-60 period based on long-term projections of potential GDP - from the OECD Economic Outlook, No. 91 and population from different data sources. Table 1 reproduces their projections to 2060.

Table 1. Breakdown of the projections of public health care expenditure for each driver

\begin{tabular}{|c|c|c|c|c|c|}
\hline & Demographic effect & $\begin{array}{l}\text { Income } \\
\text { effect }\end{array}$ & $\begin{array}{c}\text { Residual } \\
\text { effect }\end{array}$ & Total & $\begin{array}{c}\text { Health care expenditure } \\
\text { as a } \% \text { of GDP }\end{array}$ \\
\hline & \multicolumn{4}{|c|}{ Increase in \% points of GDP 2010-60 } & 2060 \\
\hline Australia & 0.8 & -0.8 & 6.3 & 6.3 & 12.0 \\
\hline Austria & 0.6 & -0.6 & 6.3 & 6.3 & 12.9 \\
\hline Belgium & 0.2 & -0.7 & 6.3 & 5.8 & 11.6 \\
\hline Canada & 0.7 & -0.7 & 6.3 & 6.3 & 12.2 \\
\hline Chile & 1.8 & -1.1 & 6.3 & 7.1 & 10.2 \\
\hline Czech Republic & 0.7 & -0.9 & 6.3 & 6.1 & 11.6 \\
\hline Denmark & 0.3 & -0.7 & 6.3 & 5.9 & 12.2 \\
\hline Estonia & 0.6 & -1.1 & 6.3 & 5.8 & 10.1 \\
\hline Finland & 0.3 & -0.7 & 6.3 & 5.9 & 11.2 \\
\hline France & 0.3 & -0.6 & 6.3 & 6.1 & 13.5 \\
\hline Germany & 0.6 & -0.7 & 6.3 & 6.2 & 13.5 \\
\hline Greece & 0.7 & -0.6 & 6.3 & 6.4 & 11.8 \\
\hline Hungary & 0.4 & -1.0 & 6.3 & 5.8 & 10.6 \\
\hline Iceland & 0.2 & -0.7 & 6.3 & 5.9 & 11.7 \\
\hline Israel & 0.7 & -0.7 & 6.3 & 6.4 & 10.4 \\
\hline Ireland & 0.5 & -0.5 & 6.3 & 6.4 & 11.9 \\
\hline Italy & 0.7 & -0.6 & 6.3 & 6.4 & 12.6 \\
\hline Japan & 0.8 & -0.8 & 6.3 & 6.3 & 12.5 \\
\hline Korea & 2.0 & -0.8 & 6.3 & 7.6 & 10.9 \\
\hline Luxembourg & 0.7 & -0.2 & 6.3 & 6.9 & 11.3 \\
\hline Mexico & 1.6 & -1.1 & 6.3 & 6.9 & 9.4 \\
\hline Netherlands & 0.7 & -0.7 & 6.3 & 6.3 & 12.7 \\
\hline New Zealand & 0.8 & -0.9 & 6.3 & 6.3 & 12.7 \\
\hline Norway & 0.5 & -0.7 & 6.3 & 6.1 & 11.2 \\
\hline Poland & 1.0 & -0.9 & 6.3 & 6.4 & 10.5 \\
\hline Portugal & 0.8 & -0.7 & 6.3 & 6.5 & 13.0 \\
\hline Slovak Republic & 1.1 & -0.9 & 6.3 & 6.5 & 11.9 \\
\hline Slovenia & 1.0 & -0.8 & 6.3 & 6.6 & 11.8 \\
\hline Spain & 1.0 & -0.6 & 6.3 & 6.7 & 12.3 \\
\hline Sweden & 0.3 & -0.7 & 6.3 & 5.9 & 12.4 \\
\hline Switzerland & 0.9 & -0.8 & 6.3 & 6.5 & 12.2 \\
\hline Turkey & 1.8 & -1.1 & 6.3 & 7.0 & 10.9 \\
\hline United Kingdom & 0.2 & -0.7 & 6.3 & 5.9 & 12.4 \\
\hline United States & 0.5 & -0.7 & 6.3 & 6.1 & 13.2 \\
\hline$O E C D$ average & 0.8 & -0.8 & 6.3 & 6.3 & 11.8 \\
\hline Brazil & 1.7 & -1.1 & 6.3 & 7.0 & 10.7 \\
\hline China & 1.7 & -1.7 & 6.3 & 6.4 & 8.3 \\
\hline India & 0.9 & -1.7 & 6.3 & 5.5 & 6.7 \\
\hline Indonesia & 1.3 & -1.5 & 6.3 & 6.2 & 7.3 \\
\hline Russia & 0.2 & -1.0 & 6.3 & 5.5 & 8.6 \\
\hline South Africa & 0.0 & -1.2 & 6.3 & 5.2 & 8.4 \\
\hline Non-OECD average & 1.0 & -1.4 & 6.3 & 5.9 & 8.3 \\
\hline Total average & 0.8 & -0.8 & 6.3 & 6.3 & 11.3 \\
\hline
\end{tabular}

Source: De la Maisonneuve and Oliveira Martins (2013). 
17. De la Maisonneuve and Oliveira Martins (2013) choose an elasticity of health spending to GDP equal to 0.8 , based on a review of empirical studies. Using their data and allowing for different effects of GDP in periods of economic expansion and contraction reveals that the elasticity of health spending to income is not the same. The elasticity of real per capita health spending is estimated to be around 0.8 when real GDP per capita increases, whereas it is lower and not significantly different from zero when real GDP per capita diminishes.

18. The vulnerability of future health spending to GDP shocks are shown in Figure 3. Appendix A1 describes the methodology employed to simulate the GDP paths over the coming decades and infer the vulnerability of health spending to GDP shocks. ${ }^{3}$ Figure 3 depicts the projected health expenditure as percentage of GDP in 2030 and 2060 respectively, as projected by de la Maisonneuve and Oliveira Martins (2013). They also show the distribution of health-spending to GDP ratios due to GDP shocks. According to these estimates, the $90 \%$ confidence bands of the health spending-to-GDP ratio in 2030 goes from 7.2 to $7.9 \%$ for OECD countries and from 3.8 to $4.7 \%$ for BRIICS, against central projections of 7.5 and $4 \%$ respectively. Overall the impact of GDP shocks on prospective health spending is modest for most countries as GDP contributes little to explain health spending variations

19. In some countries, however, health care systems appear to be more vulnerable to GDP shocks. Confidence bands are especially large for Portugal, Ireland, Estonia, Spain and Iceland because of the large GDP shocks these countries have experienced in the past. Indonesia is the country with the largest confidence bands, but overall in the BRIICS health care systems do not seem to be significantly more vulnerable to GDP shocks than in OECD countries. In 2060, confidence bands are larger than in 2030 as the effect of positive of negative shocks cumulate over a longer time, but the same cross-country picture emerges.

3. They are based on an elasticity of health-care expenditure to income equal to 0.8 when GDP expands and zero when GDP contracts. 
Figure 3. The vulnerability of public health spending to GDP shocks is not overwhelming Health spending as \% of GDP
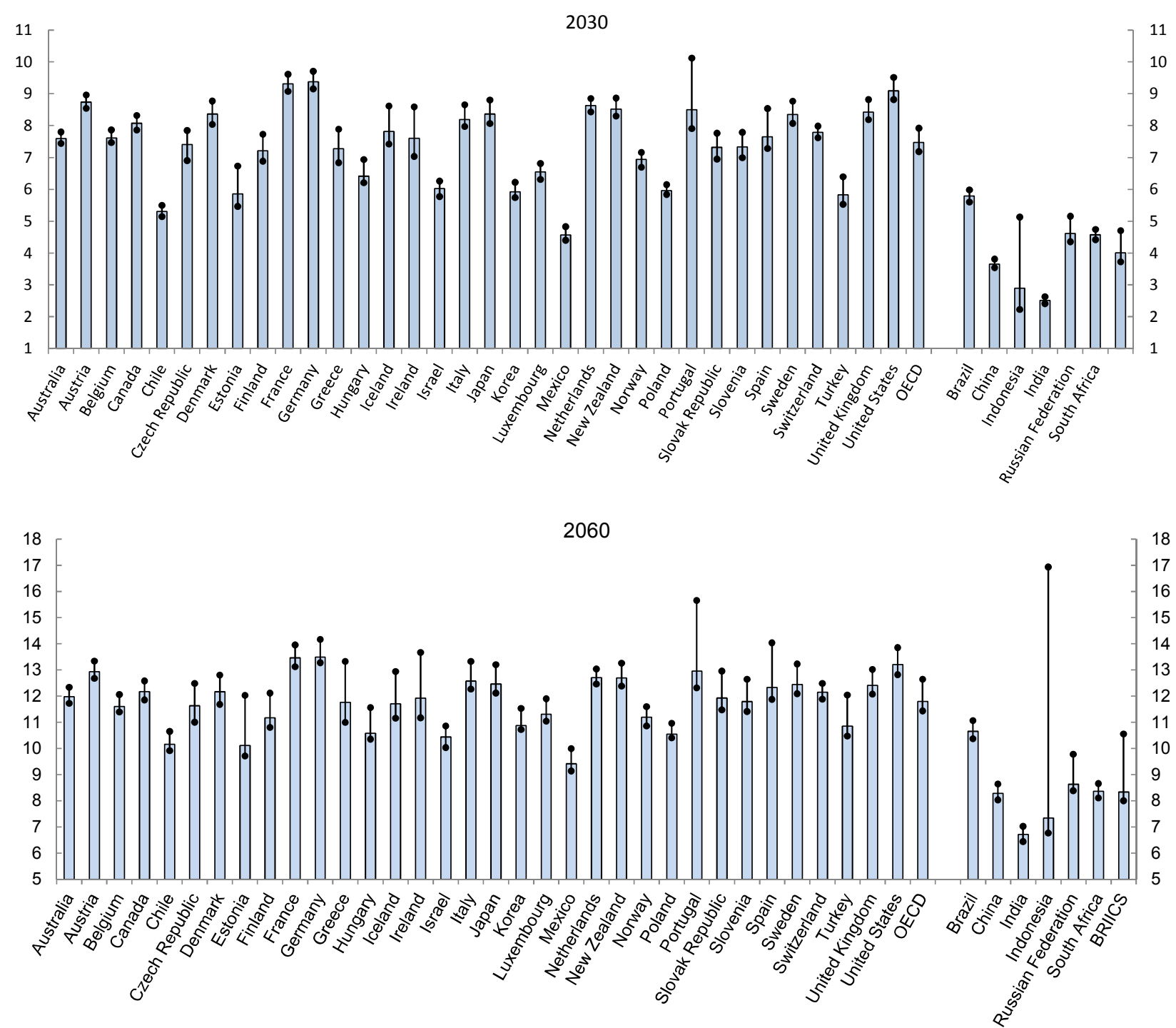

Note: The bars show the health spending to GDP ratio projections under the cost-pressure scenario of de la Maisonneuve and Oliveira Martins (2013). The top and bottom circles represent the 95th and 5th percentiles of the simulated health care spending distribution in 2060. They are obtained assuming an elasticity of health-care expenditure to GDP equal to 0.8, when real GDP rises and zero when GDP diminishes in line with the estimates provided in Pareliussen (2014).

Source: OECD calculations; OECD Long-term Database Economic Outlook 93; and de la Maisonneuve and Oliveira Martins (2013).

\section{Epidemic shocks}

20. Epidemics represent one of the major risks health care systems face, as shown by the alerts and global responses that the avian flu in the mid-2000s and SARS in early 2000s generated. Epidemic prevention and control have the characteristics of a public good (Smith et al., 2003) and for this reason, the responsibility for dealing with epidemics rests with public authorities. The prevention and control of epidemics through public health care programmes requires a high degree of coordination among different authorities and the prompt mobilisation of physical and financial resources. Most countries have legislation to avoid the spread of epidemics consisting of two parts: the identification of a health problem, and the actions taken to control it (Smith et al., 2003). 
21. Even in countries with a large share of private insurers, private insurance plays virtually no role in the prevention and control of epidemics. Losses due to epidemics cannot be insured as they are not characterised by definite and calculable losses. The individual risks associated with infectious epidemics are not independent. Furthermore, their probability and the ensuing losses are difficult - if not impossible to calculate with any degree of accuracy because they are rare events. As the total potential losses caused by epidemics can be very large, even if insurance companies offered health policies covering such events, premiums could be so high that a large share of the population could not afford them.

22. The risk of rapidly spreading epidemics across national borders - ensuing from the large international flows of people and goods - requires global coordination for epidemic control. The International Health Regulations, under the responsibility of the world Health Organization (WHO), are the only binding international agreement on public health, whereby all WHO members have agreed to notify the start of certain epidemics and limit the measures they can take to protect themselves (e.g. travel and trade restrictions) (Smith et al., 2003). The WHO also established in 2000 the Global Outbreak and Alert Response Network (GOARN) with the aim of managing disease outbreak and alerts at the international level. However, some have questioned whether current GOARN places too much emphasis on avoiding epidemic outbreaks spreading to developed countries rather than preventing such outbreaks in developing countries in the first place (Davies, 2008; Elbe, 2010).

\section{Long-term trends}

Ageing and health care systems

23. Increasing life expectancy explains little of the rising health care costs experienced in previous decades. Assuming that longevity gains will translate into additional years in good health (i.e. healthy ageing), a longer life is not among the main determinants of the projected rise in spending over the coming decades (de la Maisonneuve and Oliveira Martins, 2013).

24. Figure 4 shows that the health care spending-to-GDP ratio in 2060 is greatly affected by the assumption about healthy ageing. "Morbidity expansion" (which assumes that longevity gains do not translate into more years in good health) raises the projected health care spending-to-GDP ratio by 1.2 percentage points for the OECD countries on average and by 2.3 percentage points for the BRIICS countries. On the other hand, "morbidity compression" (which assumes that longevity gains lead to even more years spent in good health) leads to noticeably lower health care spending as a share of GDP. On average, morbidity compression could reduce the health care spending to GDP ratio by a 1 percentage point for the OECD countries and by more for the BRIICS countries. 
Figure 4. Health status in old age affects public health care spending

Projections of public health care spending to GDP ratio, 2060

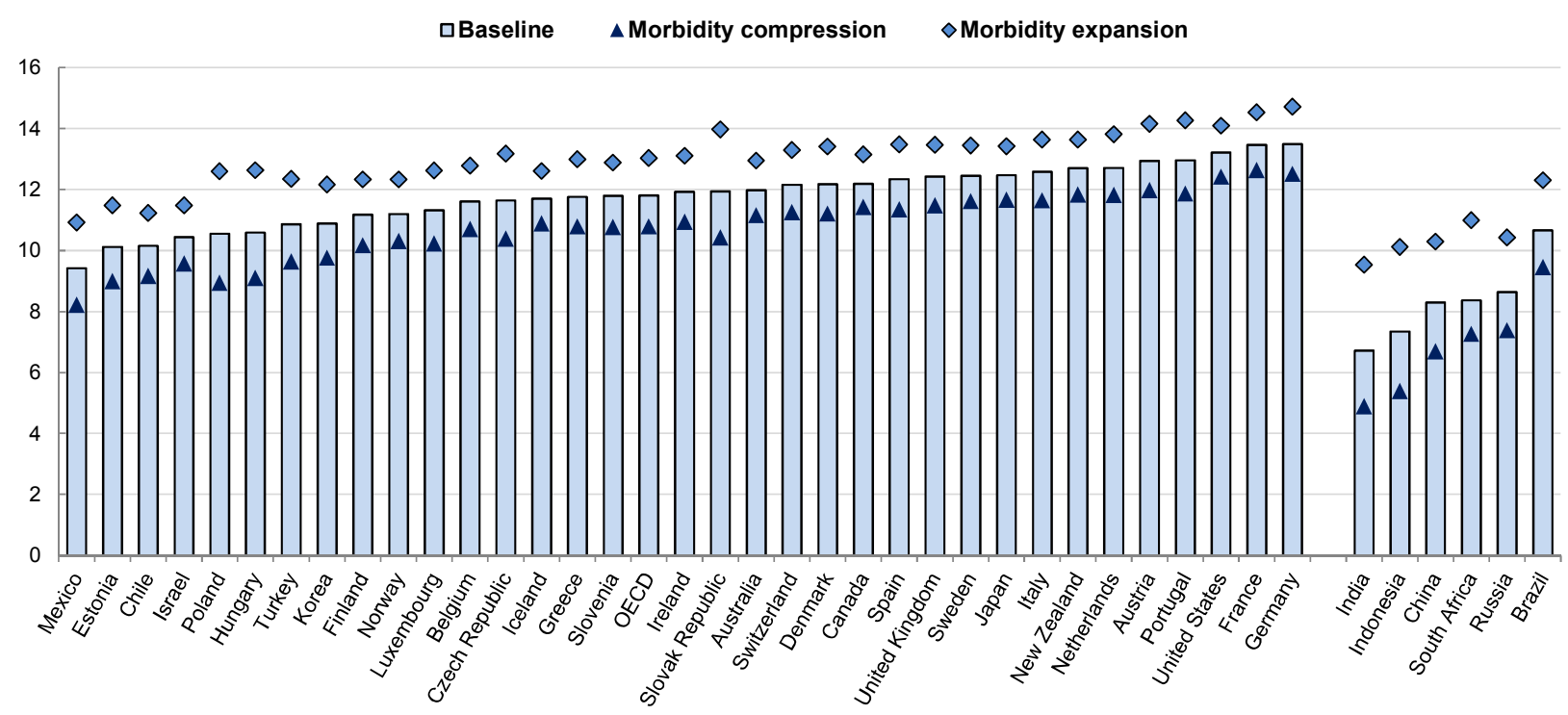

Note: In the baseline it is assumed that longevity gains translate into as many years spent in good health; "morbidity expansion" assumes that longevity gains do not translate into more years in good health; "morbidity compression" assumes that longevity gains lead to more years spent in good health.

Source: OECD calculations and de la Maisonneuve and Oliveira Martins (2013).

Lower aggregate productivity growth

25. Lower economy-wide productivity growth affects the public health spending-to-GDP ratio over the long run only marginally (Figure 5). A lower trend productivity growth rate of half percentage point was assumed and the productivity changes were translated into new GDP growth paths using the OECD Long-term Model. The effect of lower GDP on the health spending to GDP ratio is small, because the elasticity of health spending to GDP is relatively high, being 0.8 (de la Maisonneuve and Oliveira Martins, 2013).

Figure 5. The public health spending to GDP ratio is little affected by productivity changes Health spending-to-GDP ratio (2060)

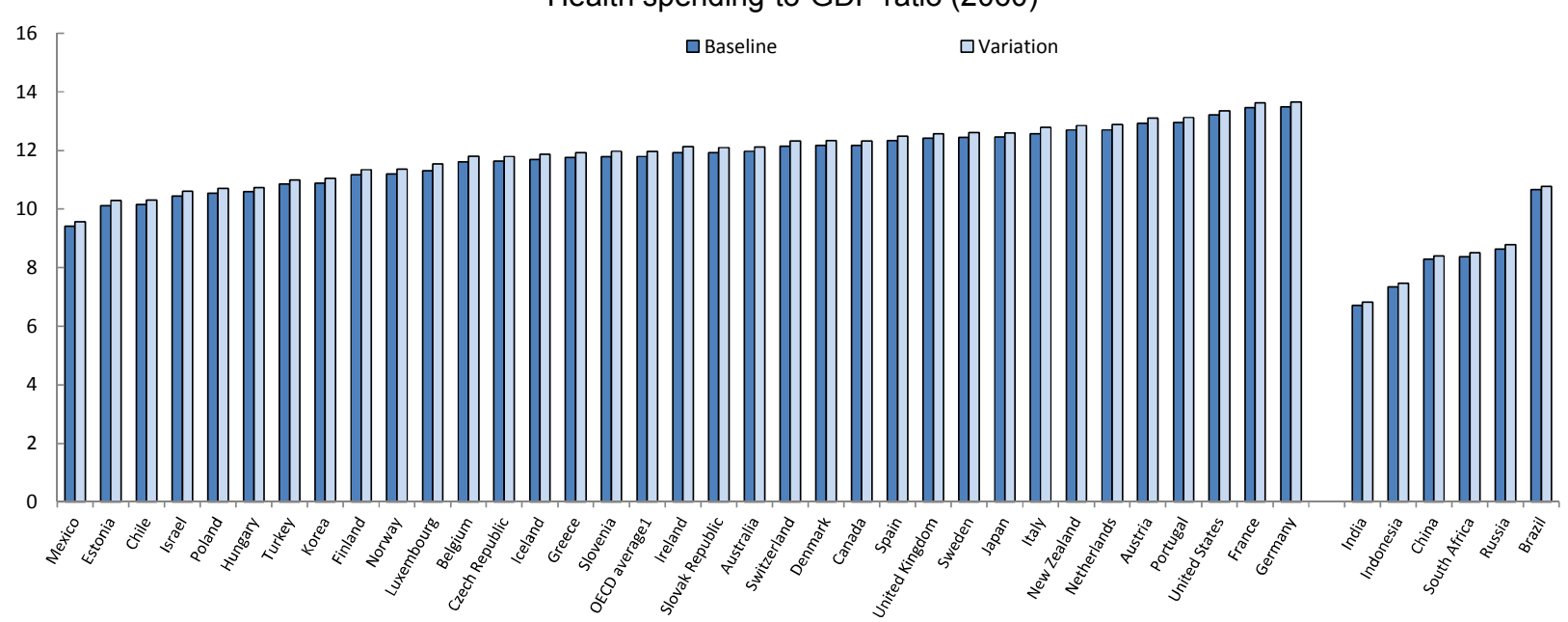

Note: The variant refers to a scenario with a $1 \%$ yearly productivity growth rate instead of $1.5 \%$ as in the OECD long-term baseline scenario. The elasticity of health spending to GDP is 0.8 .

Source: de la Maisonneuve and Oliveira-Martins (2013) and OECD Long-term Database Economic Outlook 93. 
Price and technology developments

26. Price and health technology developments are an important determinant of health spending growth. De la Maisonneuve and Oliveira Martins (2013) show that for OECD countries they explain about $50 \%$ of the public health care spending variation from the 1990 s to the late 2000 s and $40 \%$ for the BRIICS countries. The rest is due to demographic and income effects.

27. Figure 6 shows that the impact of alternative price and technological developments to 2060 on the projected health care spending-to-GDP ratio could be large. The difference between the cost-pressure and cost-containment scenarios, as defined by de la Maisonneuve and Oliveira Martins (2013), approaches 4 percentage points. The cost-pressure scenario assumes that health care spending attributable to price, technology and health care policies and institutions will keep growing as in the past (1.7\% annually). The cost-containment scenario assumes a gradual decrease in the yearly growth of health care spending relating to price, technology and health care policies and institutions from $1.7 \%$ to zero in 2060 .

Figure 6. Price and technological developments affect the public health spending-to-GDP ratio Projection for 2060

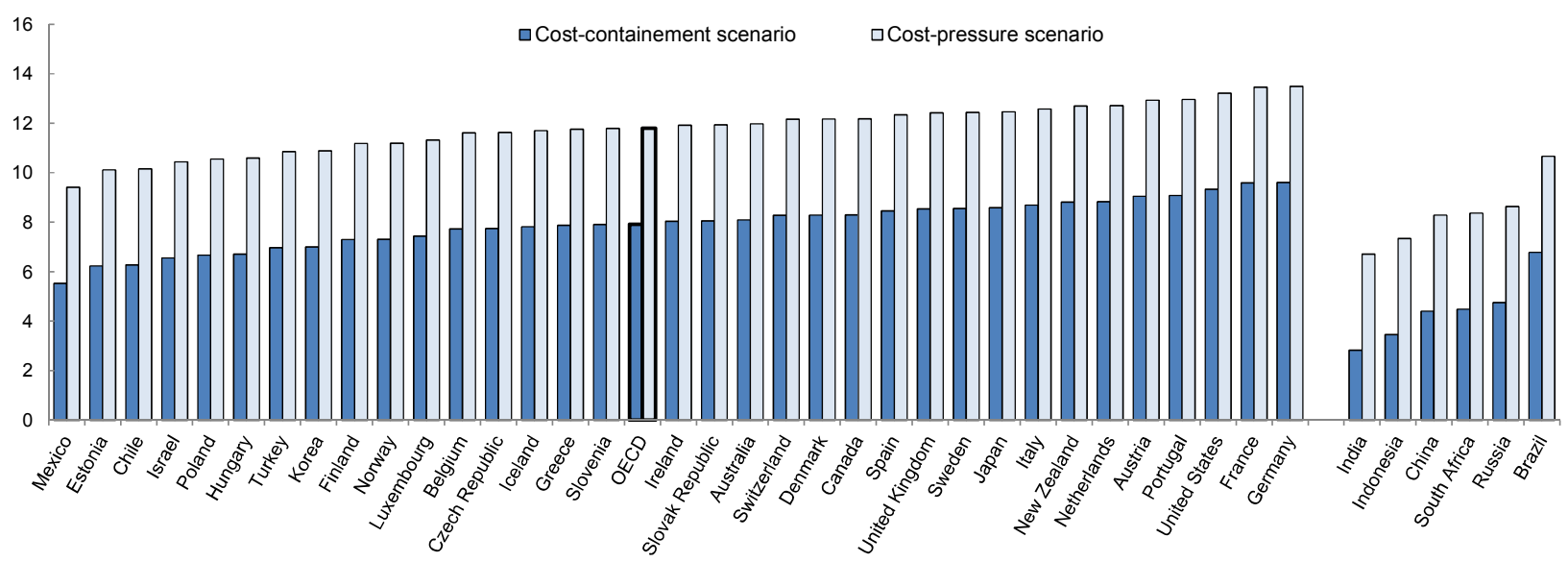

Note: The cost-pressure scenario is based on the assumption that the health care spending attributable to price, technology and health are policies and institutions will keep growing as in the past $(1.7 \%$ annually). The cost-containment scenario assumes a gradual decrease in the yearly growth of health spending relating to price, technology and health care policies and institutions from $1.7 \%$ to zero in 2060.

Source: de la Maisonneuve and Oliveira Martins (2013).

\section{Main determinants of health care spending and policies to contain it}

28. The long-term health care cost drivers can be broadly subdivided into demographic and nondemographic factors. Demographic factors include the age structure of the population and its health status whereas the non-demographic ones encompass income, technology and relative prices. Health care institutions and policies determine the importance of non-demographic factors. A recent study reveals that for the OECD countries demography and income have accounted for about $50 \%$ of the health care expenditure growth since the 1990s (de la Maisonneuve and Oliveira Martins, 2013, Table 2.1). The remaining share is explained by technology, relative prices and health-care sector institutions and policies. In Brazil, China, India, Indonesia, Russia and South Africa, the health spending increase due to technology, prices, institutions and policy is lower but still sizeable (at around $40 \%$ ).

29. Hall and Jones (2007) offer a more sanguine view on the rising share of health spending in GDP. They argue that as income per capita increases the composition of spending should shift towards health 
outlays since better health lengthens life expectancy. Longer lives allow individuals to enjoy additional periods of utility. ${ }^{4}$ According to their simulations, the optimal level of health spending in the United States could reach $30 \%$ of GDP by mid-century against $18 \%$ in 2011 .

30. However, even if a large share of the secular increase in health expenditure has an economic rationale, market failures and incentives built in health care policies and institutions can lead to overspending. For instance, systems based on third party payments tend to oversupply medical services as the payer - either the state or the insurer - is divorced from the decisions of doctors and patients (Barr, 2012). Moreover, recent research has questioned the marginal health benefits of additional health spending in developed countries (Garber and Skinner, 2008).

31. Controlling health care spending is key to enhance the sustainability of health care systems. The main reforms aiming at controlling the secular increase in health spending and their impact on health care systems' adequacy and sustainability are analysed in this section. Following the framework by Joumard et al. (2010) and Moreno-Serra (2013) the reforms to control health care spending can be classified into three categories: demand side, supply side, and cross cutting issues. ${ }^{5}$

\section{Demand side}

\section{Cost sharing}

32. Cost-sharing schemes aim at restraining the demand for health care services by requiring users to pay a share of the medical or prescription bills. Some countries use cost sharing arrangements more intensively than others (Figure 7). Overall, cost sharing has proved to be effective in curbing public health spending growth, at least in the short run (Baicker and Goldman, 2011; Moreno-Serra, 2013). Yet, if adopted indiscriminately, cost sharing can heighten the vulnerability of both individuals and health systems to shocks. First, cost sharing shifts parts of health risks and associated costs to individuals, thus effectively reducing risk pooling. Second, cost sharing usually fails to discriminate between high and low-value health care treatments, leading less well-off people to postpone or forego necessary treatments or preventive care. Rising cost-sharing, especially during recessions when people are more likely to experience drops in personal income, may have nefarious health consequences over the long run, ultimately leading to higher health care costs and health inequality. ${ }^{6}$

33. Cost sharing schemes do usually not discriminate between effective and less effective treatments and medicines. Value-based cost sharing is a refinement of traditional cost sharing schemes as copayments are inversely related to the value (in terms of health benefits) of the care purchased (Thomson et al. 2013, Baicker and Goldman, 2011). The main objective of value-based cost sharing is to reduce the purchase of health care with a low-cost effectiveness. There is evidence that value-based cost sharing can be successful in reducing health costs for people with chronic conditions (the United States) and in

4. While the marginal of utility of consumption falls rapidly the marginal utility of life extension does not.

5. Joumard et al. (2010) also provided a health care system typology ranging from policy settings with a strong reliance on market mechanisms to those that rely mainly on public provision and insurance. They argue that to reap efficiency gains it is important to increase the consistency of policy settings within a system, while no system is superior to another.

6. The Rand insurance experiment and other studies in the United States have reported that higher costsharing resulted in lower rates of intake of needed medical care with no adverse impact on health, on average; however for the poorest and sickest cost-sharing led to worse health outcomes (Brook et al., 2006; Moreno-Serra, 2013). 
preventive programmes (Germany). The cost of assessing the value of health care services and operating value-based cost sharing is, however, high and several countries have thus abandoned value-based policies.

Figure 7. Degree of cost sharing

Private household out-of-pocket expenditure as a percentage of total health expenditure

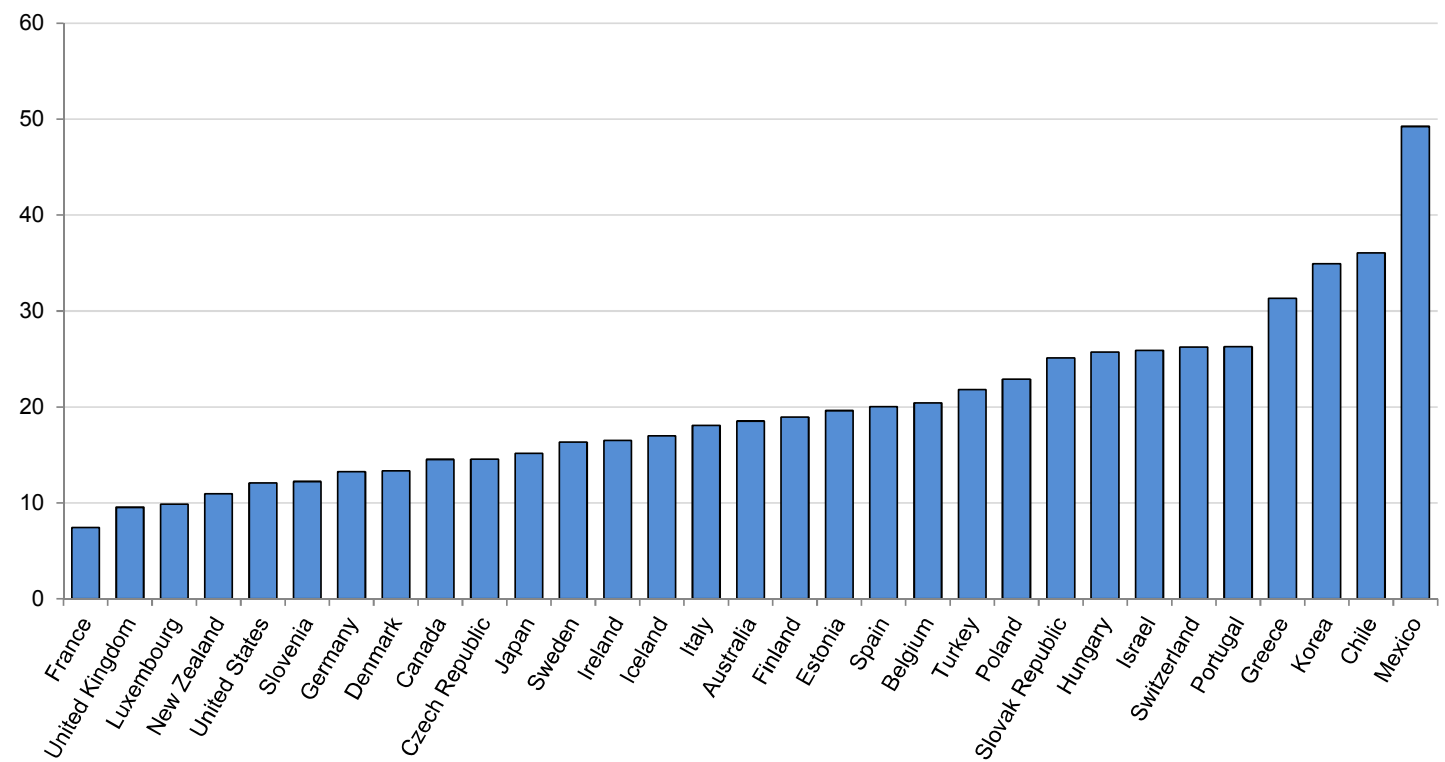

Note: Data refer to the five year average 2007-2011, with the exception of Australia and Mexico (2007-2010), Greece (2008-2011) and Turkey (2007).

Source: OECD Health Database, accessed 14 April 2014.

Private health insurance enrolment incentives

34. To contain public health spending, some governments have introduced incentives to subscribe to private medical insurance plans. These incentives generally consist of tax reliefs on health insurance premiums. The premise of this policy is that the reduction in public health expenditure due to a higher take-up rate of private insurance will outweigh the value of public subsidies. OECD countries with such incentives include Australia, Ireland, Portugal, Spain the United Kingdom and the United States.

35. Empirical evidence indicates that such tax incentives tend to be ineffective in reducing health spending. The conclusion of studies investigating the merits of these schemes is that their costs outweigh the savings they generate (e.g. Emmerson et al., 2001; López Nicolás and Vera-Hernández, 2008; Tapay and Colombo, 2004). In addition, these tax incentives appear to be highly regressive, as the subsidies accrue disproportionately to the well-off, who would buy private health insurance without subsidies. 
Gatekeeping

36. Gatekeeping requires primary-care physician referrals to access specialists and/or secondary care. Its use varies considerably across countries (Figure 8).

Figure 8. Gatekeeping

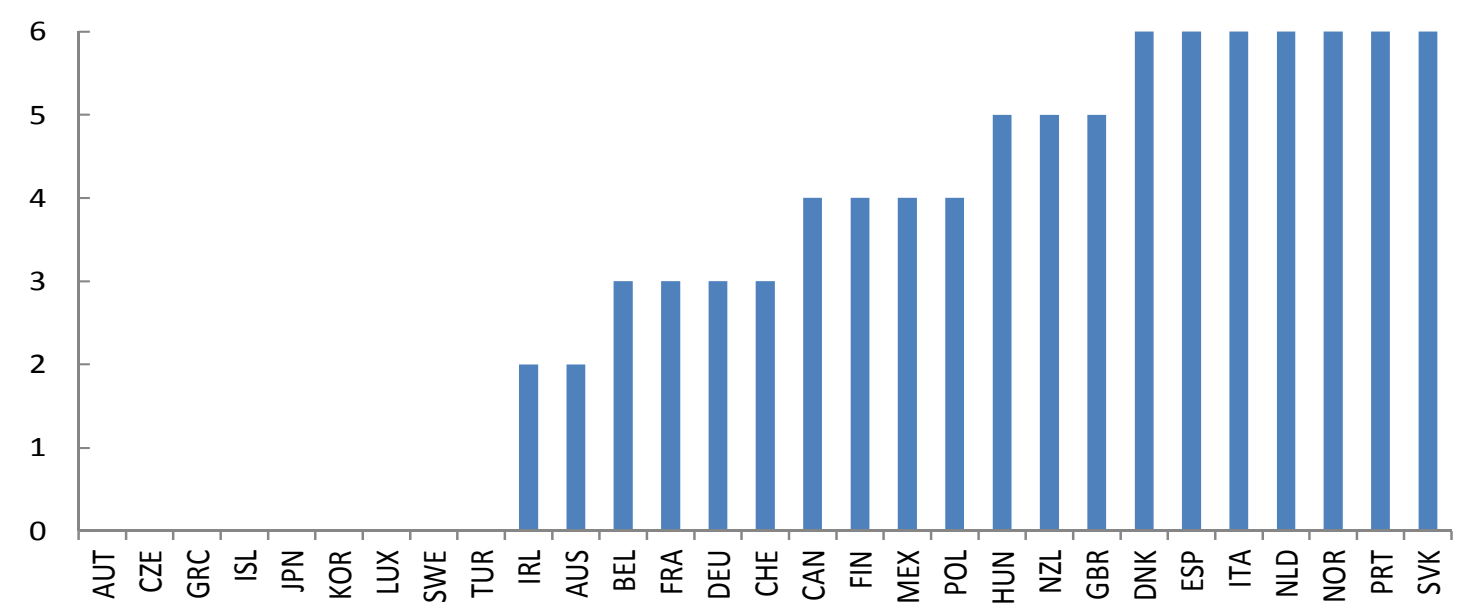

Note: $A$ " 0 " score is attributed to countries where patients face no obligation or incentive to register with a GP and to obtain referral to access secondary care.

Source: OECD Survey on Health System Characteristics 2008-09.

37. Cross-country evidence indicates that gatekeeping arrangements have contributed to contain health expenditure (Gerdtham et al., 1998). Country-specific evidence also corroborates that gatekeeping is effective in containing health costs. Dusheiko et al. (2006) show that the introduction of gatekeeping in the United Kingdom, accompanied by new capitated-budget-fundholding rules (see below), restrained spending. ${ }^{7}$ Similarly detailed evidence on gatekeeping schemes is scant, however. Some have argued that the lower costs of health care systems relying on gatekeeping result from supply side constraints rather than demand management (Forrest, 2003). Countries that have set up gatekeeping arrangements often have traditionally had a limited supply of specialists and therefore have rationed access to them.

Preferred drug lists and mandated generic substitution

38. Preferred drug lists identify pharmaceuticals with lower co-payments with respect to others within the same class. Drugs are warded preferred status based on cost-effectiveness criteria. As regards patented drugs, preferred drug lists are used in the United States only, as insurers negotiate discounts with manufacturers. There is evidence that preferred drug lists have led to cost savings, as pharmaceutical companies lower prices to avoid going off list (Kibicho and Pinkerton 2012; Elzinga and Mills 1997).

7. Fundholding consists in fixing the budget of health care providers while assuming an arms-length position in relation to service delivery. The fundholder is expected to be to obtain services at the best price/quality ration or suffer the consequences of budget over-runs. 
39. Mandated generic substitution polices aims at steering the demand for drugs towards generic as they cheaper than their branded equivalent. This policy has been implemented, to a different extent, in some OECD countries, such as Australia, Denmark, Finland, Germany, the Netherlands, Sweden, Slovakia, the United States (Vogler et al., 2008; Ferner et al., 2010). During the 2000s, several EU countries adopted policies promoting generics (indicative generic substitution) and as a result the share of generics rose. Central and eastern European countries have traditionally been a centre of production of generics and consequently the share of generics has always been high (around 50\%). Overall, the common view is that these policies have been helpful in curbing pharmaceutical expenditure growth (Morgan et al. 2004; Andersson et al. 2007 and 2008; Shrank et al., 2010; Vogler et al. 2008) with no negative health effects.

\section{Supply side management}

\section{Budgetary caps}

40. Historically, budget caps have been deployed in the hospital sector as it accounts for a large share of total health costs (Docteur and Huxley, 2003). To minimise cost shifting to parts of health systems not covered by caps, they have often been complemented with global and supplementary spending ceilings on ambulatory care and pharmaceuticals. The OECD Survey on Health System Characteristics 2008-09 shows that countries with an integrated health care systems - i.e. those relying on public provision and insurance whereby the financing and supply of health care are managed by the same entity, such as New Zealand, Norway, Poland, Portugal, Sweden and the United Kingdom - have the most stringent budget controls. ${ }^{8}$

41. Many countries where health care systems are financed through social insurance contributions (e.g. Belgium, France, Luxembourg) feature relatively mild budgetary constraints. In this setting, budget caps have tended to provide indicative rather than binding targets. Targets are set in relation to expected social insurance contributions and the government has limited direct control over them as social security rates are determined, to a different extent across countries, by the social security funds (Paris and Devaux, 2010). In some countries (the Czech Republic, Japan, Luxembourg, the Netherlands, Spain and Switzerland) the legislature is less actively involved in the determination of health care spending and its allocation than in other countries.

42. Four OECD countries (Austria, Japan, Korea and Switzerland) have no prospective budget or explicit target (Figure 9). However, these countries monitor health care spending and attempt to control spending with different instruments. Japan has a five-year strategic plan, with health care expenditure projections. In Switzerland, some cantons set budget envelopes for hospital care and beyond a certain volume of care they reduce their funding of hospitals. In addition, physician services' costs are monitored through joint agreements between insurers and physician's associations, which include measures to curb spending growth, if necessary (Paris and Devaux, 2010).

8. Ireland also applies a strict budget constraint, but spending targets are based on historical costs. This practice weakens the effectiveness of budget cap to control spending. 


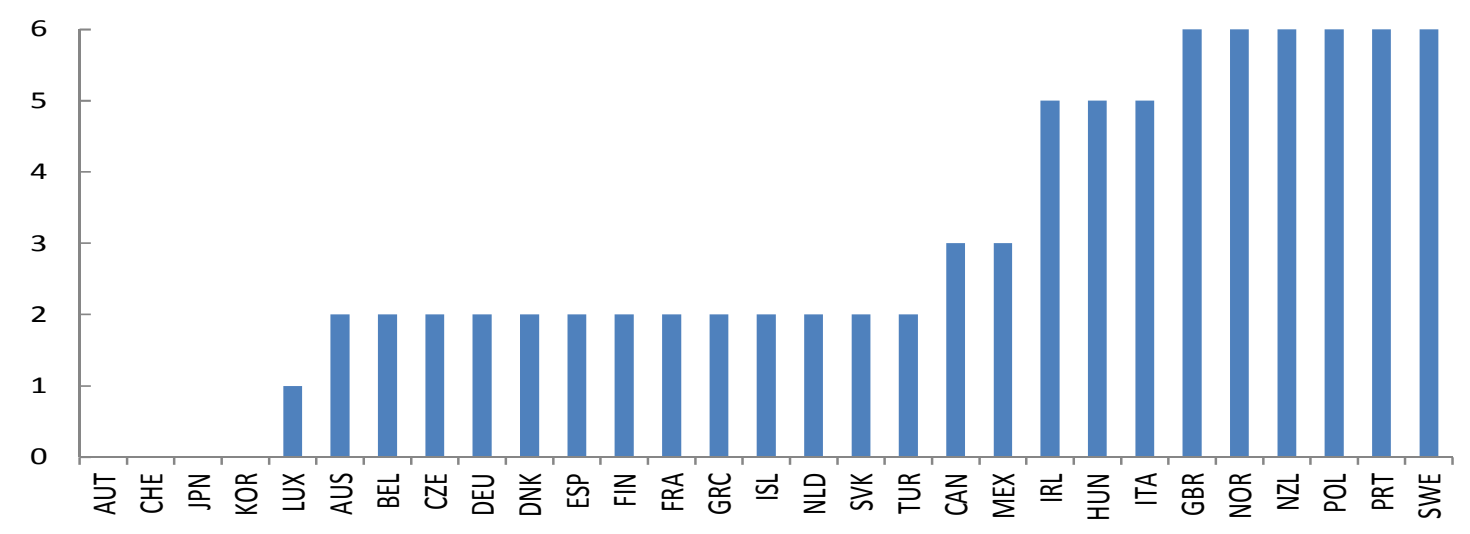

Note: A " 0 " score is attributed to countries with no budget constraint defined annually for public spending at the system level, 6 to countries with a strict health budget constraint.

Source: OECD Survey on Health System Characteristics 2008-09.

43. There is evidence that stringent budget constraints curb the growth of health spending. De la Maisonneuve et al. (2014) find for a panel of OECD countries that the indicator of budget stringency shown in Figure 10 is negatively associated with public health spending growth. This is consistent with the OECD Survey on Health System Characteristics Survey, which indicates that countries with medium or stringent budget constraints (Figure 10, right panel) are more likely to implement cost-containment policies than those with a soft or no budget constraints (Figure 5, left panel). However, there is not much difference in the share of countries reporting to have raised social security contributions or taxes or let the budget deficit increase between the two sets of countries.

Figure 10. Stringent budget constraints make the implementation of cost containment policies more likely

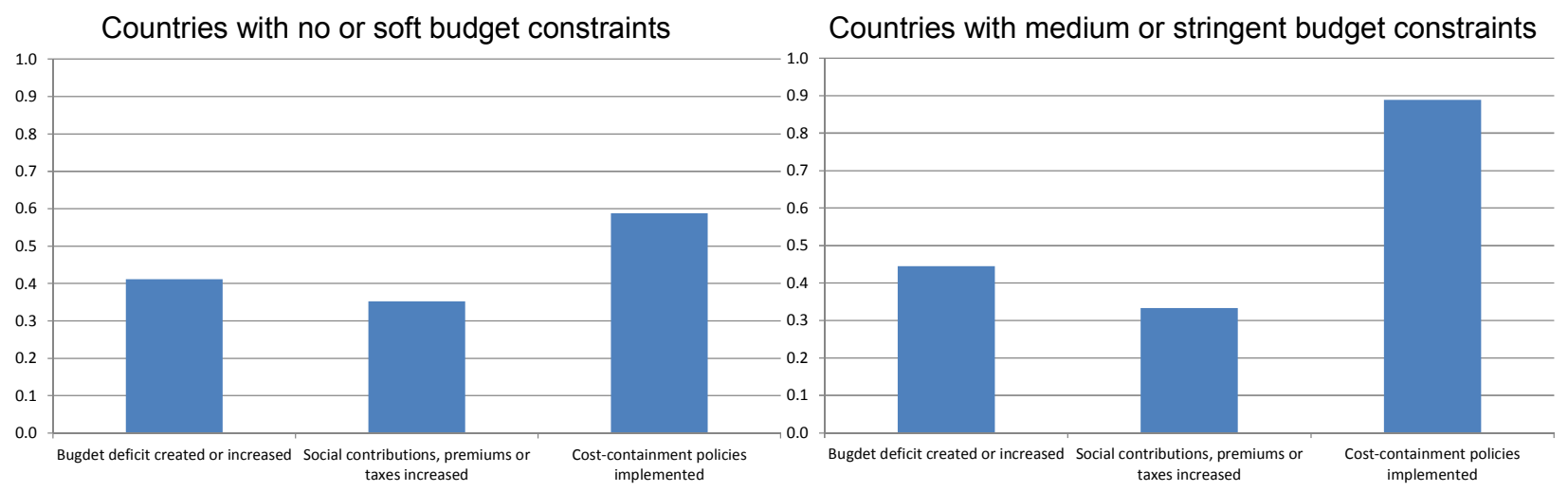

Note: The bars show the share of countries reporting to have applied the indicated policy having reached the spending or budget limits in the five years prior to 2008-09.

Source: OECD Survey on Health System Characteristics 2008-09.

Physicians' payment arrangements

44. Physician payment methods fall into three broad categories: Salaries, capitation and fee for services (Ellis and Miller, 2008). Capitation (and more generally the use of pre-defined budgets for 
physicians, i.e. fundholding) permits a stricter control over health costs as they transfer the responsibility over resource allocation to physicians. The drawback is that they may provide weak incentives to maintain or improve the quality of care. Fee-for-service and salary schemes are likely to lead to overprovision of healthcare. However, there have been attempts within fee-for-service schemes to limit cost increases by reducing fees and combining them with hard budget constraints (Moreno Serra, 2013; Paris and Devaux, 2010).

45. There is evidence for the United Kingdom that the abolition in 1999 of the general practitioners (GPs) fundholding scheme led to an increase in elective surgeries by 3.5-5.1\% (Dusheiko et al., 2006). Under the GPs' fundholding policy, GPs could choose to have a fixed budget to finance some types of elective surgery for their patients and retain any surplus. This policy provided strong incentives to limit the number of elective surgeries. Also, there is no evidence that the fundholding resulted in cost shifting to higher level care.

\section{Hospital payment arrangements}

46. Payment for hospital care can be based on provider characteristics (e.g., line-item budgets, such as salaries, supplies, transportation or drugs, or prospective global budgets); patient characteristics (e.g., diagnosis-related groups, i.e. DRGs); service characteristics (e.g., fee for service or payment per case). Payments based on provider or patient characteristics tend to provide stronger incentives to control spending than those based on service characteristics, as the latter can result in service oversupply.

47. There is evidence that DRGs lead to reductions in average spending per hospital case. The United States was the first country to adopt DRGs in the early 1980s for Medicare's in-patient payments. Several studies have shown that the introduction of DRGs cut the length of stay and costs of hospitalisation, with no adverse effect on the quality of care (Davis and Rhodes, 1988; Coulam and Gaumer, 1991; Cutler, 1995). DRGs, however, may move the locus of health service delivery from hospitals to less costly outpatient settings, thus blurring the effect of DRGs on overall health costs. Similar findings were reported, inter alia, by Moreno-Serra and Wagstaff (2010) for Eastern European and Asian countries, Louis et al. (1999) for Italy and Kwon (2003) for Korea.

48. DRGs are not without risks, however. DRGs are more effective in controlling the volume of health care services than fee-for-service payments but not in comparison with volume caps. The latter, however, may result in long waiting lists and de facto rationing health care. For instance, in Stockholm the introduction of DRGs in the 1990s - coupled with free choice of provider -resulted in a sharp increase in activity and spending, which led to the re-imposition of central expenditure control through penalties for exceeding volume limits (Docteur and Oxley, 2003). Germany, which uses "pure" DRGs as a price and reimbursement mechanism for hospitals, has experienced faster growth in the volume of hospital services than countries combining DRGs with prospective global budget, such as the United Kingdom, France and Australia (Kumar and Schoenstein, 2013).

49. Overall, DRGs accompanied by global budgets offer the opportunity of making health systems more sustainable as they provide strong incentives to improve efficiency, while avoiding the rationing of health care. DRGs can also provide incentives to discover and promote cost-effective treatments thus reinforcing the beneficial effects of cost/benefit assessments of treatments (see below). Line-item budgets along with prospective global budgets are also effective in containing costs but have the drawback of lengthen waiting lists if the allocated budgets are set too low to satisfy the genuine demand for care. 
Competition among providers and insurers

50. Whether competition among insurers and health care providers contain cost is a contested issue. The seminal contribution by Arrow (1963) underlined how the pervasive market failures in health care markets lead unfettered competitive forces to lower rather than raise welfare. Nonetheless, several OECD countries have recently strengthened competition by introducing regulated choice mostly among providers and to a lesser extent among insurers. These reforms are based on the presumption that competition coupled with a good regulatory setting will improve health care service quality while limiting the adverse effects of unfettered market forces, most notably cream skimming, selective coverage, and unequal access to services.

51. In more than half of the OECD countries, patients have considerable choice among health care providers (Figure 11). Recent evidence, mostly covering the United Kingdom and the United States, shows that competition among hospitals, if accompanied by strong and effective regulation, can lower expenditure and/or enhances quality of care (Gaynor et al., 2013; Cooper et al., 2011; Kessler and McClellan, 2000). An early evaluation of the reforms initiated in Sweden in 2007 with the goal of increasing choice of primary care doctors indicate that they have improved access to health care (Anel et al., 2012). For a panel of OECD countries, de la Maisonneuve et al. (2014) corroborates these findings as the choice among providers is negatively related with total health spending growth.

Figure 11. Patient choice

Among health care providers ${ }^{1}$

Among insurers ${ }^{2}$

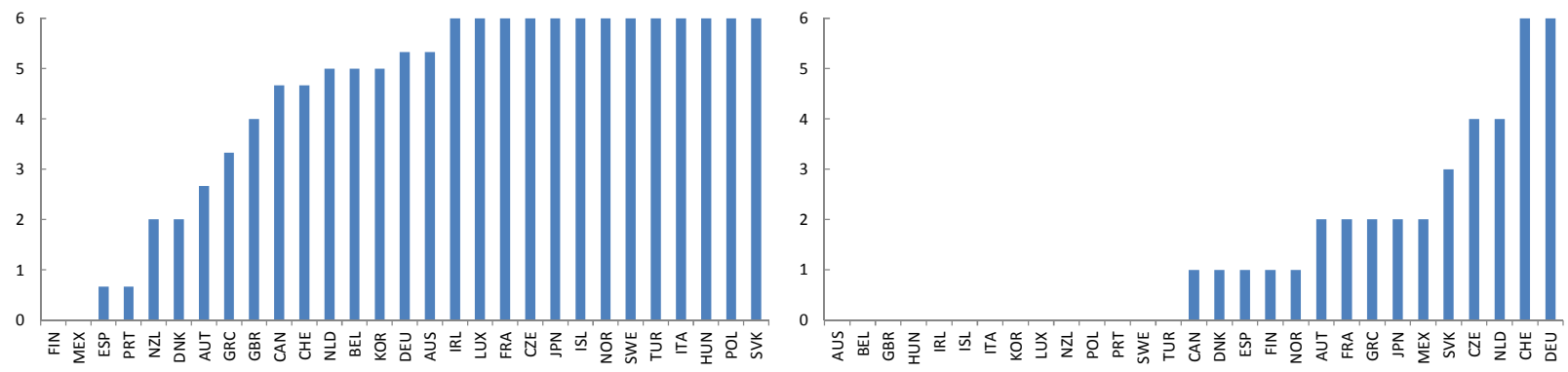

1. Degree of freedom in choosing among primary care physicians, specialists and hospitals. A "0" score is attributed to countries where patients face severe limitations when choosing a primary care physician, a specialist and a hospital.

2. A "0" score is attributed to countries with a single national scheme (NHS or single-payer system).

Source: OECD Survey on Health System Characteristics 2008-09.

52. Various institutional aspects of the health care systems mediate the impact of competition on hospital costs and patients' health outcomes. In the United States, competitive pressures have fostered the development of Health Maintenance Organisations (HMOs) since the 1980s (Kessler and McClellan, 2000). HMOs appear to have contributed to control costs and improve efficiency relative to "traditional" private health insurance plans, by negotiating service prices with competing hospitals, and directing HMO participants to hospitals with the most cost-effective services (e.g. Baker, 1999; Miller and Luft, 2002). However, effective health quality monitoring by regulators is crucial as recorded quality care improvements may be due to hospitals focussing on monitored quality indicators while neglecting unmonitored and unobserved quality aspects (Propper et al., 2008).

53. The overall experience is that regulated competition among private insurers has contributed to better align benefit packages to purchasers' preferences, but health care cost reductions have proved elusive. Some OECD countries featuring multiple health insurers have experimented with greater 
competition by allowing users to choose health insurers (the Czech Republic, the Netherlands, Germany, the Slovak Republic, Switzerland). The United States features the most developed health insurance market, but it has not succeeded in containing total costs in addition to failing to ensure full coverage. ${ }^{9}$ This is consistent with the results by de la Maisonneuve et al. (2014) who find that choice among insurers for basic health coverage has no statistical significant effect on total health care spending and a positive and statistical significant effect on public health care spending.

54. One likely reason for the absence of saving is that competitive forces in insurance markets have not spilled over to health care providers (van Ginneken et al., 2013). Contractual relationships between insurers and providers are complex and still rare. Health insurers in the Czech Republic, the Netherlands and the Slovak Republic are allowed to select health care providers but this opportunity is rarely used. Insurers and providers negotiate as collective groups under governmental regulatory oversight and negotiated prices will apply to all. Moreover, insurers still face large informational asymmetries vis-à-vis providers, lessening their bargaining power. ${ }^{10}$

55. Overall, strengthening competition in the health care sector, if accompanied by appropriate regulation, has the potential of increasing the sector's resilience to shocks by lowering spending pressures. Effective regulation seems to be paramount as market forces - if unchecked - are likely to result in overprovision of health care services, especially in periods of economic bonanzas, and reduction in coverage and services - at least for some part of the population - during recessions. Regulated competition can also better align health care service characteristics with patient preferences, allows for the setting and enforcing quality-of-care standards, promotes access to care (with, for instance, means-tested subsidised insurance premiums) and strengthens incentives to achieve efficiency gains. Well-regulated systems can yield cost savings and help ensure an adequate level of care, but getting the regulatory setting right has proved to be challenging.

\section{Workforce supply, wage and equipment controls}

56. Baumol (1996) attributed the ever rising health care costs to stagnant labour productivity coupled with wage increases for health care personnel. He called this phenomenon the "cost disease". As a response, several OECD countries have deployed, to a different extent, workforce supply and wage controls along with controls of high-tech hospital equipment (Figure 12).

57. Wage controls have been more frequent in countries with public-integrated systems and where health-care personnel are paid on a salary basis (e.g. Denmark, Finland, Ireland, Spain, Sweden and the United Kingdom). Overall, in the short-term tight wage controls can be effective in containing spending (Docteur and Oxley, 2003).

58. Entry regulations for medical schools do not explain the large variation across OECD countries in the supply of physicians per capita. Only in four OECD countries the number of medical students is unregulated: the Czech Republic, Germany, Japan and Luxembourg. However, in these countries, doctor density is not dissimilar from OECD countries that apply entry regulations (Paris et al. 2010). Overall, the net effect of limiting the supply of the healthcare workforce on the wage bill and spending is unclear. Some

9. The Patient Protection and Affordable Care Act - passed in 2010 - introduces important reforms to the health care system. The individual mandate aims at reaching full health coverage.

10. The selection of providers on the part of insurers requires the development of a national quality framework and clear benchmarks against which the performance of providers can be compared. Provider profiling also necessitates substantial investment in data infrastructure by insurers. 
countries, such as the Canada and the United States, that have restrained the number of practicing medical professionals recorded stronger wage pressures, partially offsetting the lower number of professionals (Moreno-Serra, 2013).

Figure 12. Regulation of the health workforce and equipment control

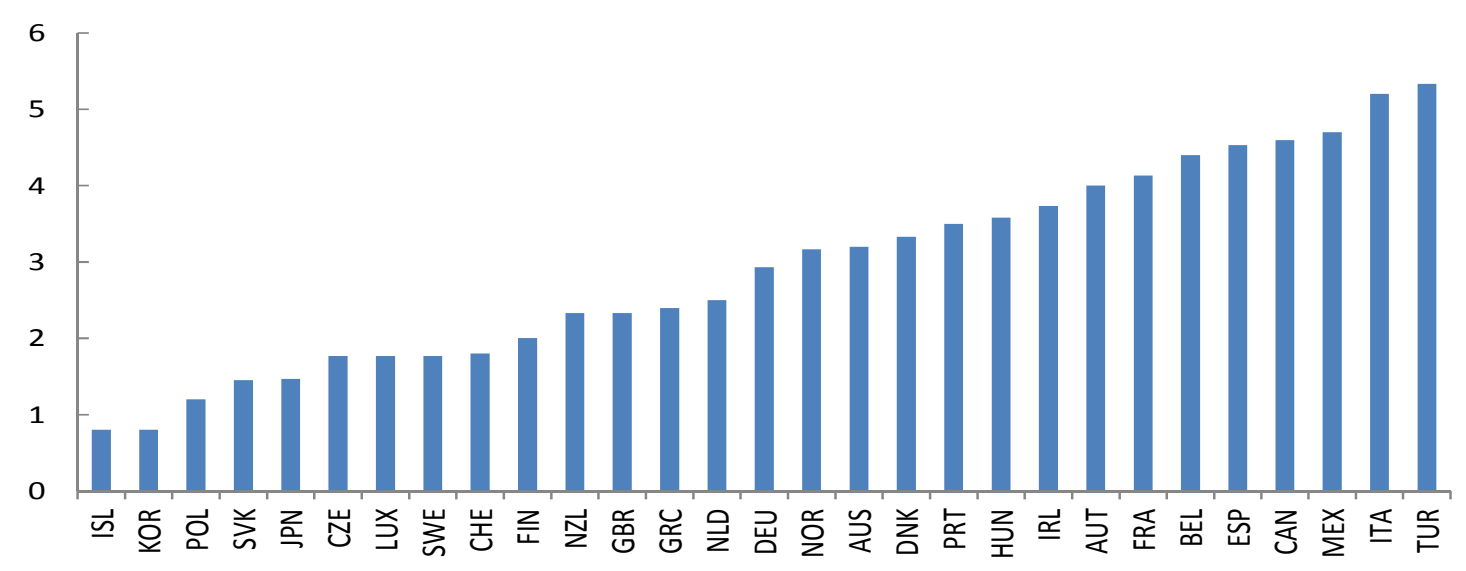

Note: A low score reflects low levels of regulation on in-patient high-tech equipment, activities and staff as well as out-patient physicians.

Source: OECD Survey on Health System Characteristics 2008-09 and OECD estimates.

59. Both workforce supply and wage controls pose risks to health systems in the long run. If used over a long period of time, wage controls might reduce labour supply, resulting in an under supply of skilled personnel, which may be difficult to reverse. For instance, in Finland the reduction in the number of doctors enacted in the early 1990s to curb health spending resulted in a steep drop in the number of medical students, resulting in an insufficient number of doctors in the following years that is slowly being reversed (OECD, 2012a).

Pharmaceutical price controls and procurement

60. Drug price controls usually fix a maximum price for drugs or set a cap on the profits of pharmaceutical firms. The vast majority of OECD countries apply some form of pharmaceutical price regulation (Paris et al., 2010). Direct price regulation is the most common type (e.g. France, Italy, Japan and Spain). Some countries also apply reference reimbursement prices for groups of drugs having similar therapeutic effects, usually based on the cheapest product within each group (e.g. Germany, the Netherlands and New Zealand). The United Kingdom does not directly regulate prices but instead sets yearly limits on the profits drug companies can earn from sales to the NHS.

61. These policies seem to have lowered pharmaceutical spending growth (Moreno-Serra, 2013). However, the medium and long-term effects of these policies need to be evaluated as they might have important supply-side effects, as lower profits could lead to reduced R\&D spending and hinder the development and supply of new drugs or the introduction of cheaper alternatives. De la Maisonneuve and Oliveira Martins (2013) show that over the long term, new technologies - as inferred from the residuals of their regressions - could play an important role in limiting the growth of health expenditure. 


\section{Cross-cutting issues}

Decentralisation

62. Decentralisation involves the transfer of different aspects of financing and/or delivery of health care services to sub-national authorities. The rationale behind decentralisation is that local authorities can be more responsive to local preferences and needs, thereby resulting in a better allocation of resources and higher cost efficiency (Saltman et al., 2006). Some countries show a high degree of decentralisation (Figure 13).

Figure 13. Degree of decentralization

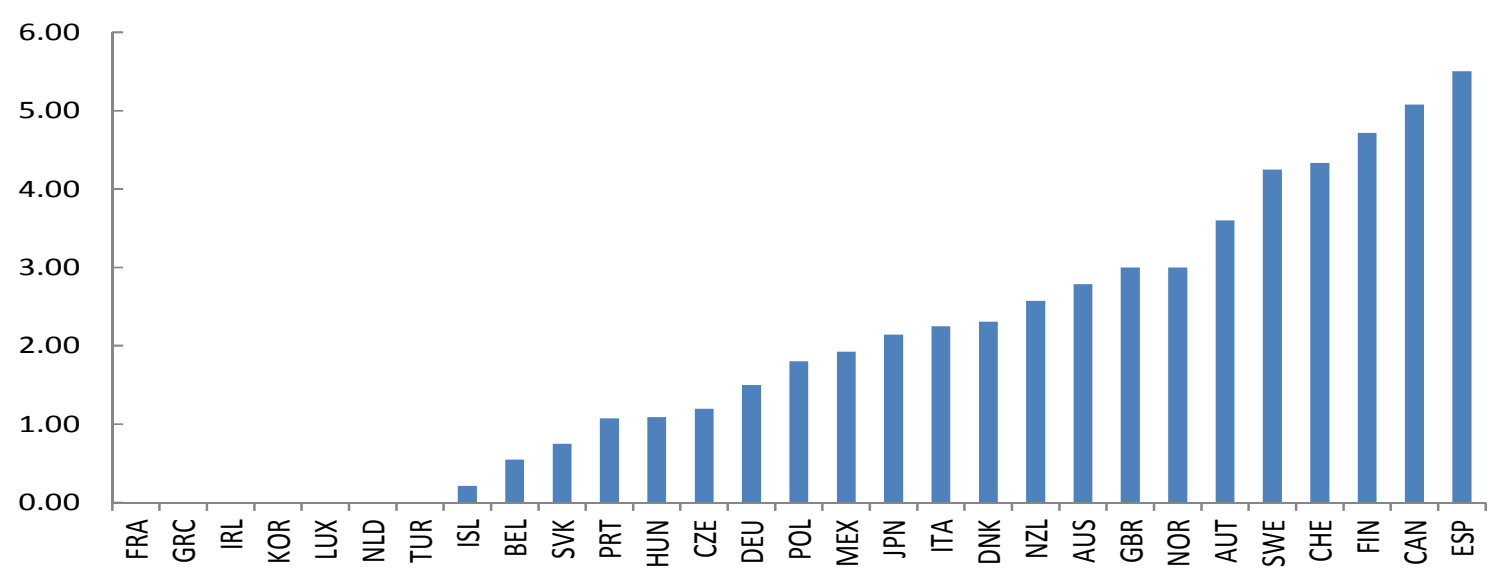

Source: OECD Survey of Health System Characteristics 2008-09 and OECD estimates.

63. In some countries (e.g. in Italy and Finland), decentralisation appears to have coincided with slowing health cost growth. In these countries, however, the devolution of responsibilities to local health authorities was accompanied by budget cuts and the imposition of hard budget constraints at the local level (Giannoni and Hitiris, 2002; Linna, 2000). In other countries, such as Denmark, Norway, and Spain decentralisation has not generated the expected savings mainly because of soft budget constraints, coordination issues and duplication of services (Magnussen et al., 2006; Costa-Font and Pons-Novell 2007). As a result, some of them (Denmark and Norway) have recentralised key aspects of health systems.

64. Although decentralisation - if accompanied by a hard budget constraint at the local level - can reduce health care spending, it can also widen interregional health disparities. Devolving responsibilities for managing and/or financing health care can widen the inter-regional variation in per-capita health spending and efficiency levels because of different managerial and organisational capacity. National guidelines, performance criteria and equalisation funds across areas can offset this tendency but at the same time these tools will limit the autonomy of local entities (Koivusalo et al., 2006).

Health technology assessment and cost-effectiveness research

65. The introduction of new technologies in health care has often led to cost increases. New technologies improve health outcomes as they enable the treatment of previously neglected or undiagnosed 
conditions or existing ailments in more effective ways, but they also often result in higher spending with no clear health benefits. ${ }^{11}$ HTA helps remedy those market failures relating to asymmetric information among patients, doctors and producers of drugs and equipment and may thus nudge doctors and patients into adopting the most cost effective ones (King et al., 2013).

66. HTA involves the assessment of the costs and benefits of new technologies and therapies with the aim of identifying those that are most cost effective. HTAs can inform decisions on healthcare guidelines (e.g. inclusion of drugs in pharmaceutical formularies), cost-sharing schedules (e.g. lower user charges for cost-effective preventive interventions) and the definition of publicly funded benefit packages (MorenoSerra, 2013).

67. Most OECD countries have established HTAs (Paris et al., 2010), but the type and goals of HTAs is not the same across countries. Most OECD countries use HTA to determine the coverage of medical procedures, medicines and high-cost equipment. In many OECD countries, reimbursement policies, especially for drugs, are based on HTA. For instance, in Iceland and Ireland, HTA is solely used to help determine pharmaceutical coverage.

68. Over the medium and long run, HTA has the potential to generate substantial savings (Chandra et al., 2011). The main lesson from the experiences of Australia, Canada and the United Kingdom is that HTA has provided useful evidence to inform reimbursement policies as well as improved patients' access to cost-effective treatments (Lopert and Elshaug, 2013; Clement et al., 2009). Reviewing 20 years of HTA studies in the United Kingdom, Raftery and Powell (2013) claim that more than half of them indicate that new technologies are no better than traditional ones. However, in the short term, HTA is likely to add to health management and administration costs. Indeed, de la Maisonneuve et al. (2014) find that HTA is positively related to health care cost growth.

69. HTA based on strict cost-effectiveness analyses has attracted much public criticisms because of fears of establishing "death panels". ${ }^{12}$ In this context, HTA based on comparative effectiveness research may be a useful, albeit limited, alternative (Chandra et al., 2011). Comparative effectiveness research compares the effectiveness of two or more medical treatments or health care delivery methods without taking into account costs. In this form, HTA still holds promise as it enables to identify the advantages of different treatments and therefore improve services adequacy. Yet, in the absence to any reference to costs it is unlikely to generate cost savings.

11. A recent example is that of robotic surgical devices. Examining the studies on costs of robot-assisted procedures published between 2005 and 2010, Barbash et al. (2010) have found that, on average, the variable cost of using robot-assisted procedures is about $6 \%$ higher than the cost of the traditional procedure and $13 \%$ higher if the cost of robots is included. There is evidence that in the case of prostate cancer, robotic technology may have increased both the cost per surgical procedure and the volume of surgeries and it has promoted a shift from non-surgical to surgical procedures. Despite the short-term benefits of robot-assisted procedures (i.e. faster postoperative recovery), robotic technology does not seem to have improved patient outcomes or quality of life in the long run.

12. For instance in the United States, in the debate surrounding the health care reform bill Congress forbade the use of cost-effectiveness analyses in government programmes. In France, HTA is used, but cost effectiveness and affordability analyses are not taken into account. 
ECO/WKP(2014)28

\section{Complementary policies and preventive care}

70. The health status of a population is also influenced by socio-economic determinants. Wilkinson and Marmot (2003) review the most important ones, which include: absolute and/or relative income; stress; early life conditions; social exclusion; work environment; unemployment; social support; and addiction, food and transport-related issues. ${ }^{13}$

71. Among the socio-economic determinants, life-style choices are of particular relevance. For instance, smoking is estimated to cause $22 \%$ of the total cardiovascular diseases in industrialised countries, and affect some cancers and chronic respiratory diseases strongly; alcohol abuse is considered to be the source of $8-18 \%$ of the total burden of disease in men and 2-4\% in women (WHO, 2002). A recent OECD study (Sassi and Hurst, 2008) has found that, in any given year, obese people incur $25 \%$ higher health expenditure than people of normal weight. Obesity is also deemed responsible for $1-3 \%$ of total health spending in most OECD countries and between 5-10\% in the United States.

72. Governments can encourage the adoption of healthier lifestyles through different prevention programmes which can be based on:

- Information campaigns: These aim at making people aware of the health risks involved in certain lifestyle choices; as their goal is to correct market failures due to the lack of information, information campaigns are the least intrusive form of government intervention (Sassi and Hurst, 2008).

- Market mechanisms: These involve altering the relative prices to induce people to choose a healthier lifestyle. For instance, cost sharing or insurance premia could be linked to regular check-ups. Estonia provides a positive experience on how to use payment methods to promote preventive care by primary care doctors (IMF, 2010). Also "sin" taxes (e.g. on alcohol and tobacco) change relative prices.

- Imposing standards and banning goods and services: They are the most intrusive form of government intervention as it encroaches on people's choices. As such, they should be used when the first two options are not effective (e.g. addiction, child protection). It can be justified on the ground that some people cannot make adequate choices. Examples of such interventions include forbidding sales of unhealthy food in schools, safety belt obligations and other driving regulations or forbidding the sale of alcohol to youngsters below a certain age.

73. Evidence suggests that well-designed prevention policies result in better health outcomes and curb health care spending. For instance, prevention strategies to reduce obesity could avoid 155000 deaths per year from chronic diseases in Japan, 75000 in Italy, 70000 in England, 55000 in Mexico and 40000 in Canada (Sassi, 2010). The annual cost of these strategies may range from USD 12 (Mexico) to USD 32 (Canada) per capita, equivalent to a tiny fraction of per capita health care expenditure on prevention.

\section{Adequacy of health care services}

74. The adequacy of health care services is determined by three main aspects of basic health care coverage: its breadth (i.e. the percentage of people covered), its scope (i.e. the range of goods and services

13. Other social policies can also improve the resilience of the health system to shocks by contributing to curb health spending. For instance, child-support and family policies can have a positive impact on children health, which are likely to persist in adulthood. High unemployment rates are associated with more frequent illness (especially mental health problems) and premature death. 
included in the basic benefit package) and its depth (i.e. the amount of costs covered for key goods and services by the public sector, the level of coverage by health insurance and out-of pocket payments).

75. Most OECD countries have reached near-universal health coverage for a core set services (Figure 14). Four OECD countries fall short from providing universal health coverage - Chile, Mexico, Turkey and the United States - leaving $20 \%$ or more of their population exposed to the financial consequences of health risks. However, in most of these countries, policy changes will increase coverage. In Mexico large increases in health coverage have been achieved by the introduction of "Seguro Popular" in 2004, a voluntary health insurance scheme aimed at the poor and uninsured. As concerns the United States, the main aims of the Patient Protection and Affordable Care Act passed in 2010 is to reach universal health care coverage. In Turkey, increasing public health spending has resulted in rising coverage in recent years, reaching over $80 \%$ in 2009 . Finally, Chile is characterised by a dual health care system consisting of the public National Health Insurance Fund and private health insurance companies and other non-profit agencies. However, a large share of the population is covered by neither of them.

Figure 14. Coverage of health care services
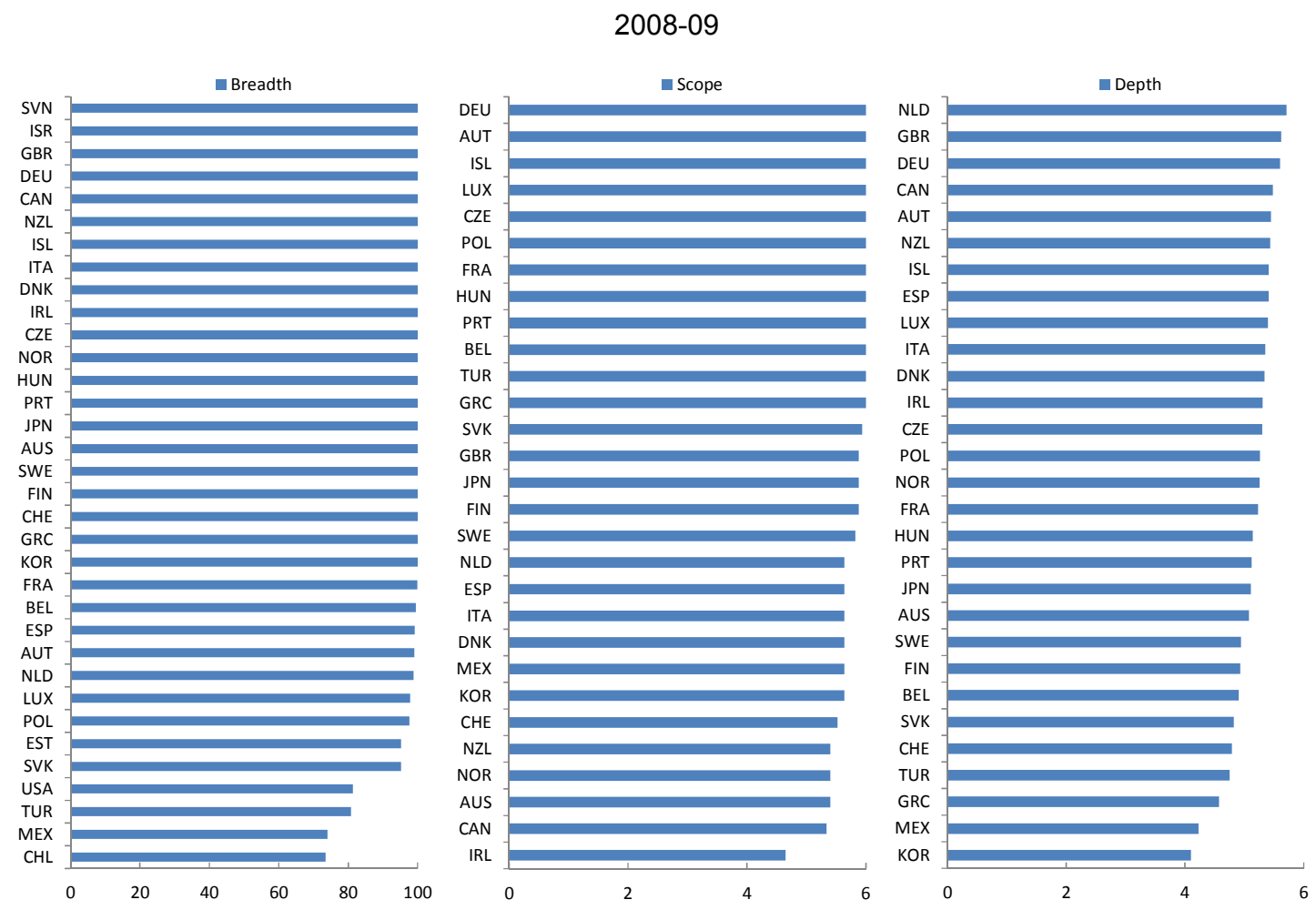

Note: The breadth of coverage is the proportion of the population covered by basic health insurance; the scope of basic coverage represents the range of goods and services covered by basic insurance; the depth of coverage represents the level of the costs covered for key goods and services included in the basic benefit package, the actual level of coverage by health insurance (public and private) and out-of pocket payments for essential care.

Source: OECD Survey on Health System Characteristics 2008-09 and OECD (2013), Health at Glance 2013.

76. The range of services included in the basic benefit package varies across countries. It usually includes a variety of consultations with doctors and specialists, tests and examinations, and surgical and therapeutic procedures, which in many cases involve cost sharing (OECD, 2011). The services included in the basic package ultimately depend on societal preferences, in addition to the level of economic development. 
77. In virtually all the 29 countries covered by the OECD Survey on Health System Characteristics 2008-09, the basic health care services include in-patient care, out-patient consultations with general practitioners and specialists, clinical laboratory tests as well as diagnostic imaging. Several countries do not include eyeglasses, dental care and dental prostheses in the basic package (e.g. Australia, Canada, Ireland, New Zealand and Norway) or include only some of these (e.g. Denmark, Finland, Italy, Japan, Korea, Mexico, Netherlands, Spain, Sweden, Switzerland and the United Kingdom). Overall, however, the data suggest that there is limited variation in the scope of basic coverage across OECD countries (Joumard et al., 2010).

78. As concerns the depth of coverage, in 11 countries the cost of the basic package is fully covered for in-patient and out-patient care; several others cover between 51 and $75 \%$ of out-patient care costs. In several countries (especially Canada, France, Ireland and Switzerland) complementary, supplementary and/or duplicative insurance cover out-of-pocket payments. Overall, the depth of insurance coverage is lowest in Greece, Korea, Mexico, Switzerland and Turkey and highest in Germany, the Netherlands and the United Kingdom (Joumard et al., 2010).

\section{Private health spending and coverage are sensitive to negative income shocks}

79. Irrespective of how basic health care services are determined and delivered, the issue arises on how to ensure that public and private health entities can deliver on their promises, if a large shock hits the economy. In principle, public health programmes may be better placed than private insurance schemes to manage large common economic shocks as they pool risks among a larger number of individuals. Most advanced economies have achieved universal access to basic health care services and health reforms aiming at containing costs should seek to maintain this pillar of the safety net.

80. As people without public health care coverage have to finance their health care services through private insurance or out-of-pocket payments they are especially sensitive to a drop in personal income. This is especially true for low income people who may forego or postpone health care services because too expensive. Devaux and de Looper (2012), comparing equity of access to health care services in 19 OECD countries, find that in countries with higher public expenditure the frequency of doctor visits are more equally distributed among people of different incomes. Also, Devaux and de Looper (2012) show that inequality in specialist (dental) visit is increasing in the share of out-pocket payment as percentage of total expenditure on specialist (dental) care. Therefore, in times of crisis and personal income losses public health care programmes are more likely to maintain a certain degree of equity of access to services than private-funded health care.

81. Private health insurance coverage is also affected by disposable income shocks. Figure 15 shows that over the 2008-11 period changes in private health insurance coverage were positively related with changes in net household real disposable income. This suggests that negative personal income shocks are likely to result in lower private health insurance coverage.

82. For instance, in the United States most uninsured people attribute their lack of health coverage to the high cost of premiums (OECD, 2011). Holahan and Chen (2011) report that between 2007 and 2010 the number of US adults without health care coverage increased markedly because of rising poverty rates in addition to a drop in employer-sponsored plans. ${ }^{14}$ The rise in adults without health coverage was concentrated among low-income people as they could no longer afford to buy private health insurance.

14. Employer-sponsored coverage declined also among people with full-time jobs. 
Figure 15. Real disposable income shocks affect private health insurance coverage

2008-11 change

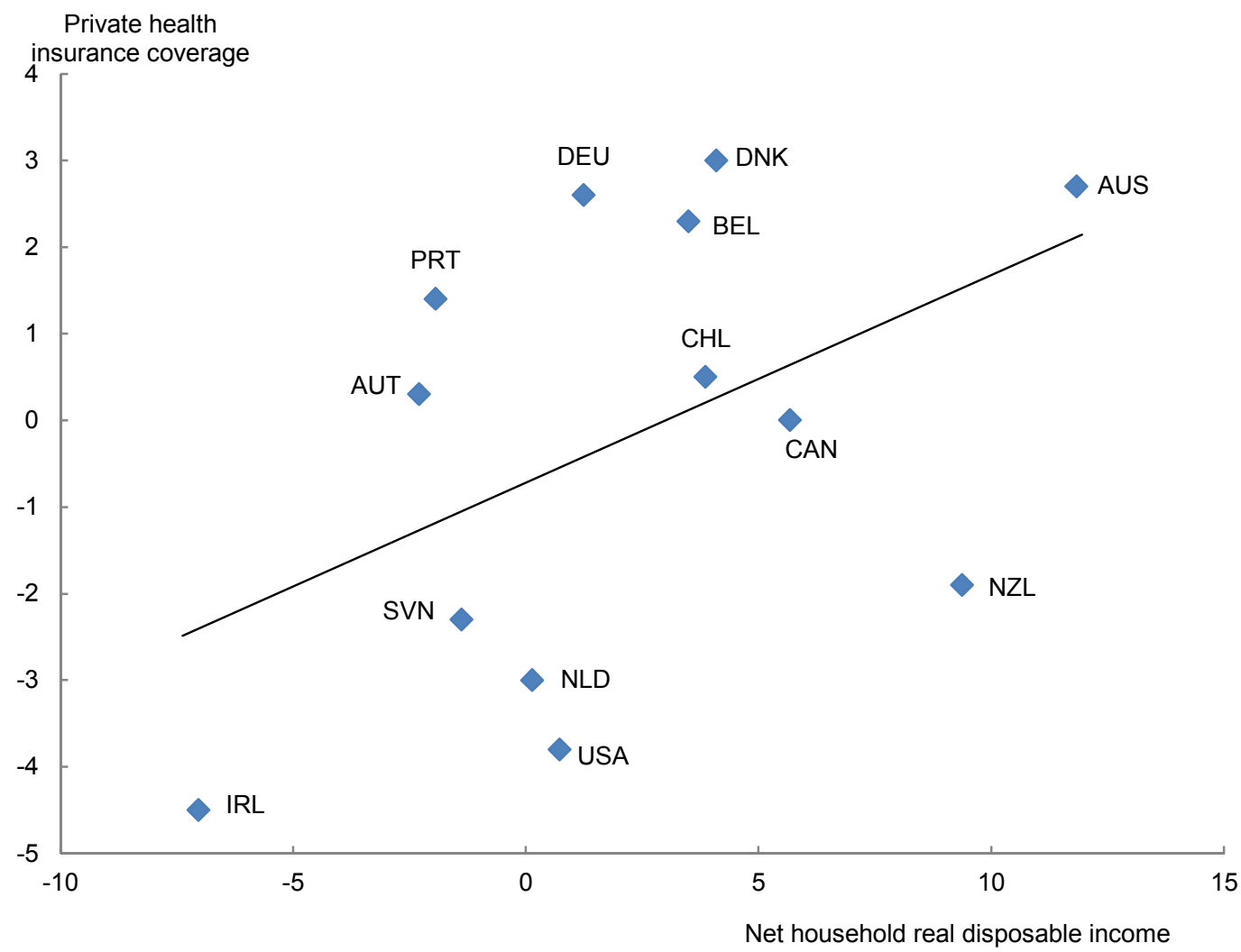

Note: The change in private health insurance coverage is in percentage points; the change in household real disposable income is in per cent.

Source: Health Statistics and OECD Economic Outlook, No. 91.

\section{Delaying reforms makes sudden reduction in adequacy more likely}

83. Delaying necessary reforms to improve the sustainability of public health care programmes makes sudden and deep cuts to health care services more probable. The absence of any strict requirement to balance spending and revenue in public health care systems may lead to the continuous postponement of necessary adjustments to improve sustainability because of time inconsistency problems. Large negative economic shocks are likely to make it impossible to delay reforms further. Abrupt policy changes in crisis periods risk being highly sub-optimal and result in large welfare losses, because of a limited consultation process, absence of popular support and difficulties for people and health care providers to adjust.

84. Reforms undertaken in periods of crisis may not properly distinguish between effective and ineffective programmes. Cutting effective programmes aiming at attaining quick cost savings might endanger the health status of the population and result in higher costs, eventually. Greece offers a recent example of such cuts as they have resulted in an increase in HIV and tuberculosis infections along with the re-emergence of malaria (Stuckler and Basu 2013; OECD, 2013).

85. Cost containment reforms need to be carefully implemented and phased to minimise any potential adverse effects on the poor. For instance, cuts unrelated to people's income - such as higher copayments - are doubly regressive because: 1) given the same health care needs, the poorer will still spend a 
larger share of their income on health care; 2) poorer people report worse health status than well-off individuals and are more likely to need health care (Fijters et al., 2005; Gardner and Oswald, 2007; Jones and Wildman, 2008).

86. More extensive use of means-tested programmes in health care could result in cost saving while protecting the most vulnerable individuals from adverse shocks. For instance, linking co-payments to income can be administratively challenging but reforms in this direction are likely to make the health care system fairer. Also, it will make health care systems more resilient to shocks as resources are spent where they are most needed.

\section{Policy reforms could make health care systems more resilient to shocks}

87. To identify reform options, country diamonds have been constructed. These use sustainability and adequacy indicators in addition to those policy measures - discussed above - that are likely to ease the sustainability-adequacy trade off. The dotted line represents the OECD average, the solid line and markers represent the country shown. When the solid line falls outside the OECD average, this implies better results.

88. Figure 16 provides two examples for Japan and Turkey (see the Appendix for all other OECD countries). As regards sustainability of health spending, Turkey compares more favourably by virtues of its low current and projected health spending-to-GDP ratio. However, in Turkey the health care system is more vulnerable to GDP shocks than in Japan as its high macroeconomic volatility raises the likelihood that its health spending-to-GDP ratio will be higher than projected. In terms of adequacy, Japan's health care services are at or above OECD average. Turkey could instead raise risk pooling and limit the share of health risks borne by individuals by improving its basic insurance coverage and raise the share of costs covered for key goods and services. Both countries could undertake policy reforms so as to lower their health care systems' vulnerability to shocks. Although, Japan appears to have more room than Turkey for strengthening the stringency of budget constraints, the latter could benefit more from policy action in this area given also Turkey's higher macroeconomic volatility. More binding budget caps could help lowering Turkey's health care spending growth during periods of economic expansion, thus rendering the system more prepared to face large negative economic shocks and reduce the likelihood of abrupt spending cuts during crises. Japan could move away from payment methods providing incentives to increase the volume of care as these results in higher health spending without better health outcomes. 
Figure 16. Sustainability, adequacy and policy indicators

Turkey

Policy levers
Sustainability

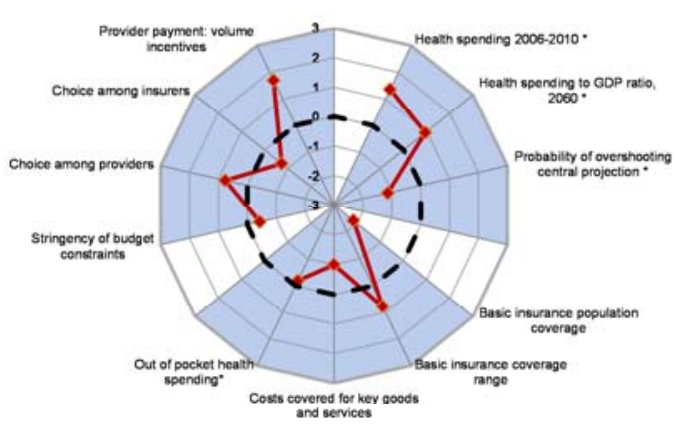

Adequacy
Japan

Policy levers
Sustainability

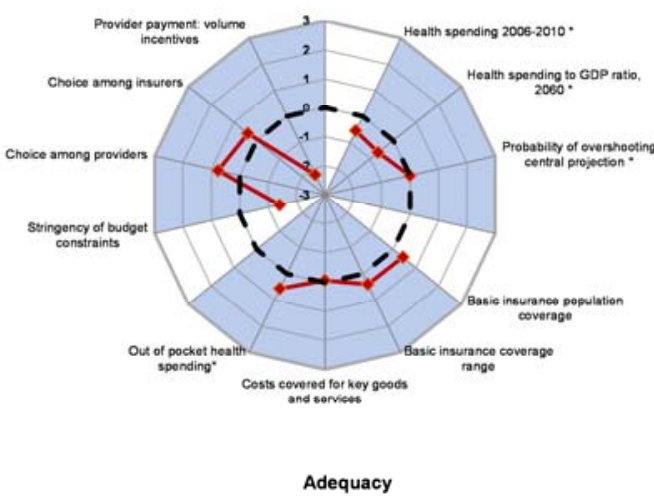

Policy levers

Stringency of budget constraints: stringency of the rules and targets to fix the health budget and its allocation across sub-sectors and regions. Choice among providers: Degree of freedom in choosing among primary care physicians, specialists and hospitals.

Choice among insurers: Type of coverage (single national or local schemes, multiple insurers). In case of multiple insurers, number of insurers, market shares and ability of people to choose their insurer.

Note: The dotted line represents the OECD average, the solid line and diamond markets represent the country shown. Where the solid line falls outside the OECD average, this implies better results than the OECD average. For instance, for Japan, out-of-pocket spending is low, but is shown as being outside the dotted line, because this is good for adequacy. The indicators are presented in standard deviation units.

\section{Funding options for health care systems}

89. Decisions about the financing of health care systems have to take into account equity-efficiency trade-offs. The equity aspect relates to their effect on the distribution of income, after-tax and health care payments; the efficiency aspect relates to the risk pooling, expenditure smoothing and deadweight losses they entail (Table 2). Overall, out-of-pocket payments are the least attractive option for financing health care as they are regressive and do not deliver any risk pooling and expenditure smoothing. On the positive side, though, they cause no deadweight losses. 
ECO/WKP(2014)28

Table 2. Health care funding options have equity and efficiency effects

\begin{tabular}{lcc|cc}
\hline & \multicolumn{2}{c|}{ Equity } & \multicolumn{2}{c}{ Efficiency } \\
\cline { 2 - 5 } & $\begin{array}{c}\text { Income } \\
\text { redistribution }\end{array}$ & Risk pooling & $\begin{array}{c}\text { Expenditure } \\
\text { smoothing }\end{array}$ & $\begin{array}{c}\text { No or minimal } \\
\text { deadweight } \\
\text { losses }\end{array}$ \\
\hline General taxation & + & + & + & + \\
Social insurance & +- & + & + & + \\
Private insurance & - & + & + & + \\
$\quad$ Community rating & - & + & + & + \\
Risk rating & - & - & - & + \\
Medical saving accounts & - & - & & + \\
\hline Out-of-pocket payments & & & +
\end{tabular}

\section{Income redistribution}

90. The degree of income redistribution achieved through the health care financing system depends on the progressivity of its funding sources. A tax or contribution is said to be progressive if the rich contribute proportionally more than the poor (i.e. the share of the contribution or tax rises with personal income). Among the different funding options:

- General taxation is in principle most progressive; its degree of progressivity depends on the share of revenue raised through different taxes. For instance, personal income taxes tend to be progressive whereas indirect taxes, such as VAT and taxes on properties, do not (Joumard et al. 2012).

- Social security contributions are generally not progressive as they are proportional to their base (i.e. wages and salaries). In addition, ceilings often apply, making them regressive. To increase their progressivity and reduce taxes on low wages - with the aim at improving work incentives some countries have reduced contribution rates for salaries below certain thresholds.

- Private insurance premiums and out-of-pocket payments are generally regressive; they tend to rise less proportionally than personal income; some measures, such as exemptions and tax reliefs targeted to low income people can increase their progressivity (e.g. Glied, 2008); private funding has a negative effect on the uptake of needed medical services, especially for low income people (Huber et al. 2008).

91. No recent cross-country study on the progressivity of health care funding sources exists. The dearth of sufficiently detailed data has hampered quantitative research on this issue financing. Only Wagstaff et al. (1999) present evidence on the progressivity of health care system financing in 12 OECD countries. Although their results are based on data from the early 1990s or late 1980s, they are instructive as they show how different funding sources affect the progressivity of health care finance. The overall conclusions of this study are: 1) those health care financing systems relying on general taxation were proportional or only mildly progressive; 2 ) opt out clauses lowered the degree of progressivity of socialinsurance-based health care finance as better off people opted for private health insurance plans; 3 ) countries where private health insurance was most important had regressive health care systems finance. 
Risk pooling

92. Health care funding systems ensure a certain degree of risk sharing by raising revenue independently from health risks (Breyer and Haufler, 2000). Risk sharing can be present even in the absence of any income redistribution. For instance, compulsory health insurance with community rated premiums (e.g. the basis of the Swiss health care system) offers a high degree of risk pooling with minimal income redistribution. Overall, among the different health care revenue sources:

- General taxation tends to ensure the highest degree of risk pooling as taxes are not related to health risks; also, in tax-funded health care systems, the health care coverage extends to all residents by default.

- Social health insurance funds also achieve a high degree of risk sharing, but risk pooling is limited to the participants of social insurance funds. The presence of many social insurance funds results in fragmented risk pools, which lower risk pooling, but risk-adjustment mechanisms (e.g. Switzerland, Netherlands, Germany) can mitigate this problem.

- Voluntary private health insurance schemes achieve only limited risk pooling; their risk pools are generally smaller than those of social insurance funds and tax-funded health care systems; a large number of private health insurers has the benefit of putting downward pressures on premiums (because of greater competition) but at the same time lowers risk pooling. Community rated premiums allow for a larger degree of risk pooling than risk rated ones as the latter enable to pool people with approximately the same level of risk, only.

- Medical saving accounts and out-of-pocket expenditure do not allow for any risk pooling as people provide for their medical needs individually.

\section{Expenditure smoothing}

93. With the exception of out-of-pocket payments, all funding options smooth health expenditure over time. Through general taxation, social insurance contributions, private insurance premiums - as well as medical saving accounts - individuals acquire the right to receive certain medical services as needs arise. On the other hand, out-of-pocket payments have to be paid at the point of use. At the individual and social level this is likely to result in welfare losses, ceteris paribus, because of potentially large health spending, insufficient preventive care (due to myopic behaviour) and inability to afford expensive treatments. Out-of-pocket payments generate additional welfare losses for risk-averse individuals.

\section{Deadweight losses}

94. Financing systems for the provision of public goods generate deadweight losses as they distort choices about consumption, work and investment. Health care financing is no exception. Abstracting from any tax incentives, private insurance, out-of-pocket payments and medical saving accounts are likely to entail less deadweight losses than general taxation and social insurance contributions as they reflect personal choices (Glied, 2008). However, the deadweight losses associated with tax-financed health care depends on the structure of the tax systems. For instance, consumption and property taxes are less distortive than personal income taxes. Social security contributions can be highly inefficient as they distort the supply of and demand for labour. 


\section{Vulnerabilities associated with the health care funding mix}

General taxation versus social security contributions

95. The main advantage of the social insurance model is that it earmarks a relatively predictable stream of revenue - based on social insurance contributions - to health care. However, the government has generally less cost oversight over social insurance-based health care systems than over tax-financed ones as social insurance schemes are characterised by weaker budgetary controls over their funding and spending decisions. Also, contributions can have large distortionary effects on the labour market. Although this should not be the case as contributions paid by employees yield entitlements (Summers, 1989), they may nonetheless lower labour supply as workers may see them as disguised employment taxes. ${ }^{15}$

96. Trend changes have contributed to weakening the case for the social-insurance funding model. For instance, self- and part-time employment have become more frequent, as well as career breaks and unemployment spells; capital income, wealth and corporation taxes could also be tapped for health care financing along with wages and salaries.

97. Some countries have shifted part of the health care system financing burden from social insurance contributions to general taxation. For instance, in the late 1980s Iceland and Spain shifted their main health care funding source from social contributions to general taxes. France widened the tax base from earnings to include non-wage income and lowered social security contributions at the lower end of the wage distribution, with the creation of contribution sociale généralisée (CSG) in 1990. In 2005, the Netherlands introduced reforms whereby insurers receive half of their revenue from payroll contributions and the rest from flat-rate direct premiums paid by participants (with subsidies targeted to low income groups). In 2009, in order to compensate the revenue loss in the National Health Insurance Fund due to reducing employers' contribution rates (as a means to stimulate the labour market), Hungary increased the general tax revenues transferred to the Fund (Gaál et al., 2011).

\section{Hypothecated taxation}

98. Hypothecated taxation can be an important revenue sources for health care. ${ }^{16}$ Like social security contributions, it has the benefit of making the link between revenue and spending transparent and rendering spending decisions less susceptible to political interference. The transparent link between revenue and spending and the reduced risk of political intrusion can potentially enhance public support for tax increases, if additional resources are needed (WHO, 2010).

99. Yet, tax hypothecation has the drawback of increasing budget rigidities. This poses risks since it weakens public scrutiny on spending decisions. In addition, a tight link between spending and revenues means that health spending may follow the business cycle too closely rather than being determined by medical needs. Extensive use of hypothecation could result in excessive spending, waste and inefficiency in buoyant periods and uncritical cuts during recessions. Finally, hypothecated taxation for health care

15. For instance, on the related issues on pension contributions Disney (2004) provides evidence about their negative effect on women's participation in the labour market.

16. Examples of taxation earmarked for health abounds. For instance, the Australian state of Victoria established a health promotion agency funded by tobacco taxes, and several US states (California, Massachusetts, Arizona, and Oregon) have hypothecated part of tobacco excise revenues for tobaccorelated education and tobacco-control activities; alcohol revenue are used for alcohol-related education and prevention programs in New Jersey, Ohio, Texas (Sassi et al., 2013 and references therein). 
tends to disconnect health care from other social spending, thus preventing an integrated approach to health problems as there is evidence that social spending can have beneficial health effects (Mossialos and Dixon, 2002).

\section{Local versus central taxation}

100. Local taxes can be an important source of revenues, especially in decentralised health care systems (e.g. Denmark, Finland, Italy, Sweden) ${ }^{17}$ Local taxes have the advantage of creating a strong link between payers and health care service beneficiaries, thus potentially increasing accountability. In addition the level of local taxation may be set in line with local preferences about the level and quality of medical services.

101. However, in the absence of a centrally managed risk-adjusted transfer mechanism, decentralisation lowers risk pooling and might result in larger interregional health disparities. Economically retarded regions may find it difficult to raise the revenues necessary to ensure the same level and quality of services as other areas, although equalisation funds and block grants can partly offset differences across regions. Economic shocks can compound these problems as a drop in local revenues may be associated with cuts of central government transfers.

\section{Vulnerabilities in the BRIICS countries}

102. The most immediate objective for the BRIICS countries should be to enhance services adequacy, by expanding coverage and improving quality. However, over the next decades fast population ageing and rising income will make the health care challenges for the BRIICS more similar to those of OECD countries as the rising demand for better and more equitable services will result in higher health expenditure as \% of GDP (Table 3).

103. Excessive reliance on out-of-pocket spending in the BRIICS countries renders the health care systems more inequitable and discourages the take up of curative and preventive care, especially among the poor. Cost sharing also reduces risk pooling by shifting health risks to individuals and results in a high risk of catastrophically high health expenditure. Recent evidence for a developing country (Thailand) show that the significant reduction in co-payments of the early 2000's has led to a more equitable access to healthcare and lowered the infant mortality rates of poorer regions to the same level as in richer ones (Gruber et al., 2014).

104. BRIICS countries rely, to a different extent, on social insurance contributions to finance the public health care sector. Increasing the role of general taxation will make the financing of health care system less sensitive to the fast ageing of populations (and the attendant erosion of the total wage bill due to rise in the dependency ratio) more equitable (as general taxation is a more progressive than social insurance contributions) and will augment risk pooling (e.g. Wagstaff, 2010). Also, in countries with large labour market informality, it may be difficult and expensive to collect contributions and expand coverage.

17. For instance, municipalities are involved in financing all types of services in Denmark and Finland. However, even in countries with more centralised health care systems, local taxes can play a significant role. In Hungary, they help financing physician services, in Iceland and Norway primary care services, and in Austria and Switzerland hospital care (Paris et al., 2010). 
ECO/WKP(2014)28

Table 3. The projected growth in public health care expenditure for the BRIICS countries Projected health care expenditure to 2030

\begin{tabular}{|c|c|c|c|c|c|c|}
\hline & \multirow{2}{*}{$\begin{array}{l}\text { Private health } \\
\text { spending as a \% of } \\
\text { GDP in } 2006-10\end{array}$} & \multirow{2}{*}{$\begin{array}{c}\text { Public health } \\
\text { expenditure as a } \% \\
\text { of GDP in 2006-10 }\end{array}$} & \multirow{2}{*}{$\begin{array}{c}\% \text { point increase in public } \\
\text { health expenditure as \% } \\
\text { of GDP by } 2030\end{array}$} & \multicolumn{3}{|c|}{$\begin{array}{c}\text { Share of the \% point increase } \\
\text { due to }\end{array}$} \\
\hline & & & & Demography & Income & Residual \\
\hline Brazil & 4.9 & 3.7 & 2.1 & 0.4 & -0.3 & 0.9 \\
\hline China & 2.4 & 1.9 & 1.7 & 0.5 & -0.6 & 1.1 \\
\hline India & 2.9 & 1.2 & 1.3 & 0.3 & -0.7 & 1.5 \\
\hline Indonesia & 1.8 & 1.2 & 1.7 & 0.3 & -0.5 & 1.1 \\
\hline Russia & 2.1 & 3.1 & 1.5 & 0.1 & -0.4 & 1.3 \\
\hline South Africa & 4.6 & 3.2 & 1.4 & 0.0 & -0.5 & 1.4 \\
\hline BRIICS average & 3.1 & 2.4 & 1.6 & 0.3 & -0.5 & 1.2 \\
\hline OECD average & 2.6 & 5.5 & 2.0 & 0.2 & -0.2 & 1.0 \\
\hline
\end{tabular}

Note: The percentage point increase in public health spending refers to the cost pressure scenario in de la Maisonneuve and Oliveira Martins (2013).

Source: WHO World Health Statistics (accessed November 2013) and de la Maisonneuve and Oliveira Martins (2013).

105. Extending coverage to the whole population and augmenting risk pooling is a necessary step to reduce the risk of catastrophic health spending. Sustainable health system leaving a fraction of the population exposed to such risks is not performing one of its fundamental functions, which is protection against idiosyncratic health risk. Increasing the financing role of general taxation will make progresses in this are less dependent on successes in combating labour market informality.

106. The development of health technology assessment (HTA) in BRIICS countries has the potential of harnessing useful technological innovation in medical care without excessive cost increases. Even if HTAs might raise costs in the short term, they can contribute to substantially reduce cost pressures over the medium term as coverage will be extended to the whole population. The establishment of HTA early on in the process of developing a national health care system could then speed up the adoption of cost effective treatments.

\section{China}

107. During the initial reform period, starting from the late 1970s, China's health care system fell into neglect as the overriding policy priority was to increase output and income. ${ }^{18}$ As a result, health care services, although publicly provided, became increasingly privately financed. The government has enacted several reforms in the last 15 years, including the launch of new social insurance schemes for rural and urban areas and has finally set the explicit aim of reaching universal coverage, portability of health care benefits and affordable and effective basic health care by 2020. These initiatives enabled to raise the percentage of the population with health insurance from less than $10 \%$ in 2003 to about $85 \%$ in 2008 (OECD, 2010a).

108. Health care services are still overwhelmingly provided by the public sector and financed through social insurance schemes. Public health care provision is generally a local responsibility. Because of the

18. From the the1950s to the late 1970s, China developed a community-based health care system (cooperative health insurance) which eventually covered about $90 \%$ of the rural population. This system, however, collapsed when reforms started in the late 1970s (Hussein, 2000). 
limited involvement of the central government in health care financing, the level of care is low in poor counties. In 2007, the central government directly financed only $0.3 \%$ of total health spending; the earmarked transfers to local governments amounted to $5.6 \%$ of total spending.

109. Notwithstanding the recent reforms and coverage increases, access to health care services remains highly inequitable, even within urban areas, because of the hukou system. The social insurance system covering the urban population is employment based and a share of contributions goes to finance individual medical saving accounts. This system does not allow migrant workers and their families to access local health care services, and other social protection services more in general. Children of migrant workers are especially disadvantaged, as the health insurance provided by employers covers employees only, but not their children (OECD, 2010a). ${ }^{19}$

110. Reform of the hukou system is an important step in improving the adequacy of health care services by ensuring more equitable access to health care services. Reforms should focus on granting all residents in urban areas the same access to local services. The prefecture of Suzhou initiated such reforms in 2011 and by mid-2012 the new policy covered almost entirely the migrant population (Koen et al., 2013). However, reforming of the hukou system may be difficult to achieve in a short time and healthcare coverage could be extended independently from it.

111. Risk pooling is highly fragmented and catastrophic - but also chronic - illnesses still risk pushing a considerable number of people into poverty. Indeed, health benefits tend to be negatively related to the seriousness of the disease - as people falling seriously ill are treated in higher-level and better hospitals, which have lower reimbursement rates (Koen et al., 2013). Also, real catastrophic illness (i.e. that costing above two years of the average income) is not covered at all. Much higher reimbursements rates are needed to reduce significantly the financial risks associated with catastrophic illness.

112. The supply of primary care has thus far been limited, as hospitals have provided the bulk of health care services (which focus on curative care, unlike in Brazil for instance). International experience has shown the importance of primary care, with a focus on prevention, to enhance health outcomes a while containing costs. The government plans to expand primary care in rural areas by establishing county level hospitals and local health care facilities (Eggleston, 2012).

113. To lower interregional disparities in the quality and quantity of health care services in addition to increasing risk pooling, the financing from the general government could increase, possibly through general taxation. In China, as in other the BRIICS and developing countries, social-insurance health care systems face the challenge of collecting social security contributions because of large labour market informality and other issues, such as lack of information sharing among funds and scarce use of ITC. The government has launched different initiatives to tackle these problems including the integrated collection of contributions for five social insurance programmes and more advanced use of ITC (ISSA, 2013).

114. In a fast-ageing society, however, an overreliance on social insurance contributions to finance health care pose risks as the dependency ratio will become less favourable over the coming decades. If general taxation does not play a more important role, social insurance contributions will have to be increased, with the attendant large distortionary effects and lower "official" employment rates.

19. The introduction of a contributory (but subsidised) social health insurance scheme has had only limited effects as households can only enrol in the scheme of the locality where they are registered and not where they live and work. 
ECO/WKP(2014)28

\section{Indonesia}

115. The Indonesian health care system is still underdeveloped. As a per cent of GDP public health spending, at $1 \%$, is among the lowest in the world. The Indonesian health care system is highly fragmented. It comprises a mix of private and social insurance schemes in addition to government-financed programmes targeting low-income individuals. Social health insurance schemes are employment based. The three main social insurance funds cover: civil servants; police and armed forces; private-sector employees. The latter, however, does not cover informal sector workers and individuals working in firms employing less than 10 employees who account for most of the employed (OECD, 2010b).

116. Health care coverage is low but increasing. It was estimated to have risen from about $20 \%$ of the total population in 2005 to $40 \%$ in 2011 (World Bank, 2013). Government spending on health care and utilisation rates are very low. Because of the low coverage of public health care programmes, health care expenditure is mostly privately financed, with out-of-pocket payments accounting for the bulk of it. In 2009 , the government introduced the requirement to spend 5 and $10 \%$ of central and local government budgets, respectively, on health care (excluding wages and salaries).

117. Health care service provision is highly decentralised. Provinces and local governments have responsibilities for managing government-financed healthcare facilities and medical personnel, setting fees and user charges for public health services and allocating central government transfers. Overall, this leads to limited risk pooling. Transfers to sub-national authorities to finance health care spending are calculated on historical costs rather than medical needs.

118. General supply-side constraints have hampered the delivery of health care services and helped contain public health care expenditure due to low utilisation rates. For instance, barriers to entry in the medical profession (limiting also the entry of foreign doctors) have contributed to the low number of doctors and midwives, especially in rural areas.

119. Although declining, the risk of catastrophic health payments is still high especially among the poor. The government introduced publicly financed programmes in the late 1990s and extended them in the 2000s with the aim of mitigating catastrophic health risks on poor and near-poor individuals. The programme is progressively being expanded to cover the entire targeted population of poor and near-poor individuals.

120. The government plans to consolidate all existing contributory and non-contributory healthinsurance schemes by 2014 so as to provide uniform benefits within a single payer model and reach universal coverage by 2019 (OECD, 2012b; World Bank 2013). The new system will rely to a large extent on social security contributions from salaried, self-employed and informal workers. While mechanisms to collect contributions from salaried employees are already in place (although enforcement is weak), no such mechanisms yet exist for self-employed and informal workers. Inability or delays in developing these mechanisms will lead to revenue shortfalls for the new social security fund, which in turn will either derail the objective of reaching universal coverage by 2019 or result in a larger-than-expected share of general tax revenue to fund health care services.

121. As in other countries, the rapidly ageing population poses additional risks to health care system financing (Table 3). Population aging will result in a higher dependency ratio and contribute to erode the income base which social contributions are based on (i.e. the wage bill). Improving general tax revenue collection, which the government of Indonesia is doing, and devoting part of it to finance health care services could offer an alternative way - less distortive and more in line with the reality of the Indonesian labour market - to fund the planned expansion in health care services. 


\section{India}

122. The Indian health care system is underdeveloped and underfunded. Government spending on health still amounts to only slightly more than 1\% of GDP. Although India has a national health care system granting free consultations in public hospitals, these have usually long waiting lists, are short of staff and drugs often unable to meet the rising demand for health care. As a result, effective health care coverage is low, covering only $10 \%$ of the population with only government or employees of large firms enjoying comprehensive health insurance (Kumar et al., 2011).

123. Private health care has partially filled the gap left by the low public sector provision. Private health expenditure account for more than $70 \%$ of total health care spending (higher than in the other BRIICS countries). Private care varies in quality - as private practitioners are often not qualified and private facilities are inadequate (Rao et al., 2011) - and is too expensive for most of the population. As a consequence, the occurrence of catastrophically-high health expenditure is still a significant risk for a large share the population. ${ }^{20}$

124. The public health care system is highly fragmented. There is a plethora of central and state government medical programmes, social and private insurance plans and community-based health organisations. This results in highly fragmented risk pooling. Rampant labour market informality has hindered the expansion of social health insurance coverage. Also, poor households have difficulties in meeting regular payments because of highly variable incomes and social insurance funds face high costs in collecting small contributions from a large number of people on a regular basis (OECD, 2011).

125. Public health care finance and delivery are to a large extent decentralised. States have the responsibility of implementing health care programmes that are partly funded by the central government. This has resulted in large differences in health spending and outcomes among states. The per-capita health spending among states can differ by three times and life expectancy by more than eight years (Kumar et al., 2011). ${ }^{21}$ Transfers from the central government have largely proved insufficient to create additional fiscal space in the poorest jurisdictions so as to equalise health spending across states.

126. The government plans to increase public health care spending to $3 \%$ of GDP in the next few years and initiated various reforms. For instance, in the late 2000s it launched a new national insurance system providing free health coverage to households below the poverty line, up to an annual limit. The scheme is still being phased in and expanded to those above the poverty line. States have also started various programmes the aim at extending health care coverage. These have often been through publicprivate partnerships with health insurance companies (ISSA, 2013).

127. Rising government spending is paramount to improve health care provision. Financing the expansion of the public health care system through general taxation may be more effective to reach universal coverage and increase risk pooling, given the large labour market informality and the high number of self-employed. Yet, higher public spending need be accompanied by reforms to improve accountability in service delivery and better regulation and oversight of private providers. ${ }^{22}$

20. In the mid-2000s, 47 and $31 \%$ of hospital admissions in rural and urban areas, respectively, were financed by loans or the sale of family assets (Kumar et al., 2011).

21. The large difference in health outcomes is also explained by state-level policies complementary to health such as nutrition, water and sanitation, education, and basic infrastructure.

22. For instance, no national guidelines concerning treatment protocols for health care exist, so over-diagnosis, over-treatment, and mal-treatment are common. 
128. Preventive and primary care provision could be enhanced, especially among children, through cash transfers towards families with children conditional on regular health checks (and school attendance). The experience of Brazil and Mexico, amongst others, with similar programmes is positive as they have succeeded in improving health outcomes and reducing poverty at the same time.

\section{Brazil}

129. In 2011, Brazil's total health care spending was about 9\% of GDP. Although this level of spending is comparable to OECD countries, on average, health outcomes are not always commensurate with it, suggesting inefficiency in service delivery (OECD, 2009). Health care coverage is formally universal but problems persist in access to quality health care services, especially in small municipalities. One difference between the Brazilian health care system and that in other BRIICS countries is its emphasis on preventive care. For instance, the Programa Bolsa Familia (PBF) makes cash transfers to very poor families with children younger than 17 conditional on regular health care visits, in addition to children's school attendance.

130. Health care services are provided by both the public and private sectors. The public sector health care system is highly decentralised as it involves, in different roles the federal state, states and municipalities. Responsibilities for providing health care services differ across municipalities, depending on their level of development and administrative capacity. This arrangement has resulted in greatly heterogeneous levels and quality of services; for instance, around $30 \%$ of the municipalities, mostly in the poorest regions, do not provide urgent medical care and $8 \%$ of them do not have a resident public-sector doctor (ISSA, 2013). This is an especially important issue in Brazil given its continental size and the shortcomings of its transportation network.

131. The private supply of health care services relies on insurance companies, cooperatives and company-sponsored plans. There is evidence that more sophisticated procedures are largely unavailable to more than half of the population without private insurance plans as they mainly are supplied by the private sector only (ISSA, 2013). This has contributed to make access to health services inequitable - not only according to urban/rural divide - but also according to income levels.

132. Financing is characterised by budget rigidities because of a mandated aggregate spending floor and revenue hypothecation. Public health care is financed through the Social Security Budget. This is funded through a mix of payroll taxes, value added tax, taxes on earnings, profits and lotteries, many of them hypothecated for specific uses. While this system has ensured stable and diversified source of financing, it has undermined efficiency by shielding programmes with low cost-effectiveness from regular reviews. The elimination of such spending floors and earmarking could inject more flexibility into the health budget and discontinue the least cost-effective programmes (OECD, 2009).

133. Brazil's public health care expenditure is projected to increase substantially over the next 20 years, with a large contribution coming from population ageing (Table 3). Public health care expenditure is expected to reach 5.8\% of GDP in 2030 from an average of about 3.7\% over the 2006-10 period (de la Maisonneuve and Oliveira Martins, 2013). This is the largest increase among the BRIICS countries and close to the highest among OECD countries. Around $40 \%$ of the public health care spending rise will be due to demographic trends against an average of 30 and $20 \%$ for the other BRIICS and OECD countries, respectively. 


\section{South Africa}

134. The South African health care system is highly fragmented and mostly privately financed. The poor are particularly vulnerable to catastrophic health expenditure. The high HIV and TB infection rates have severely strained the health care system, contributing to the poor showing of health indicators. The current supply of health care services is hospital-centred and focuses on curative care rather than primary and preventive care. This has blunted the effectiveness of the health care system and made access to care unequal, as the poor and rural populations are underserved.

135. To remedy this situation, the government plans to introduce a national health insurance (NHI) system. The process was launched in 2011 and will be phased in over 14 years. It will involve significant changes to existing administrative and management systems. Various aspects of the NHI are being tested in ten districts.

136. The overarching aim of the NHI is universal access to healthcare services and protection against catastrophic health risks. To attain a high degree of risk pooling and equity the plan envisages the creation of a single NHI fund (in 2014/2015) with contributions being based on ability to pay (with no opt-out) and health benefits determined by medical needs. Efforts are being made to fill the shortage of doctors and nurses in addition to rebalancing the supply of health care services towards primary and preventive care, through establishing local and school-based primary health care centres.

137. The government plans to explore the use of health technology assessment (HTA) as a way to curb health care costs. The effective use of HTA to evaluate the treatment and drugs' cost-effectiveness will need to be backed by appropriate legislation. In this regard, collaboration is being explored with the United Kingdom's centre responsible for HTA (the National Institute for Health and Clinical Excellence).

138. It is not yet clear how the NHI will be funded. The options under consideration include a payroll tax (payable by both employees and employers), a higher value-added tax rate or a surcharge on taxable income, or some combination of these. As in other developing countries given the wide-spread labour market informality and population ageing, a payroll tax may not be the best funding instrument to raise sufficient revenue to fund adequate health care services. Funding the NHI through a higher value added tax or by general tax revenue would spread the financing burden more equitably across the population based on the ability to pay and will make financing less vulnerable to setbacks in the fight against labour market informality.

\section{Russia}

139. Russian health outcomes are well below those of OECD countries or countries of similar income level. Russian life expectancy was 69 years in 2010, more than ten years below the OECD average and about seven years shorter than in countries with a similar income level, such as Chile and Poland. Health outcomes gaps with respect to OECD countries emerged over the transition period as a result of cuts in health expenditure and systemic changes. However, poor health outcomes have also to be ascribed to poor life styles, as epitomised by high alcohol consumption and smoking.

140. Health care provision is tilted towards high-cost hospital and specialist care, with primary and preventive care receiving scant attention. Health care services are often inadequate for the medical needs of patients and access to care is highly unequal because of geographic and income-related factors.

141. Public health spending is low at around 3.5\% of GDP; $40 \%$ of it is financed through social security contributions flowing to regional health insurance funds. This configuration limits risk pooling across regions as regional health care spending and financing largely depend on local employment 
dynamics and the fiscal capacity of regional governments to fund health coverage for non-workers. For this reason, per-capita health spending and health outcomes vary markedly across regions, more than in other federal OECD countries (OECD, 2012c).

142. Even though people are entitled to a package of free basic health care services, health care access is often determined by income. The share of out-of-pocket payments in total health spending is large, but lower than in China, Indonesia and India. It is, however, probably underestimated because of the common practice of making informal payments to medical professionals. The share of private spending in total health care spending is $35 \%$, the lowest level among the BRIICS countries but higher than in the OECD on average.

143. The government has committed substantial funds to the health care sector. However, higher public outlays need be accompanied by policies promoting healthier life styles and strengthening preventive and primary care. Also, reforms should aim at increasing risk pooling, enhancing the efficiency and effectiveness of the system and making it more responsive to patient needs (OECD, 2012c). Without these complementary reforms, additional public health care spending risk failing to yield the expected benefits.

144. Preventive care needs to be improved by securing long-term financing. As the benefits of preventive care appear only after a long and uncertain time lag, short-term financing risks being discontinued before benefits are realised. There is scope to increase excise taxes, as for instance tobacco taxes are low. The government has replaced the Unified Social Tax with higher social insurance contributions to regional social insurance funds. While this may raise additional revenues in the short term, there is a risk that reduced transfers from the regional and federal budgets will offset them. Also, higher social insurance contributions - by distorting labour markets and lowering "official" employment rates may not generate the expected revenue increase. Increasing health care funding through general taxation is less distortive and more consistent with current population dynamics. 


\section{BIBLIOGRAPHY}

Andersson, K., G. Bergström, M. G. Petzold, and A. Carlsten (2007), "Impact of a Generic Substitution Reform on Patients' and Society's Expenditure for Pharmaceuticals", Health Policy, Vol. 81(2-3), $376-384$.

Andersson, K. A., M. G. Petzold, P. Allebeck, and A. Carlsten (2008), "Influence of Mandatory Generic Substitution on Pharmaceutical Sales Patterns: a National Study over Five Years", BMC Health Services Research, Vol. 8(1), 50.

Arrow, K.J. (1963, "Uncertainty and the Welfare Economics of Medical Care", The American Economic Review, Vol. 53(5), pp. 941-973

Baicker, K. and D. Goldman (2011), "Patient Cost-Sharing and Healthcare Spending Growth", Journal of Economic Perspectives, 25(2), 47-68.

Baker, L. C. (1999), "Association of Managed Care Market Share and Health Expenditures for Fee-forService Medicare Patients", JAMA, Vol. 281(5), 432-437.

Barbash, G.I. and S.A. Glied (2010), "New Technology and Health Care Costs - The Case of RobotAssisted Surgery", New England Journal of Medicine, Vol. 363, 701-704.

Barr, N. (2012), Economics of the Welfare State, Oxford University Press.

Baumol, W. J. (1996), "Children of Performing Arts, the Economic Dilemma: The Climbing Costs of Health Care and Education", J Cult Econ, Vol. 20(3), 183-206.

Breyer, F. and A. Haufler (2000), "Health Care Reform: Separating Insurance from Income Redistribution?", International Tax and Public Finance, 7(4-5), 445-461.

Brook, R.H., E.B. Keeler, K.N. Lohr, J.P. Newhouse, J.E. Ware, W.H. Rogers, A. Ross Davies, C.D. Sherbourne, G.A. Goldberg, P.Camp, C. Kamberg, A. Leibowitz, J. Keesey, D. Reboussin (2006), "The Health Insurance Experiment: A Classic RAND Study Speaks to the Current Health Care Reform Debate", Research Brief RB-9174-HHS, RAND Corporation, available at www.rand.org/pubs/research_briefs/RB9174.html

Chandra, A., A. B. Jena, and J. S. Skinner (2011), "The Pragmatist's Guide to Comparative Effectiveness Research", Journal of Economic Perspectives, Vol. 25(2), 27-46.

Clement, F.M. (2009), "Using Effectiveness and Cost-Effectiveness to Make Drug Coverage Decisions: A Comparison of Britain, Australia, and Canada", JAMA, Vol. 302(13), 1437-1443.

Congressional Budget Office (2005), Quantifying Uncertainty in the Analysis of Long-Term Social Security Projections, Washington. 
Cooper, Z., S. Gibbons, S. Jones, and A. McGuire (2011), "Does Hospital Competition Save Lives? Evidence from the English NHS Patient Choice Reforms", The Economic Journal, Vol. 121(554), F228-F260.

Costa-Font, J. and J. Pons-Novell (2007), "Public Health Expenditure and Spatial Interactions in a Decentralized National Health System”, Health Economics, Vol. 16(3), 291-306.

Coulam, R. F. and G. L. Gaumer (1991), "Medicare's Prospective Payment System: A Critical Appraisal”, Health Care Finance Review Annual Supplement, 45-77.

Cutler, D. M. (1995), “The Incidence of Adverse Medical Outcomes under Prospective Payment”, Econometrica, Vol. 63(1), 29-50.

Davies, S. E. (2008), “Securitizing Infectious Disease”, International Affairs, Vol. 84(2), 295-313.

Davis, C. K. and D. J. Rhodes (1988), "The Impact of DRGs on the Cost and Quality of Health Care in the United States", Health Policy, Vol. 9(2), 117-131.

Devaux, M. and M. de Looper (2012), "Income-Related Inequalities in Health Service Utilisation in 19 OECD Countries, 2008-2009", OECD Health Working Papers, No 58, OECD Publishing, Paris.

Disney R. (2004), “Are Contributions to Public Pension Programmes a Tax On Employment?”, Economic Policy, Vol. 19(39), 267-311.

Docteur, E. and H. Oxley (2003), "Health-Care Systems: Lessons from the Reform Experience", OECD Health Working Papers, No. 9, OECD Publishing, Paris.

Dusheiko, M., H. Gravelle, R. Jacobs and P. Smith (2006), "The Effect of Financial Incentives on Gatekeeping Doctors: Evidence from a Natural Experiment", Journal of Health Economics, Vol. 25(3), 449-478.

Eggleston, K. (2012), "Health Care for 1.3 billion: An Overview of China's Health System”, Asia Health Policy Program Working Paper \# 28, Stanford, California: Stanford University.

Elbe, S. (2010), "Haggling over Viruses: The Downside Risks of Securitizing Infectious Disease", Health Policy and Planning, Vol. 25(6), 476-485.

Ellis, P. and M.M. Miller (2008), "Provider Payment Methods and Incentives", in Harald Kristian (eds), International Encyclopedia of Public Health, (Kris) Heggenhougen, Academic Press, Oxford.

Elzinga, K. G. and D. E. Mills (1997), "The Distribution and Pricing of Prescription Drugs." International Journal of the Economics of Business, Vol. 4 (3), 287-300.

Emmerson, C., C. Frayne and A. Goodman (2001), "Should Private Medical Insurance be Subsidised?", Health Care UK, pp.49-65, available at www.ifs.org.uk/docs/private_med.pdf.

Ferner, R. E., W. Lenney and J. F. Marriott (2010). "Controversy over Generic Substitution”, BMJ, Vol. 340, c2548-c2548.

Forrest, C. B. (2003), "Primary Care Gatekeeping and Referrals: Effective Filter or Failed Experiment?", $B M J$, Vol. 326(7391), 692-695. 
Frijters, P., J. P. Haisken-DeNew and M. A. Shields (2005), "The Causal Effect of Income on Health: Evidence from German Reunification", Journal of Health Economics, Vol. 24(5), 997-1017.

Gaál, P., S. Szigeti, M. Csere, M, Gaskins and D. Panteli (2011), "Hungary: Health System Review", Health Systems in Transition, Vol. 13(5), 1-266, available at www.euro.who.int/_data/assets/pdf_file/0019/155044/e96034.pdf.

Garber, A. M. and J. S. Skinner (2008), “Is American Health Care Uniquely Inefficient?", Journal of Economic Perspectives, Vol. 22(4), 27-50.

Gardner, J. and A. J. Oswald (2007), "Money and Mental Wellbeing: A Longitudinal Study of MediumSized Lottery Wins", Journal of Health Economics, Vol. 26(1), 49-60.

Gaynor, M., R. Moreno-Serra and C. Propper (2013), "Death by Market Power: Reform, Competition, and Patient Outcomes in the National Health Service", American Economic Journal: Economic Policy Vol. 5(4), 134-166.

Gerdtham, U-G., B. Jönsson, M. MacFarlan and H. Oxley (1998), "The Determinants of Health Expenditure in the OECD Countries: A Pooled Data Analysis", in Zweifel, P. (ed.), Health, the Medical Profession, and Regulation, Klewer, Dordrecht.

Giannoni, M. and T. Hitiris (2002), "The Regional Impact of Health Care Expenditure: the Case of Italy", Applied Economics, Vol. 34(14), 1829-1836.

Van Ginneken, E., K. Swartz and P. Van der Wees (2013), "Health Insurance Exchanges in Switzerland and the Netherlands Offer Five Key Lessons for the Operations of US Exchanges", Health Affairs, $32(4)$.

Glied, S.A. (2008), "Health Care Financing, Efficiency, and Equity”, NBER Working Paper, No. 13881.

Gruber, J., N. Hendren and R.M. Townsend (2014), "The Great Equalizer: Health Care Access and Infant Mortality in Thailand", American Economic Journal: Applied Economics, Vol. 6(1), 91-107.

Habicht, T. (2012), "Estonia: Crisis Reforms and the Road to Recovery", Eurohealth, Vol. 18(1), 10-12, available at www.euro.who.int/en/who-we-are/partners/observatory/eurohealth.

Hall, R.E. and Jones C.I. (2007), "The Value of Life and the Rise in Health Spending”, Quarterly Journal of Economics, Vol. 122(1), 39-72.

Holahan, J. and V. Chen (2011), "Changes in Health Insurance Coverage in the Great Recession, 2007-2010", Kaiser Commission on Medicaid and the Uninsured, available at www.kff.org/medicaid/issue-brief/changes-in-health-insurance-coverage-in-the.

Huber, M., A. Stanicole, J. Bremner and K. Wahlbeck (2008), Quality in and Equality of Access to Healthcare Services, European Commission Directorate-General for Employment, Social Affairs and Equal Opportunities, Luxembourg.

Hussain, A. (2000), "Social Welfare in China in the Context of Three Transitions", Working Paper, No. 66, Stanford Center for Research on Economic Development and Policy Reform.

IMF (2010), "Macro-Fiscal Implications of Health Care Reform in Advanced and Emerging Economies", www.imf.org/external/np/pp/eng/2010/122810.pdf. 
ISSA (International Social Security Association) (2013), Social Security Coverage Extension in the BRICS: A Comparative Study on the Extension of Coverage in Brazil, the Russian Federation, India, China and South Africa, International Social Security Association, Geneva, available at www.issa.int/Resources/Resources/Social-security-coverage-extension-in-the-BRICS-Acomparative-study-on-the-extension-of-coverage-in-Brazil-the-Russian-Federation-India-China-andSouth-Africa.

Johnston, J. and J. DiNardo (1997), Econometric Methods, McGraw-Hill.

Jones, A. M. and J. Wildman (2008), "Health, Income and Relative Deprivation: Evidence from the BHPS”, Journal of Health Economics, Vol. 27(2), 308-324.

Joumard, I., M. Pisu and D. Bloch (2012), "Less Income Inequality and More Growth - Are They Compatible? Part 3. Income Redistribution via Taxes and Transfers Across OECD Countries", OECD Economics Department Working Papers, No. 926, OECD Publishing, Paris.

Joumard, I., P. Hoeller, C. André and C. Nicq (2010), Health Care Systems: Efficiency and Policy Settings, OECD Publishing, Paris.

Kessler, D. P. and M. B. McClellan (2000), "Is Hospital Competition Socially Wasteful?", The Quarterly Journal of Economics, Vol. 115(2), 577-615.

Kibicho, J., and S. D. Pinkerton (2012), "Multiple Drug Cost Containment Policies in Michigan's Medicaid Program Saved Money Overall, although some Increased Costs", Health Affairs, Vol. 31(4), 816-826.

King, D., F. Greaves, I. Vlaev and A. Darzi (2013), "Approaches Based on Behavioral Economics Could Help Nudge Patients and Providers toward Lower Health Spending Growth", Health Affairs, Vol. 32(4), 661-668.

Koen, V. et al. (2013), "Policies for Inclusive Urbanisation in China", OECD Economics Department Working Papers, No. 1090, OECD Publishing, Paris.

Koivusalo, K., K. Wyss and P. Santana (2006), "Effects of Decentralization and Recentralization on Equity Dimensions of Health Systems", in Saltman, R., V. Bankauskaite and K. Vrangbaek (eds.), Decentralization in Health Care, Open University Press, Maidenhead.

Kumar, A. and M. Schoenstein (2013), "Managing Hospital Volumes: Germany and Experiences from OECD Countries", OECD Health Working Papers, No. 64, OECD Publishing, Paris.

Kumar, A. K., L. C. Chen, M. Choudhury, S. Ganju, V. Mahajan, A. Sinha and A. Sen. (2011), "Financing Health Care for All: Challenges and Opportunities", The Lancet, Vol. 377(9766), 668-679.

Kwon, S. (2003), "Payment System Reform for Health Care Providers in Korea”, Health Policy Plan., Vol. 18(1), 84-92.

Linna, M. (2000), "Health Care Financing Reform and the Productivity Change in Finnish Hospitals", Journal of Health Care Finance, Vol. 26(3), 83-100.

Lopert, R. and A. G. Elshaug (2013), "Australia's "Fourth Hurdle": Drug Review Comparing Costs and Benefits Holds Lessons for the United States", Health Affairs, 32(4), 778-787. 
López Nicolás, Á. and M. Vera-Hernández (2008), "Are Tax Subsidies for Private Medical Insurance SelfFinancing? Evidence from a Microsimulation Model”, Journal of Health Economics, Vol. 27(5), $1285-1298$.

Louis, D. Z., E. J. Yuen, M. Braga, A. Cicchetti, C. Rabinowitz, C. Laine and J. S. Gonnella (1999), "Impact of a DRG-Based Hospital Financing System on Quality and Outcomes of Care in Italy", Health Services Research, Vol. 34, 405-415.

Magnussen, J., F. Tediosi and P. Mihályi (2006), "Effects of Decentralization and Recentralization on Economic Dimensions of Health Systems", in Saltman, R., V. Bankauskaite and K. Vrangbaek (eds.), Decentralization in Health Care, Open University Press, Maidenhead.

de la Maisonneuve, C. and J. Oliveira Martins, J. (2013), "A Projection Method for Public Health and Long-term Care Expenditures", OECD Economics Department Working Paper, No. 1048, OECD Publishing, Paris.

de la Maisonneuve C., R. Moreno-Serra, F. Murtin and J. Oliveira Martins (2014), "Health Systems, Institutions and Health Expenditure Drivers", OECD Economics Department Working Papers, forthcoming.

Miller, R. H., and H. S. Luft (2002), "HMO Plan Performance Update: An Analysis of the Literature, 1997-2001”, Health Affairs, Vol. 21(4), 63-86.

Moreno-Serra, R. (2013), "The Impact of Cost Containment Policies on Health Care Expenditure: Evidence from Recent OECD Experiences", presented at the $2^{\text {nd }}$ Meeting of the Joint Network on Fiscal Sustainability of Health Systems, 25-26 March 2013, Paris.

Moreno-Serra, R. and A. Wagstaff (2010), "System-Wide Impacts of Hospital Payment Reforms: Evidence from Central and Eastern Europe and Central Asia", Journal of Health Economics, Vol. 29(4), 585-602.

Morgan, S. G., J. D. Agnew and M. L. Barer (2004), "Seniors' Prescription Drug Cost Inflation and Cost Containment: Evidence from British Columbia”, Health Policy, Vol. 68(3), $299-307$.

Mossialos, E. and A. Dixon (2002), "Funding health care: an introduction", in E. Mossialos, A. Dixon, J. Figueras and J. Kutzin (eds) Funding Health Care: Options for Europe, Open University Press, Buckingham.

OECD (2009), OECD Economic Surveys: Brazil 2009, OECD Publishing, Paris.

OECD (2010a), OECD Economic Surveys: China 2010, OECD Publishing, Paris.

OECD (2010b), OECD Economic Surveys: Indonesia 2010, OECD Publishing, Paris.

OECD (2011), OECD Economic Surveys: India 2011, OECD Publishing, Paris.

OECD (2012a), Reviews of Health Systems: Finland 2012, OECD Publishing, Paris

OECD (2012b), OECD Economic Surveys: Indonesia 2012, OECD Publishing, Paris.

OECD (2012c), Reviews of Health Systems: Russian Federation, OECD Publishing, Paris 
OECD (2013), OECD Economic Surveys: Greece 2013, OECD Publishing, Paris.

Paris, V., M. Devaux and L. Wei (2010), "Health Systems Institutional Characteristics: A Survey of 29 OECD Countries", OECD Health Working Papers, No. 50, OECD Publishing, Paris.

Propper, C., S. Burgess and D. Gossage (2008), "Competition and Quality: Evidence from the NHS Internal Market 1991-99”, The Economic Journal, Vol. 118(525), 138-170.

Raftery, J. and J. Powell (2013), "Health Technology Assessment in the UK.” The Lancet, Vol 382(9900), $1278-1285$.

Rao, M. et al. (2011), "Human Resources for Health in India”, The Lancet, Vol. 377(9765), 587-598.

Saltman, R., V. Bankauskaite and K. Vrangbaek (2006), "Introduction: the Question of Decentralization", in Saltman, R., V. Bankauskaite and K. Vrangbaek (eds.), Decentralization in Health Care, Open University Press, Maidenhead.

Sassi, F. (2010), Obesity and the Economics of Prevention: Fit, not Fat, OECD Publishing, Paris.

Sassi, F. and J. Hurst (2008), "The Prevention of Lifestyle-Related Chronic Diseases: an Economic Framework", OECD Health Working Papers, No. 32, OECD Publishing, Paris.

Sassi, F., A. Belloni and C. Capobianco (2013), "The Role of Fiscal Policies in Health Promotion," OECD Health Working Paper, No. 66, Paris.

Shrank, W. H. et al. (2010), "State Generic Substitution Laws Can Lower Drug Outlays under Medicaid, Health Affairs, Vol. 29(7), 1383-1390.

Sikk, I. (2013), "Estonian Experience on Using Health Expenditure Reserve Funds" presentation at the $2^{\text {nd }}$ Meeting of the Joint Network on Fiscal Sustainability of Health Systems, 25-26 March 2013, Paris.

Smith, R., R. Beaglehole, D. Woodward and N. Drager (2003), Global Public Goods for Health: Health, Economic and Public Health Perspectives, Oxford University Press.

Stuckler, D. and Basu, S. (2013), The Body Economic, Basic Books.

Summers, L. H. (1989), "Some Simple Economics of Mandated Benefits", The American Economic Review, Vol. 79(2), 177-183, doi:10.2307/1827753.

Tapay, N. and F. Colombo (2004), "Private Health Insurance in OECD Countries: The Benefits and Costs for Individuals and Health Systems", in OECD, Towards High-Performing Health Systems, OECD Publishing, Paris.

Thomson, S., L. Schang and M. E. Chernew (2013), "Value-Based Cost Sharing in the United States and elsewhere Can Increase Patients' Use of High-Value Goods and Services", Health Affairs, 32(4), 704-712.

Vogler, S. et al. (2008), Pharmaceutical Pricing and Reimbursement Information (PPRI), European Commission, available at http://ec.europa.eu/health/ph_projects/2004/action1/docs/action1_2004_frep_05_en.pdf.

Wagstaff, A. (2010), "Social Health Insurance Reexamined", Health Economics, Vol. 19(5), 503-517. 


\section{ECO/WKP(2014)28}

Wagstaff, A. et al. (1999), "Equity in the Finance of Health Care: Some Further International Comparisons", Journal of Health Economics, 18(3), 263-290.

WHO (2002), The World Health Report 2002, World Health Organisation, Geneva.

WHO (2010), Health Systems Financing: The Path to Universal Coverage, World Health Organization, Geneva.

Wilkinson, R. and M. Marmot (2003), The Solid Facts, WHO Regional Office for Europe, Copenhagen.

World Bank (2013), Indonesia's Path to Universal Health Coverage: Key Lessons from the Implementation of Jamkesmas, Human Development: Building the Foundation for Inclusive Growth. Washington DC: World Bank. available at:

http://documents.worldbank.org/curated/en/2013/09/18369214/indonesias-path-universal-healthcoverage-key-lessons-implementation-jamkesmas. 
ECO/WKP(2014)28

\section{APPENDIX A1}

145. To assess the sensitivity of long-term projections to shocks to the determining variables, studies often rely on Monte Carlo simulations. ${ }^{23}$ They treat one or more of the variables affecting the outcome of interest as stochastic. Stochastic shocks to the variables that determine health spending, such as GDP, generate a distribution of health care expenditure at each point in time of the projection period.

146. Monte Carlo simulations of empirical models are done in three steps: 1) a statistical model is fitted to each stochastic determining variable whose residual then represents the stochastic shock; 2) the residuals or shocks are assumed to be generated by a statistical distribution; in Monte Carlo simulations the normal distribution is often used; 3 ) a random number is generated from this statistical distribution, which, representing a shock, is fed into the stochastic input variable's projection, which in turn affect the outcome of interest - health care spending in this case. Repeating step three a large number of times for all periods of the projection horizon, yields a distribution for the outcome of interest. This distribution can then be used to evaluate the future vulnerability of health-care expenditure to shocks. A wide dispersion of the distribution around the projected central value would suggest that the outcome is highly vulnerable to shocks.

147. The results shown below treat GDP as the only stochastic variable. The shocks to GDP (step 1 above) were extracted from fitting past output gaps with a time-series model. ${ }^{24}$ These shocks reflect temporary deviations of GDP from its potential. This is consistent with the long-term health-care expenditure projections, which use potential output as income variable.

148. As concerns step two, this study departs from the normality assumption regarding the distribution of shocks. This assumption is likely to be excessively restrictive for the purpose of this exercise as it implies an exceedingly small probability of observing shocks of the magnitude experienced in 2008 and 2009. Formal statistical tests of the residuals of the estimated statistical models fitting the output gap indeed reject for most countries the null hypothesis of normally distributed residuals. Plotting the kernel distribution densities of the shocks it is possible to show that for many countries they are indeed highly asymmetric, have fat tails as extreme outcomes (i.e. often large negative ones) are more frequent than what the normal distribution predicts. The null hypothesis that the residuals are independently distributed - that is, the value of a shock does not depend on the value of past shocks - is not rejected, lending support to the statistical model used to fit output gaps.

149. This work then relies on bootstrap rather than Monte Carlo methods. Instead of generating random numbers assuming a normal distribution, bootstrap techniques involve re-sampling shocks from their actual distribution - that is the distribution of the statistical model's residuals.

150. Figure 17 shows for six OECD countries the projected output gaps from the Long Term Scenario and their $90 \%$ confidence interval generated through 1000 bootstrap replications. The $90 \%$ confidence intervals are large and encompass most of the previous variation in the output gap. For some countries,

23. For instance, the Congressional Budget Office has employed this methodology to produce confidence bands for its long-term social security revenue and outlay projections to 2110 (Congressional Budget Office, 2005).

24. An $\operatorname{ARMA}(2,2)$ for all countries was used as it produces uncorrelated error terms for all of them but Greece. Estimates used quarterly data from the earliest possible period (around mid-1980s for most countries) to 2011Q4. Yearly forecasts and confidence intervals are obtained by averaging quarterly data. 
such as Spain - and to a lesser extent for others as well - the uncertainty band is asymmetric because of tail risks of large negative shocks. ${ }^{25}$

\section{Figure 17. Projected output gaps and $90 \%$ uncertainty bands}
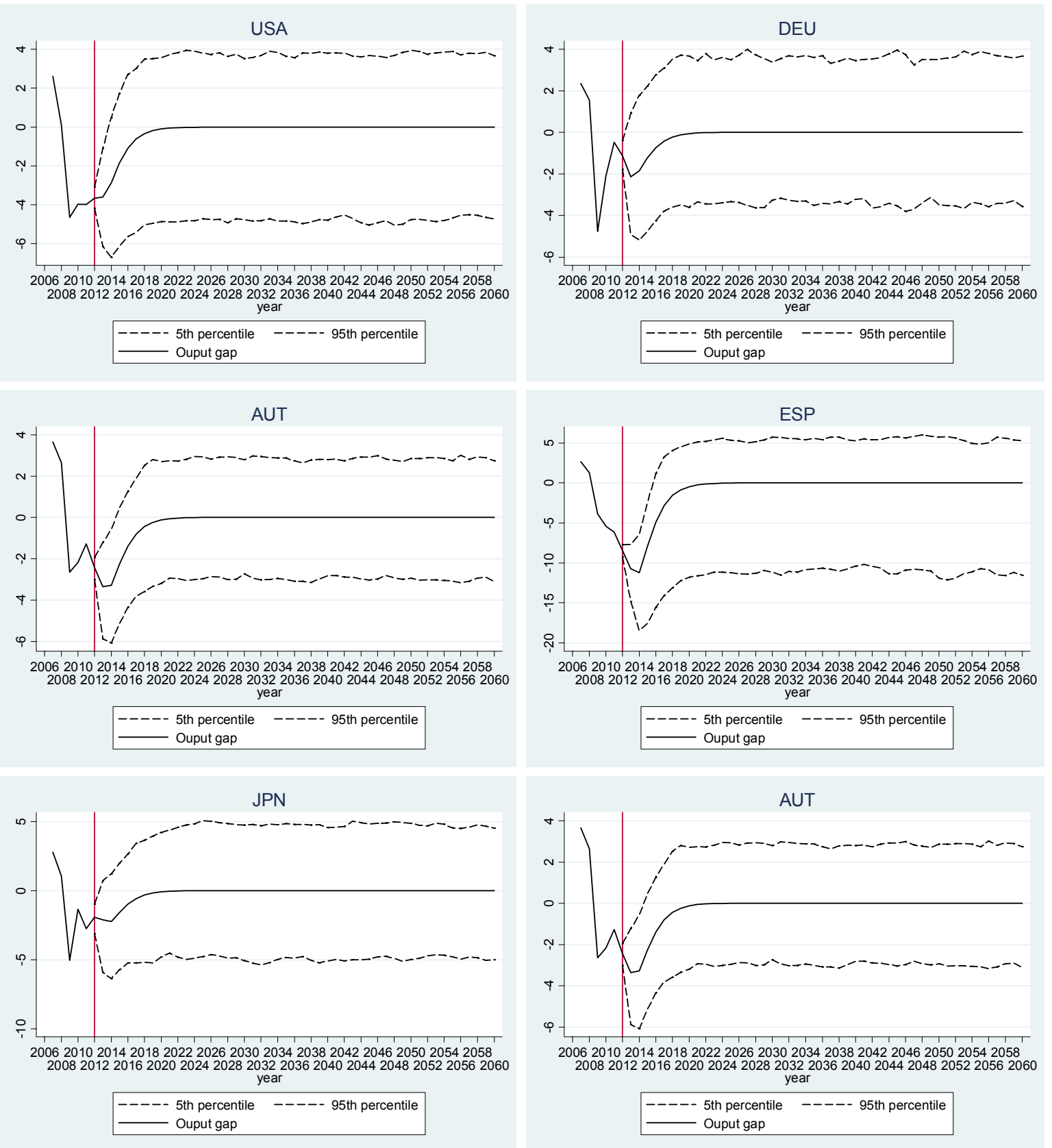

Note: The vertical line indicates the start of the projection period.

Source: OECD Economic Outlook, No. 92, and authors calculations.

25. Forecast confidence intervals become larger, before stabilising, since the mean square forecasting error approaches the unconditional variance of the variable being modelled as the forecast period tends to infinity (e.g. Johnston and DiNardo, 1997). 
APPENDIX A2

Health care system vulnerability indicators

Australia

Policy levers

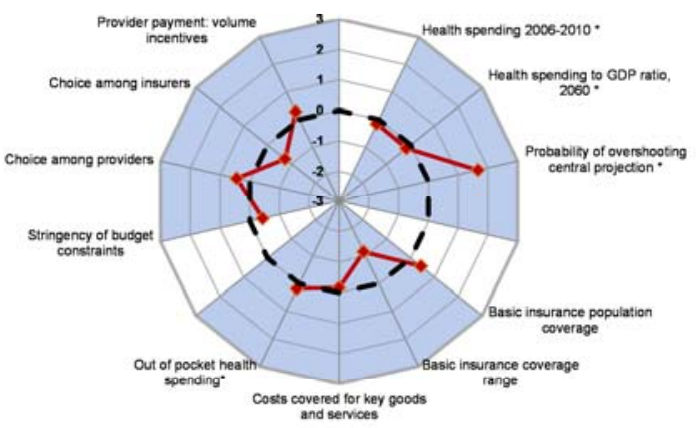

Adequacy

Belgium

Policy levers

Sustainability

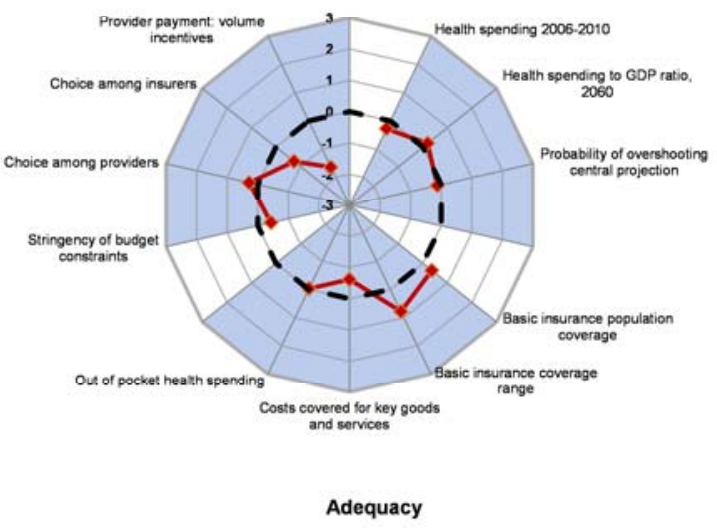

Chile

Policy levers

Sustainability

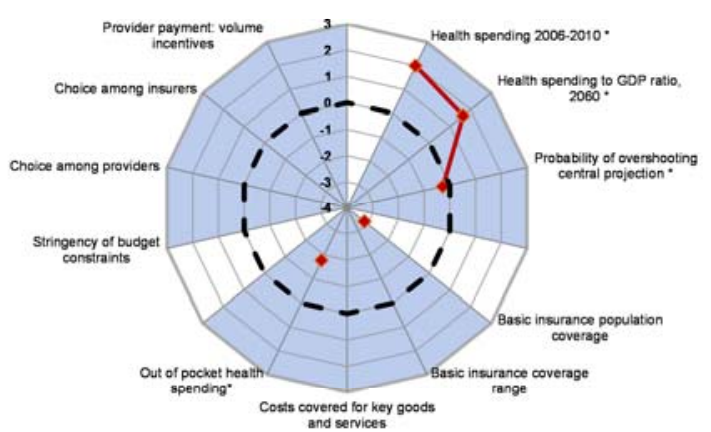

Adequacy
Austria

Policy levers

Sustainability

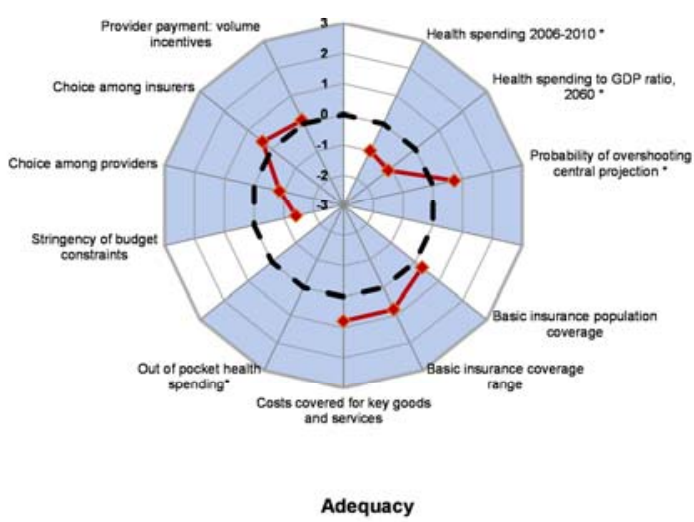

Canada

Policy levers

Sustainability

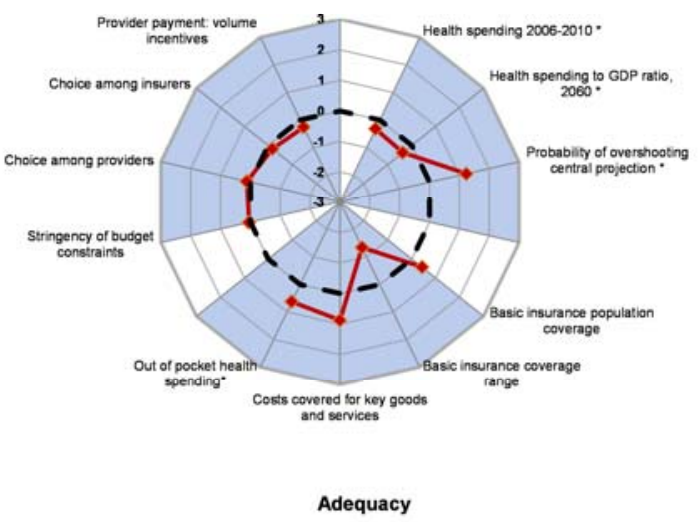

Czech Republic
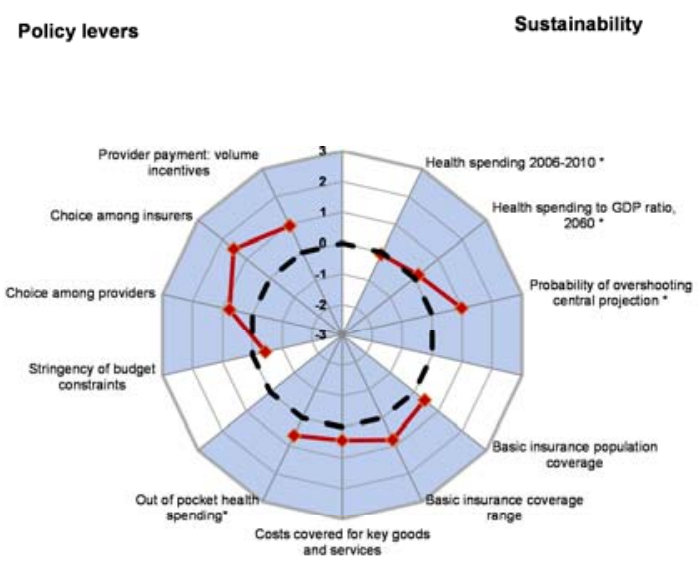

Adequacy 
Policy levers

Sustainability

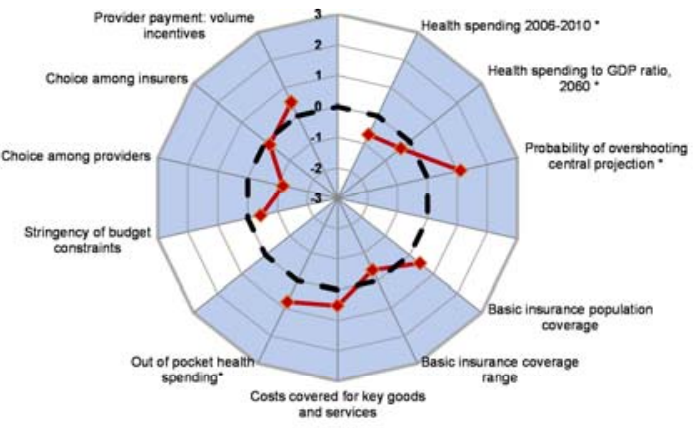

Adequacy

Finland

Policy levers

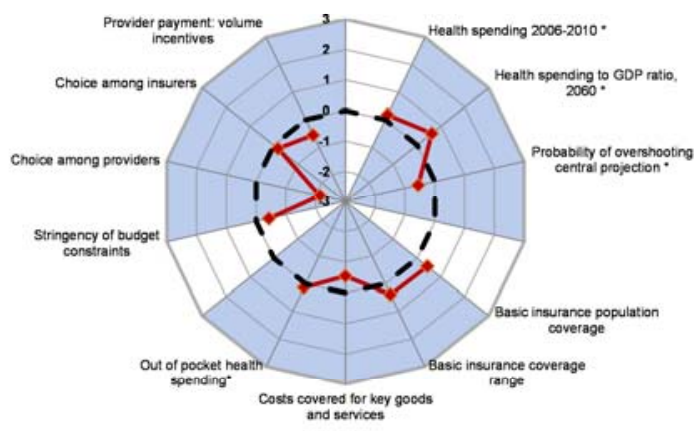

Adequacy

Germany

Policy levers

Sustainability

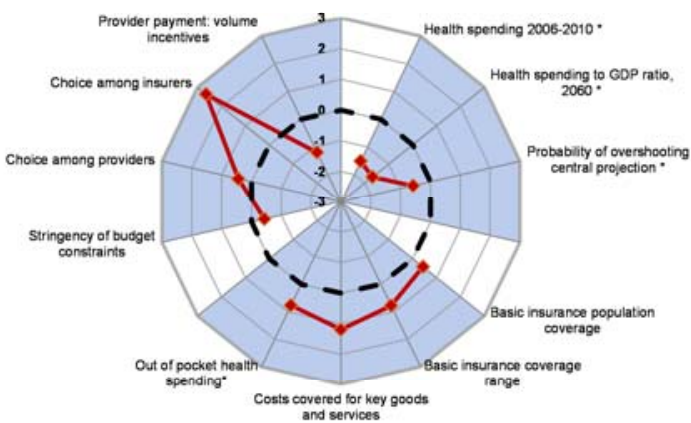

Adequacy
Policy levers

Sustainability

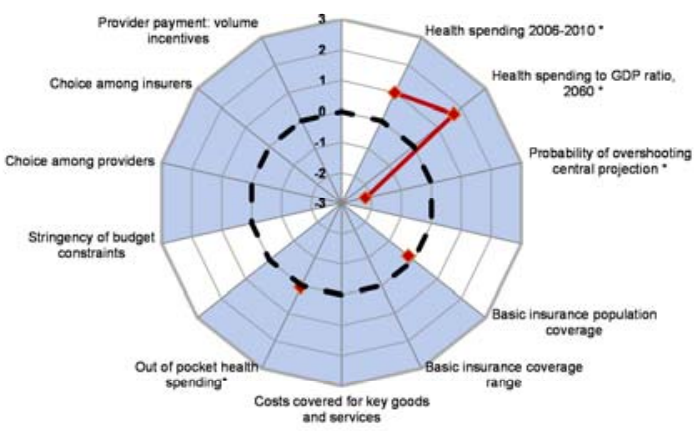

Adequacy

France

$\begin{array}{ll}\text { Policy levers } & \text { Sustainability }\end{array}$

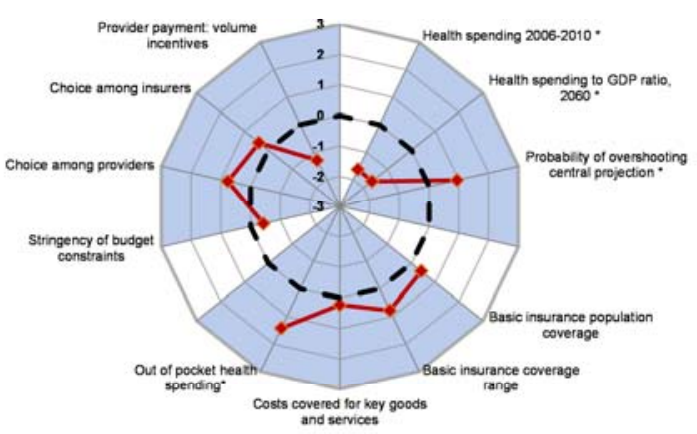

Adequacy

Greece

Policy levers

Sustainability

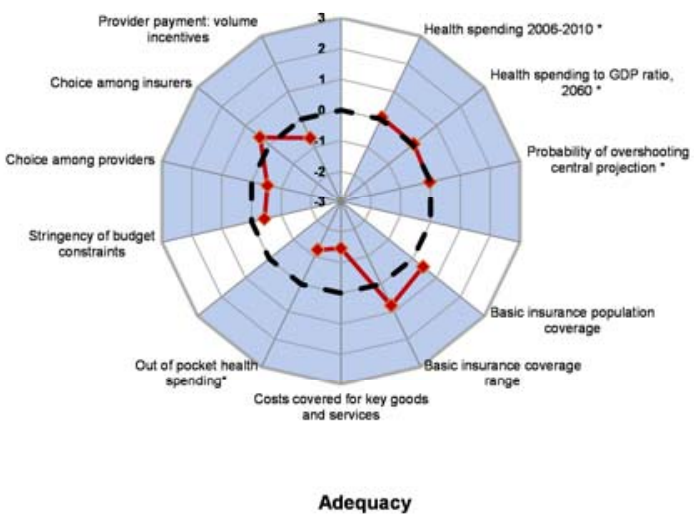


Health care system vulnerability indicators

ECO/WKP(2014)28

Hungary

Policy levers

Sustainability

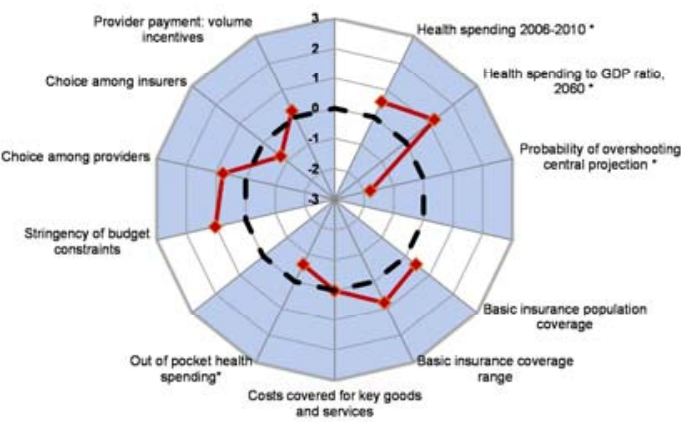

Adequacy

Ireland

Policy levers

Sustainability

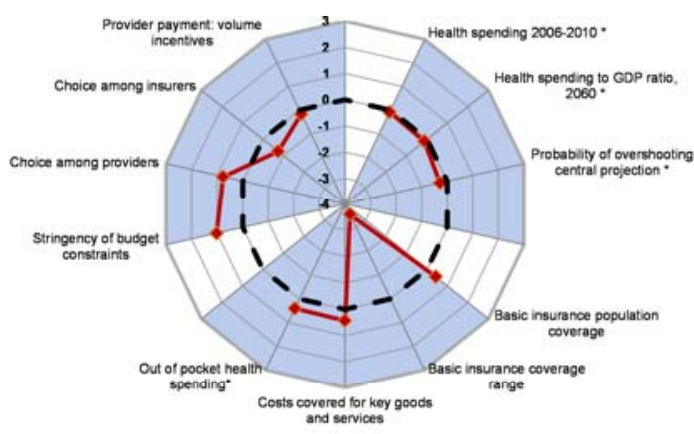

Adequacy

Italy

Sustainability

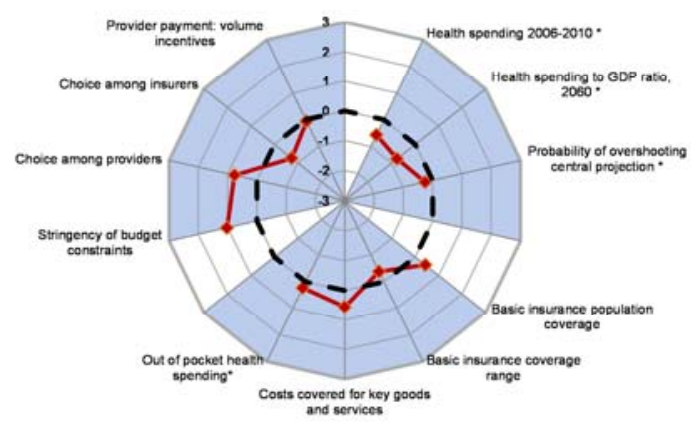

Adequacy

Iceland

Policy levers

Sustainability

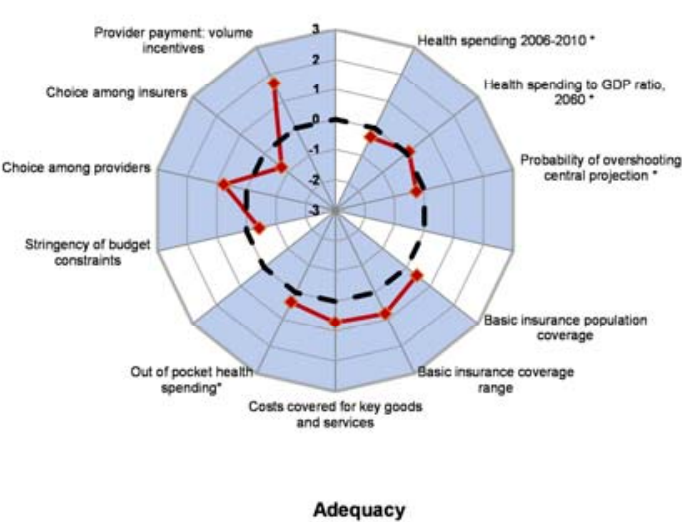

Israel

Policy levers

Sustainability

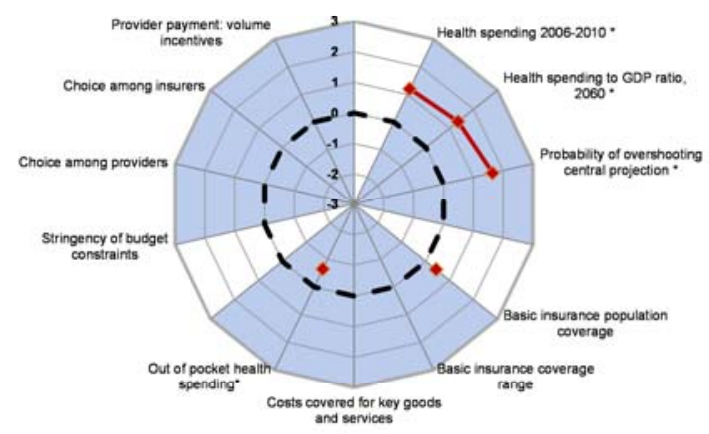

Adequacy

Japan

Policy levers

Sustainability

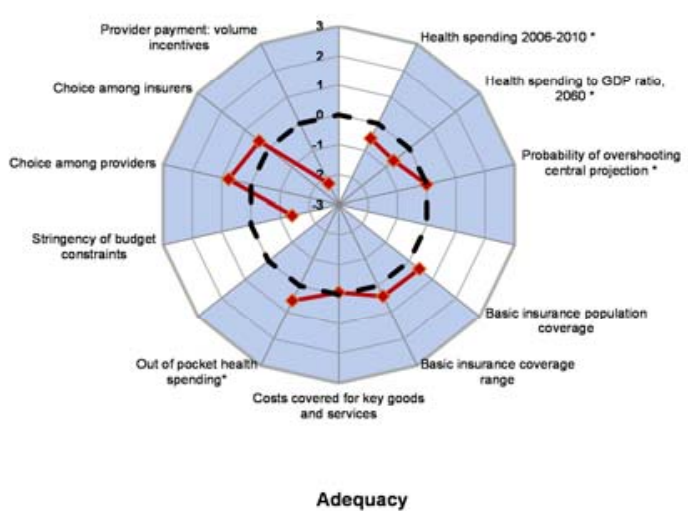


Korea

Policy levers

Sustainability

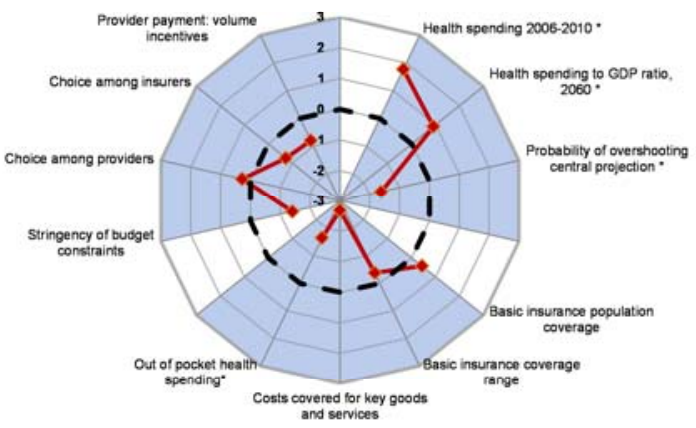

Adequacy

Mexico

Policy levers

Sustainability

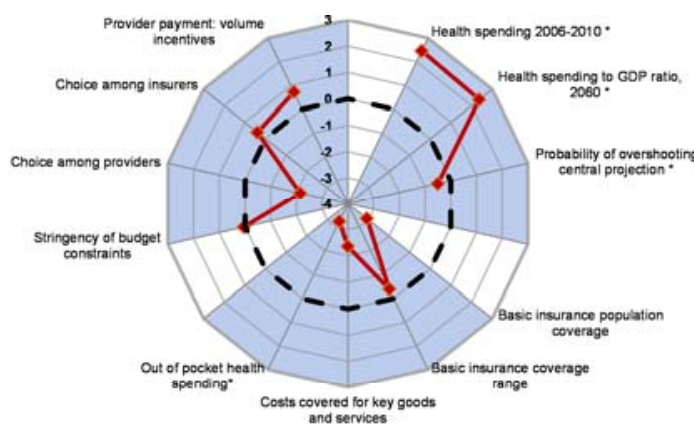

Adequacy

New Zealand

Policy levers

Sustainability

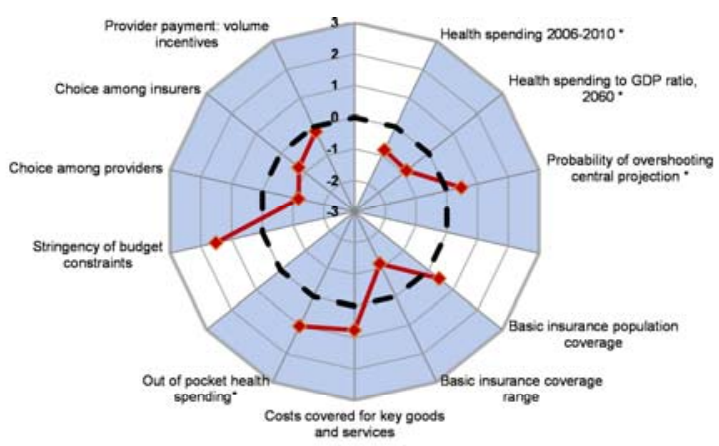

Adequacy
Luxembourg

Policy levers

Sustainability

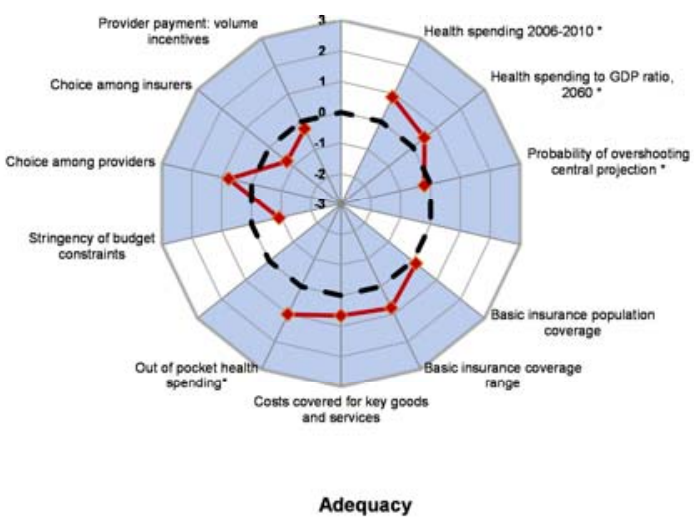

Netherlands

Policy levers

Sustainability

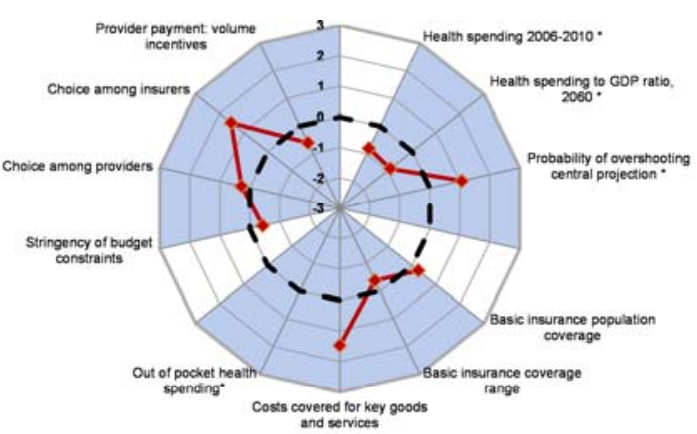

Adequacy

Norway

Policy levers

Sustainability

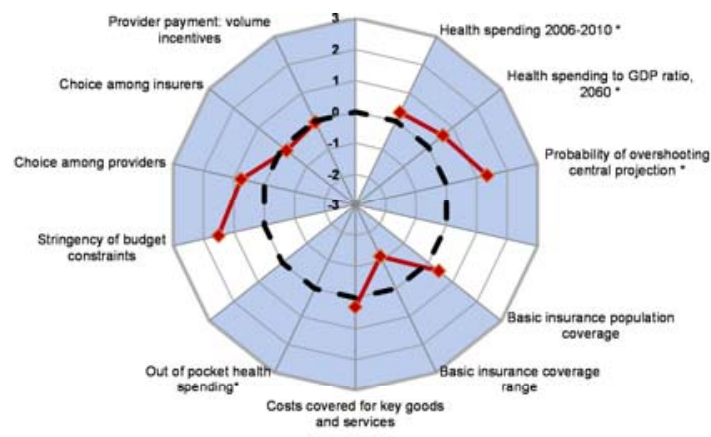

Adequacy 


\section{Health care system vulnerability indicators}

ECO/WKP(2014)28

Poland

Policy levers

Sustainability

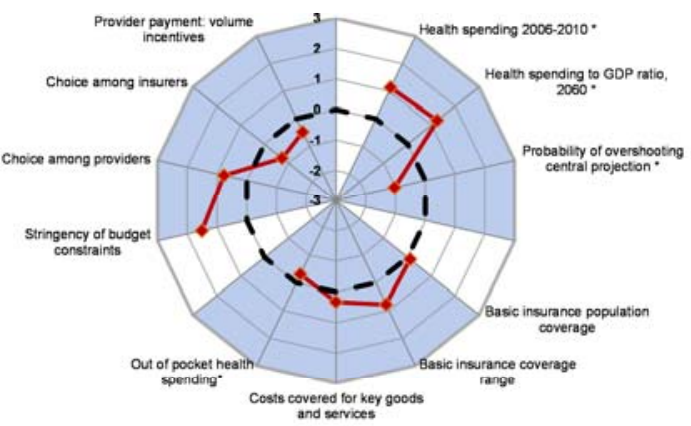

Adequacy

Slovak Republic

Policy levers

Sustainability

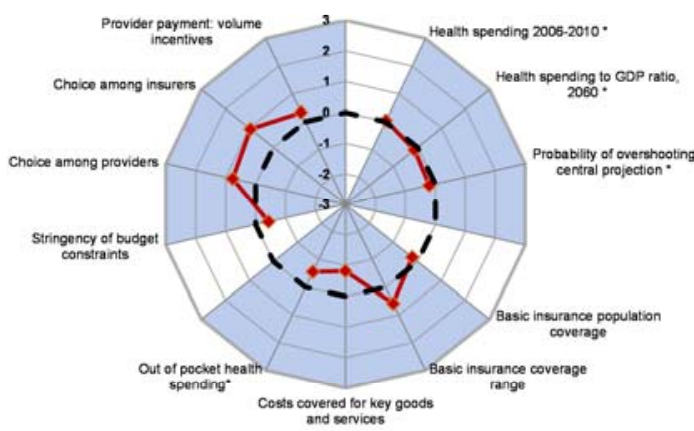

Adequacy

Spain

Policy levers

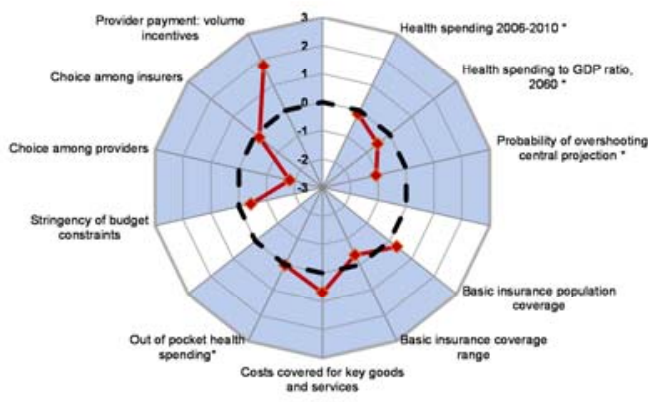

Adequacy
Portugal

Policy levers

Sustainability

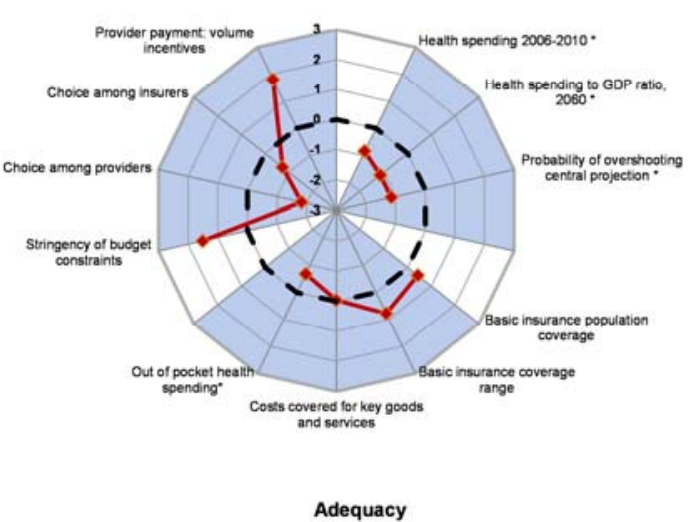

Slovenia

Policy levers

Sustainability

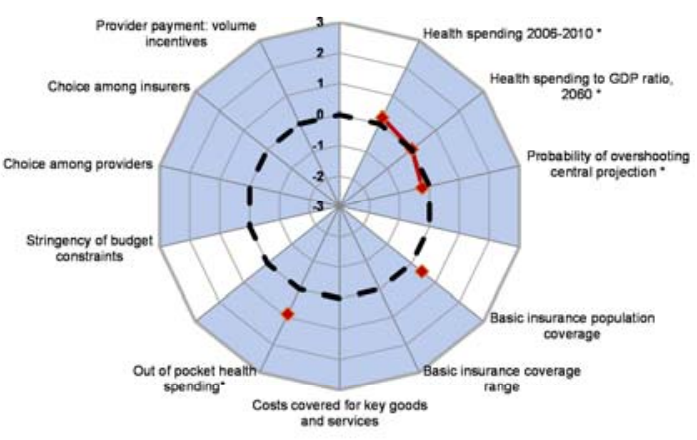

Adequacy

\section{Sweden}

Policy levers

Sustainability

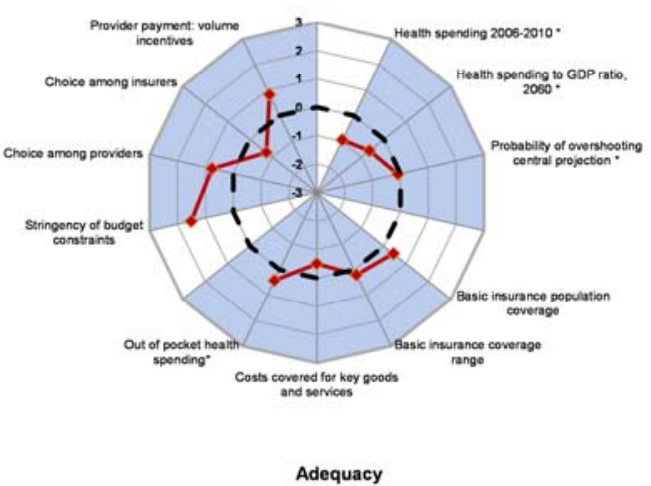


Switzerland

Policy levers
Sustainability

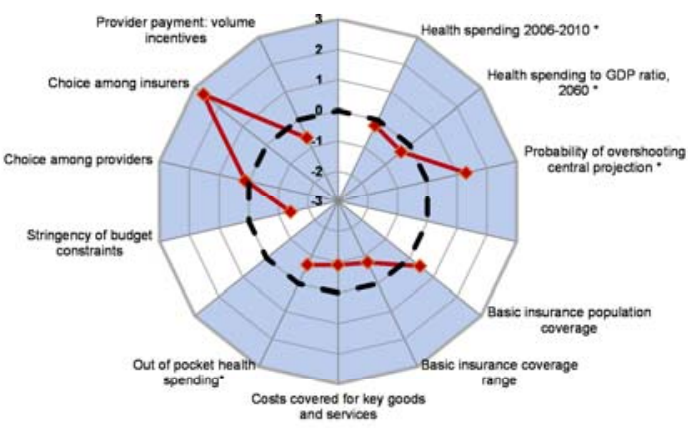

Adequacy
Policy levers

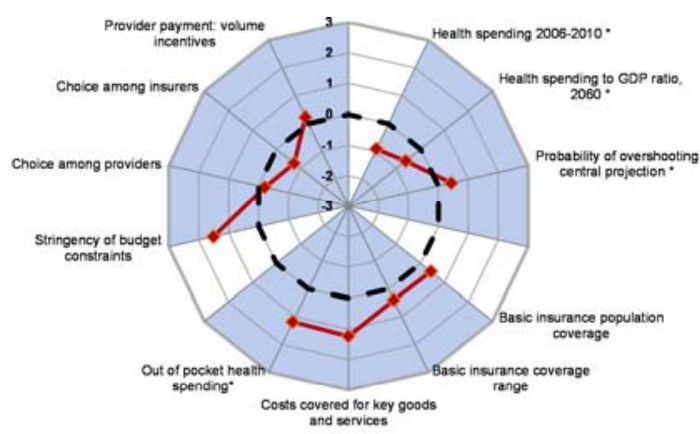

Adequacy
Turkey

Policy levers

Sustainability
United Kingdom

Sustainability

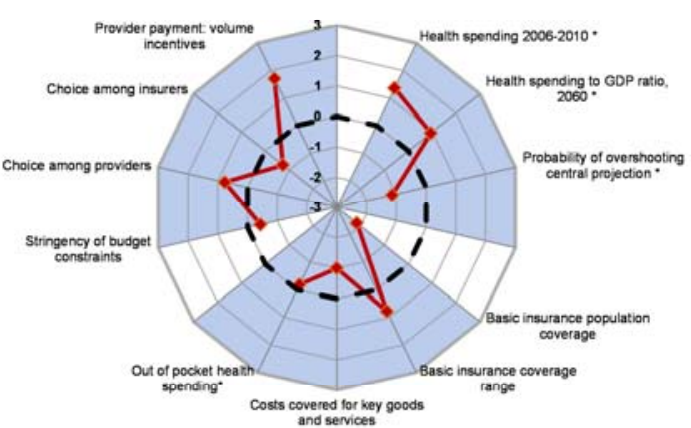

Adequacy

\section{United States}

Policy levers

Sustainability

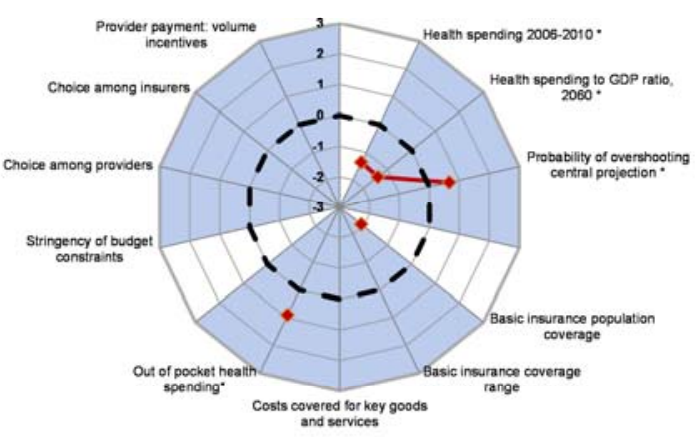

Adequacy

Note: The dotted line represents the OECD average, the solid line and diamond markets represent the country shown. Where the solid line falls outside the OECD average, this implies better results than the OECD average. For instance, for the United Kingdom, out-of-pocket spending is low, but is shown as being outside the dotted line, because this is good for adequacy. The indicators are presented in standard deviation units. Legend:

Sustainability

Health Spending 2006-10*: Average health spending-to-GDP ratio over 2006-10 (inverted).

Health spending-to-GDP ratio in 2060*: Projected health spending-to-GDP ratio in 2060 (inverted).

Probability of overshooting central projection*: The higher the value, the lower the chance to overshoot the projection in 2060 .

Adequacy

Basic insurance coverage: proportion of the population covered by basic health insurance.

Basic insurance coverage range: the range of goods and services covered by basic insurance,

Costs covered: costs covered by basic benefit package, the actual level of coverage by health insurance and out-of pocket payments.

Out-of-pocket health spending*: the share of out-of-pocket health spending in total health spending (inverted)
Policy levers

Stringency of budget constraints: stringency of the rules and targets to fix the health budget and its allocation across sub-sectors and regions. Choice among providers: Degree of freedom in choosing among primary care physicians, specialists and hospitals.

Choice among insurers: Type of coverage (single national or local schemes, multiple insurers). In case of multiple insurers, number of insurers, market shares and ability of people to choose their insurer. 


\section{WORKING PAPERS}

The full series of Economics Department Working Papers can be consulted at www.oecd.org/eco/workingpapers

1131. Overcoming vulnerability of unemployment insurance schemes (July 2014) by Jon Pareliussen

1130. Vulnerability of social institutions: Lessons from the recent crisis and historical episodes (July 2014) by Falilou Fall, Mauro Pisu, Jon Pareliussen and Debbie Bloch

1129. An update of the OECD international trade equations

(June 2014) by Myriam Morin and Cyrille Schwellnus

1128. What explains the volume and composition of trade? Industrial evidence from a panel of countries

(June 2014) by Asa Johansson, Przemyslaw Kowalski, Eduardo Olaberria and Dario Pellegrino

1127. Do resources flow to patenting firms: cross-country evidence from firm level data (June 2014) by Dan Andrews, Chiara Criscuolo and Carlo Menon

1126. Macroprudential policy tools in Norway: Strengthening financial system resilience (June 2014) by Yosuke Jin, Patrick Lenain and Paul O’Brien

1125. Strengthening competition in Poland

(June 2014) by Balász Égert and Antoine Goujard

1124. Making the labour market work better in Poland

(June 2014) by Hervé Boulhol

1123. Enhancing competition and the business environment in Hungary

(June 2014) by Alvaro Pina

1122. Tackling labour mismatches and promoting mobility in Hungary (June 2014) by Stéphane Sorbe

1121. Local public finances and municipal reform in Finland (June 2014) by Christophe André and Clara Garcia

1120. The economic consequences of ageing: the case of Finland (June 2014) by Christine de la Maisonneuve, Christophe André, Clara Garcia and Vincent Koen

1119. Making the most of skills in Denmark

(June 2014) by Stéphanie Jamet and Vincent Koen

1118. Trade specialisation and policies to foster competition and innovation in Denmark (June 2014) by Müge Adalet McGowan

1117. Policies for making the Chilean labour market more inclusive 
ECO/WKP(2014)28

(June 2014) by Aida Caldera Sanchez

1116. Spillover effects from exiting highly expansionary monetary policies

(May 2014) by Łukasz Rawdanowicz, Romain Bouis, Jérôme Brezillon, Ane Kathrine

Christensen and Kei-Ichiro Inaba

1115. Economic policies and microeconomic stability: A literature review and some empirics (April 2014) by Paula Garda and Volker Ziemann

1114. How to improve Israel's health-care system

(April 2014) by Philip Hemmings

1113. How to improve taxes and transfers in Israel

(April 2014) by Philip Hemmings

1112. New evidence on the determinants of industrial specialisation

(April 2014) by Asa Johansson and Eduardo Olaberria

1111. Economic growth from the household perspective: GDP and income distribution developments across OECD countries

(April 2014) by Orsetta Causa, Sonia Araujo, Agnès Cavaciuti, Nicolas Ruiz and Zuzana Smidova

1110. Would a growth slowdown in emerging markets spill over to high-income countries? A quantitative assessment

(April 2014) By Patrice Ollivaud, Elena Rusticelli and Cyrille Schwellnus

1109. Short-term indicator models for quarterly GDP growth in the BRIICS: A small-scale bridge model approach

(April 2014) by Thomas Chalaux and Cyrille Schwellnus

1108. The prudential regulation of financial institutions: why regulatory responses to the crisis might not prove sufficient

(March 2014) by William R. White

1107. OECD forecasts during and after the financial crisis: a post mortem

(March 2014) by Nigel Pain, Christine Lewis, Thai-Thanh Dang, Yosuke Jin and Pete Richardson

1106. Fairly sharing the social impact of the crisis in Greece

(January 2014) by Vassiliki Koutsogeorgopoulou, Manos Matsaganis, Chrysa Leventi and Jan-David Schneider

1105. Dividing the pie in Brazil: income distribution, social policies and the new middle class (January 2014) by Jens M. Arnold and João Jalles

1104. New indicators of competition law and policy in 2013 for OECD and non-OECD countries

(December 2013) by Enrico Alemani, Caroline Klein, Isabell Koske, Cristiana Vitale and Isabelle Wanner 